\title{
An evidence-based update on the pharmacological activities and possible molecular targets of Lycium barbarum polysaccharides
}

This article was published in the following Dove Press journal:

Drug Design, Development and Therapy

17 December 2014

Number of times this article has been viewed

\author{
Jiang Cheng ${ }^{1,2}$ \\ Zhi-Wei Zhou ${ }^{2}$ \\ Hui-Ping Sheng ${ }^{3}$ \\ Lan-Jie $\mathrm{He}^{4}$ \\ Xue-Wen Fan' \\ Zhi-Xu He \\ Tao Sun ${ }^{6}$ \\ Xueji Zhang ${ }^{7}$ \\ Ruan Jin Zhao ${ }^{8}$ \\ Ling $\mathrm{Gu}^{9}$ \\ Chuanhai $\mathrm{CaO}^{2}$ \\ Shu-Feng Zhou ${ }^{2,5}$
}

'Department of Neurology, General Hospital of Ningxia Medical University, Yinchuan, Ningxia, People's Republic of

China; ${ }^{2}$ Department of Pharmaceutical

Science, College of Pharmacy, University of

South Florida, Tampa, FL, USA; ${ }^{3}$ Department

of Infectious Diseases, ${ }^{4}$ Department of

Endocrinology, General Hospital of Ningxia

Medical University, Yinchuan, Ningxia,

${ }^{5}$ Guizhou Provincial Key Laboratory for

Regenerative Medicine, Stem Cell and Tissue

Engineering Research Center and Sino-US

Joint Laboratory for Medical Sciences,

Guiyang Medical University, Guiyang,

Guizhou, ${ }^{6} \mathrm{Key}$ Laboratory of Craniocerebral

Diseases of Ningxia Hui Autonomous

Region, Ningxia Medical University,

Yinchuan, Ningxia, ${ }^{7}$ Research Center for

Bioengineering and Sensing Technology,

University of Science and Technology Beijing,

Beijing, People's Republic of China; ${ }^{8}$ Center

for Traditional Chinese Medicine, Sarasota,

FL, USA; 'School of Biology and Chemistry,

University of Pu'er, Pu'er, Yunnan, People's

Republic of China

Correspondence: Shu-Feng Zhou

Department of Pharmaceutical Sciences,

College of Pharmacy, University of South

Florida, I290I Bruce B. Downs Boulevard,

MDC 30, Tampa, FL 33612, USA

Tel + I 8139746276

$\mathrm{Fax}+\mathrm{I} 8139059885$

Email szhou@health.usf.edu

Tao Sun

Key Laboratory of Craniocerebral Diseases of Ningxia Hui Autonomous Region, Ningxia Medical University, Yinchuan, Ningxia, People's

Republic of China

Tel +8695I 6980002

$\mathrm{Fax}+869516980018$

Email sunta06699@।63.com
Abstract: Lycium barbarum berries, also named wolfberry, Fructus lycii, and Goji berries, have been used in the People's Republic of China and other Asian countries for more than 2,000 years as a traditional medicinal herb and food supplement. L. barbarum polysaccharides (LBPs) are the primary active components of L. barbarum berries and have been reported to possess a wide array of pharmacological activities. Herein, we update our knowledge on the main pharmacological activities and possible molecular targets of LBPs. Several clinical studies in healthy subjects show that consumption of wolfberry juice improves general wellbeing and immune functions. LBPs are reported to have antioxidative and antiaging properties in different models. LBPs show antitumor activities against various types of cancer cells and inhibit tumor growth in nude mice through induction of apoptosis and cell cycle arrest. LBPs may potentiate the efficacy of lymphokine activated killer/interleukin-2 combination therapy in cancer patients. LBPs exhibit significant hypoglycemic effects and insulin-sensitizing activity by increasing glucose metabolism and insulin secretion and promoting pancreatic $\beta$-cell proliferation. They protect retinal ganglion cells in experimental models of glaucoma. LBPs protect the liver from injuries due to exposure to toxic chemicals or other insults. They also show potent immunoenhancing activities in vitro and in vivo. Furthermore, LBPs protect against neuronal injury and loss induced by $\beta$-amyloid peptide, glutamate excitotoxicity, ischemic/reperfusion, and other neurotoxic insults. LBPs ameliorate the symptoms of mice with Alzheimer's disease and enhance neurogenesis in the hippocampus and subventricular zone, improving learning and memory abilities. They reduce irradiation- or chemotherapy-induced organ toxicities. LBPs are beneficial to male reproduction by increasing the quality, quantity, and motility of sperm, improving sexual performance, and protecting the testis against toxic insults. Moreover, LBPs exhibit hypolipidemic, cardioprotective, antiviral, and antiinflammatory activities. There is increasing evidence from preclinical and clinical studies supporting the therapeutic and healthpromoting effects of LBPs, but further mechanistic and clinical studies are warranted to establish the dose-response relationships and safety profiles of LBPs.

Keywords: cancer, apoptosis, antioxidant, ischemic/reperfusion injury, $\mathrm{T}$ cell, natural killer, chemotherapy, anti-aging, mechanism

\section{Introduction}

As a traditional Chinese medicinal herb and food supplement, Lycium barbarum berries (also named wolfberry, Fructus lycii, Gouqizi, and Goji berries) have been used in the People's Republic of China and other Asian countries for more than 2,000 years. ${ }^{1,2}$ The berries have become increasingly popular in Western countries as an anti-aging and antioxidant product. ${ }^{3}$ L. barbarum fruits (LBFs; Figure 1A), which are red-colored and sweet in taste, are mainly found in Ningxia Province. 
A

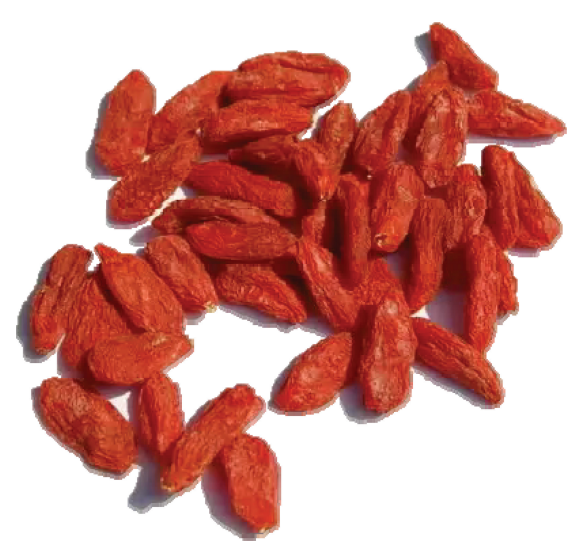

C

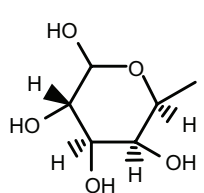

L-(-)-fucose

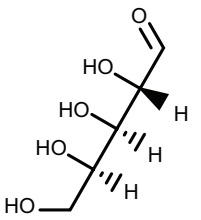

Arabinose

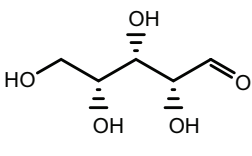

Xylose
B

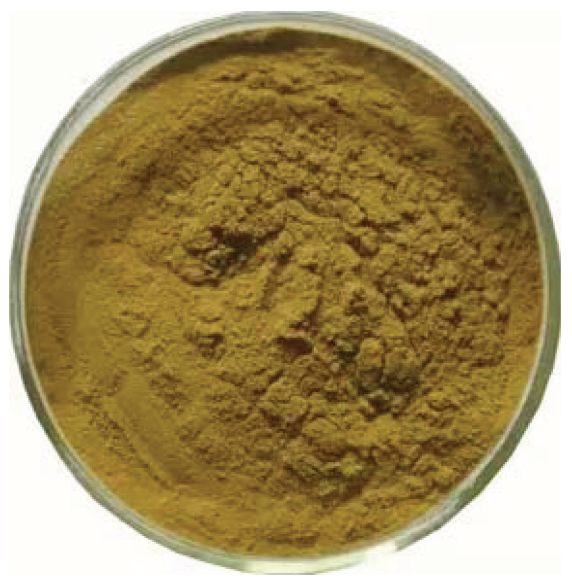

Figure I Lycium barbarum fruits (A), brown-colored LBPs (B), and six main monosaccharaides present in LBPs (C). Abbreviation: LBPs, L. barbarum polysaccharides.

People's Republic of China. These berries are eaten raw and drunk as a juice, wine, or tea. These berries also be processed to tinctures, powders, and tablets. Traditional Chinese medicine considers $L$. barbarum berries to have the ability to maintain the function of eyes and strengthen the activity of liver, kidneys, and lungs via boosting and balancing "Yin" and "Yang" in the body. ${ }^{1,2}$

LBFs contain abundant polysaccharides (LBPs, comprising $5 \%-8 \%$ of the dried fruits), scopoletin (6-methoxy-7hydroxycoumarin, also named chrysatropic acid, ecopoletin, gelseminic acid, and scopoletol), the glucosylated precursor, and stable vitamin $\mathrm{C}$ analog $2-O$ - $\beta$-D-glucopyranosyl-Lascorbic acid, carotenoids (zeaxanthin and $\beta$-carotene), betaine, cerebroside, $\beta$-sitosterol, flavonoids, amino acids, minerals, and vitamins (in particular, riboflavin, thiamin, and ascorbic acid). ${ }^{4}$ The predominant carotenoid is zeaxanthin, which exists mainly as dipalmitate (also called physalien or physalin). The content of vitamin C (up to $42 \mathrm{mg} / 100 \mathrm{~g}$ ) in wolfberry is comparable to that of fresh lemon fruits. As to the seeds, they contain zeaxanthin (83\%), $\beta$-cryptoxanthin (7\%), $\beta$-carotene $(0.9 \%)$, and mutatoxanthin $(1.4 \%)$, as well as some minor carotenoids. ${ }^{1}$ In fact, increasing lines of experimental studies have revealed that $L$. barbarum berries have a wide array of pharmacological activities, which is thought to be mainly due to its high LBPs content. Water-soluble LBPs are obtained using an extraction process that removes the lipid soluble components such as zeaxanthin and other carotenoids with alcohol. LBPs are estimated to comprise $5 \%-8 \%$ of LBFs and have a molecular weight ranging from $24 \mathrm{kDa}$ to $241 \mathrm{kDa}$. LBPs consist of a complex mixture of highly branched and only partly characterized polysaccharides and proteoglycans (Figure 1B). The glycosidic part accounts, in most cases, for about $90 \%-95 \%$ of the mass and consists of arabinose, glucose, galactose, mannose, rhamnose, xylose, and galacturonic acid. ${ }^{5,6}$ LBPs are considered the most important functional constituents in LBFs. Different fractions of LBPs have different activities and the galacturonic acid content is an imperative factor for activities of LBP. The bioactivities of polysaccharides are often in reverse proportion with their molecular weights. Increasing lines of evidence from both preclinical and clinical studies support the medicinal, therapeutic, and health-promoting effects of LBPs. Herein, we update our knowledge on the main pharmacological activities and possible underlying mechanisms of LBPs with a focus on the molecular targets and signaling pathways involved. For more information on 
the phytochemistry, pharmacology, and biology of Goji berries and LBPs, please read recent reviews. . $^{1,3,7-9}$

\section{Literature search}

An extensive literature search was performed by the authors using the following databases: Medline (via PubMed), ScienceDirect, Natural Medicines, The Cochrane Library, and Ovid (all from their inception to September 2014). All in vitro and in vivo studies on the bioactivities, benefits, actions, and mechanisms of action of Goji berries were included. Keyword search terms used included L. barbarum, wolfberry, Goji, Goji berry, and Gouqizi with combination terms including polysaccharide, pharmacology, biological activity, activity, action, effect, mechanism, target, dose, concentration, rat, mouse, and human. Literature in English, Chinese, and Japanese were all included.

\section{Pharmacological effects and underlying mechanisms of LBPs}

A number of preclinical and a few clinical studies on the pharmacological activities and possible mechanisms of LBPs have been reported in the literature (Tables 1 and 2). LBPs exhibit a wide array of therapeutic/medicinal effects on aging, fatigue, cancer, colitis, stroke, diabetes, Alzheimer's disease (AD), and glaucoma in different animal models.

\section{Anti-aging and antioxidant effects}

Goji berries have long been used in Oriental medicine as a potent anti-aging agent. Aging is a progressive deterioration of physiological function that impairs the ability of an organism to maintain homeostasis and consequently increases the organism's susceptibility to disease and death. ${ }^{10}$ The aging of the immune system (immunosenescence) is associated with dramatic reduction in immune responsiveness as well as functional dysregulation. This translates into less-effective innate and adaptive immune responses, increased reactivity against self-antigens (autoimmunity), and decreased incidences of infectious diseases and cancer. ${ }^{11}$ Oxidative damage of biomolecules increases with age and is postulated to be a major causal factor of various degenerative disorders. ${ }^{12,13}$ Oxidative stress is a condition under which increased production of free radicals, reactive species (including singlet oxygen and reactive lipid peroxidation products, such as reactive aldehydes and peroxides), and oxidant-related reactions occur, which result in cellular and organ damage. Free radical scavengers or antioxidants play an important role in retarding biological aging. Consequently, the concept of anti-aging by antioxidants such as LBPs has been supported by a line of evidence. Oxidative stress has been incriminated as one of several mechanisms that induce toxic effects in different organs due to enhanced production of oxygen free radicals and is considered as a major risk factor that contributes to increased lipid peroxidation and reduced antioxidants in aging and aging-related degenerative diseases. ${ }^{12,13}$

\section{Zebrafish}

Cellular senescence can be triggered by a number of factors including aging, DNA damage, oncogene activation, and oxidative stress. Senescence represents a stress response in which cells withdraw from the cell cycle and lose the capability to proliferate in response to growth factors or mitogens. Senescent cells show increased expression of recognized biomarkers of senescence, including staining for $\beta$-galactosidase at $\mathrm{pH}$ of 6.0 (senescence-associated- $\beta$-gal [SA- $\beta$-gal]), decreased replicative capacity, and increased expression of p53, p21, p16, and other cyclin-dependent kinase inhibitors, such as p27 and p15. ${ }^{14}$ p53, a tetrameric transcription factor and tumor suppressor, regulates cellcycle control, DNA repair, apoptosis, cellular senescence, and cellular stress responses. p53 can promote or inhibit senescence. ${ }^{14}$ p21 is the first identified downstream target of p53, and it is an essential mediator of p53-dependent cell-cycle arrest. In a recent study, Xia et $\mathrm{al}^{15}$ explored the mechanisms of action of LBPs by phenotypic and SA- $\beta$-gal assays, evaluated the survival rates in vivo, and determined expression profiling of genes related to the p53 signaling pathway in a zebrafish model. Zebrafish embryos were continuously exposed to various concentrations of LBPs $(1.0 \mathrm{mg} / \mathrm{mL}$, $2.0 \mathrm{mg} / \mathrm{mL}, 3.0 \mathrm{mg} / \mathrm{mL}$, and $4.0 \mathrm{mg} / \mathrm{mL}$ ) for 3 days. The results of fluorescent acridine orange and SA- $\beta$-gal staining indicated that cell apoptosis and senescence mainly occurred in the head at 24 hours and 72 hours post-fertilization. In addition, resistance to replicative senescence was observed at low doses of LBPs, especially at the $3.0 \mathrm{mg} / \mathrm{mL}$ concentration. ${ }^{15}$ Furthermore, the expression of genes that relate to aging, such as p53, p21, and Bax, was decreased, while Mdm2 (a p53-specific E3 ubiquitin ligase acting as the principal cellular antagonist of p53) and telomerase reverse transcriptase genes were upregulated by LBPs. The results indicate that the beneficial effects of LBPs on cell apoptosis and aging might be mediated by the p53-mediated signaling pathway (Figure 2).

\section{Mice and rats}

The effect of LBPs on age-induced oxidative stress in different organs of aged (20 months) Kunming mice was investigated by 


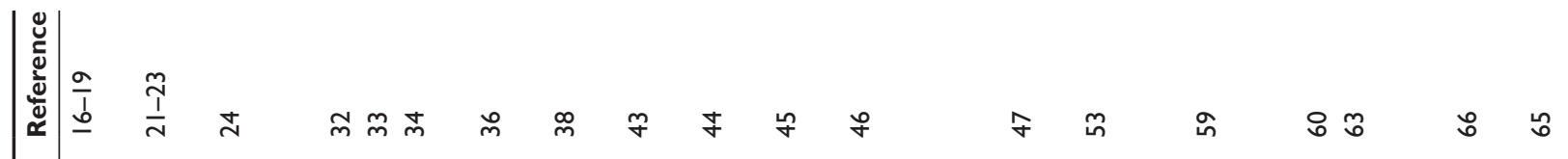

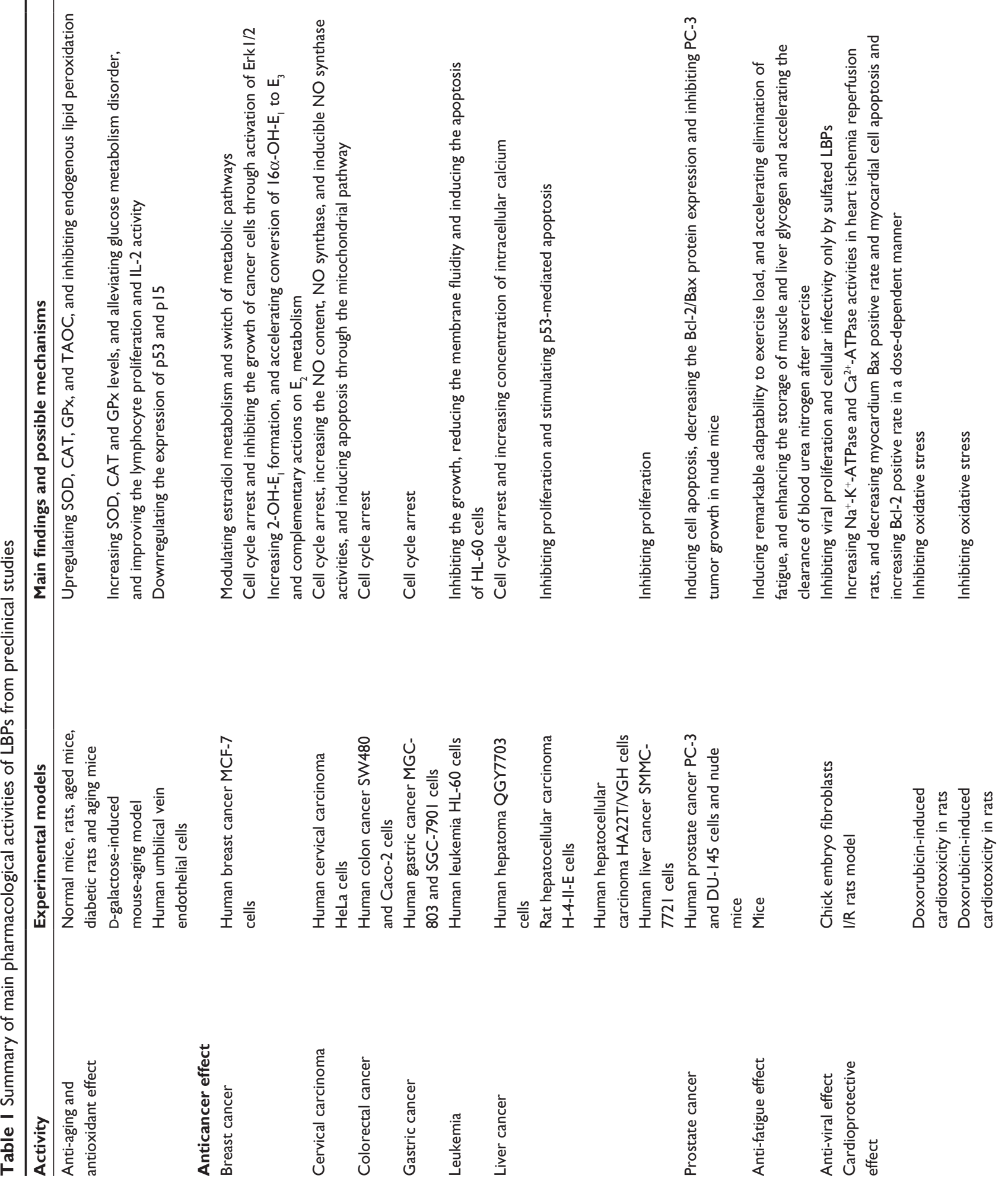




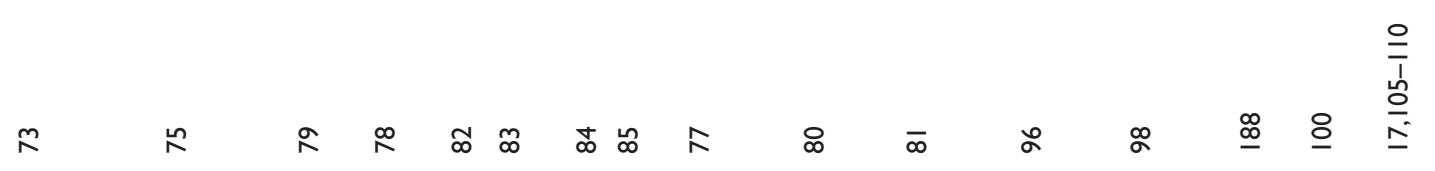
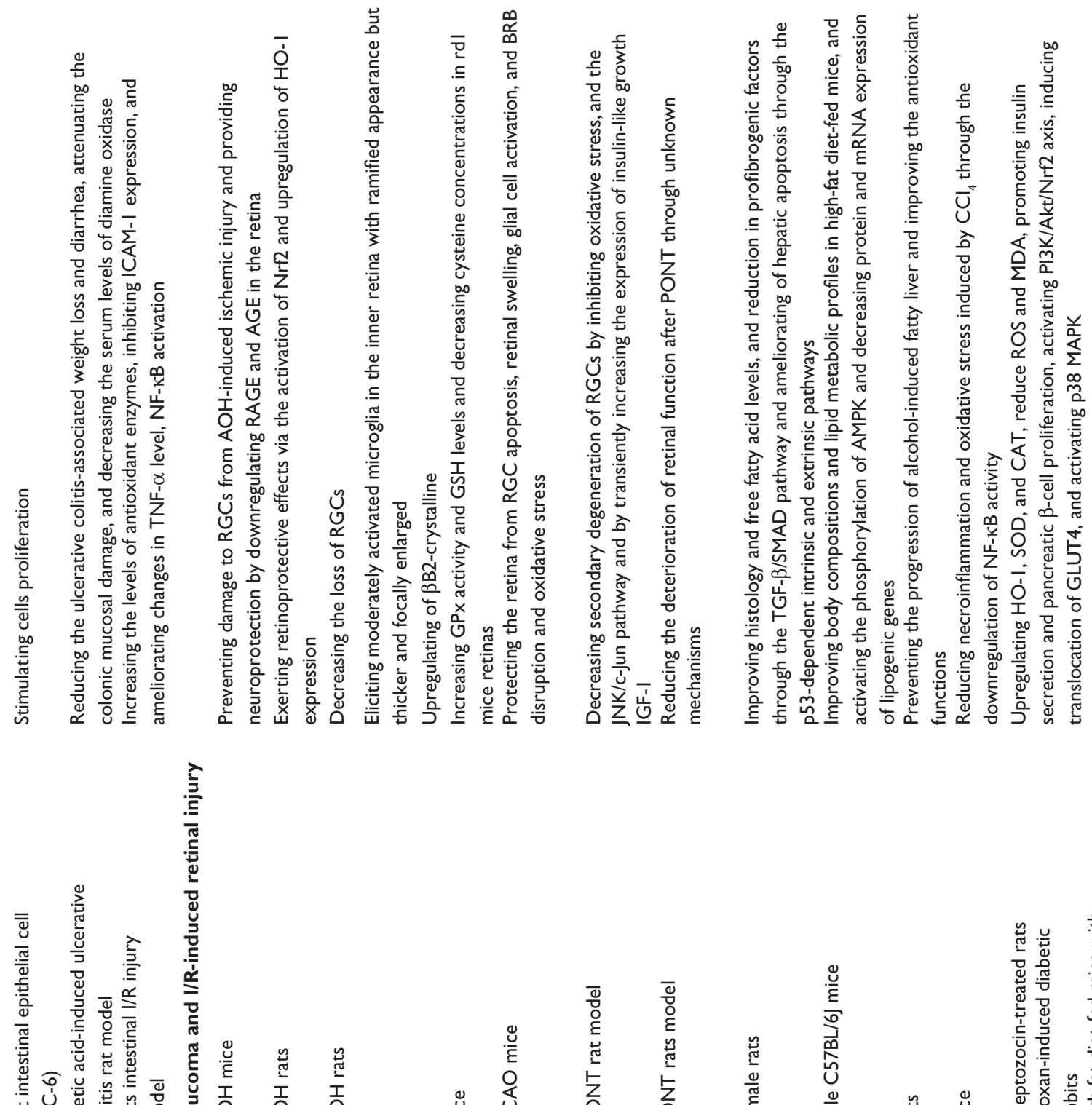

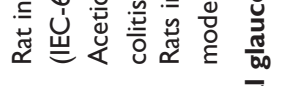
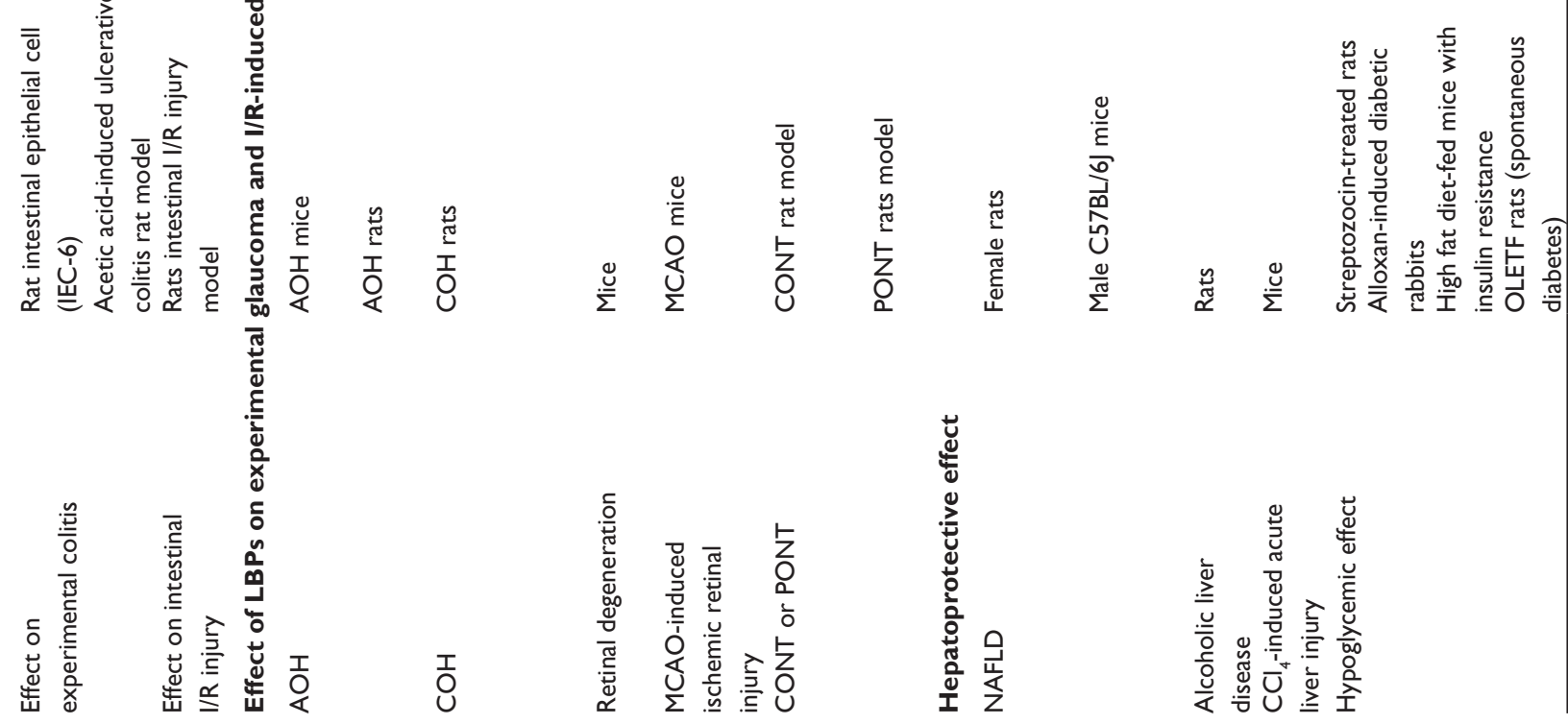


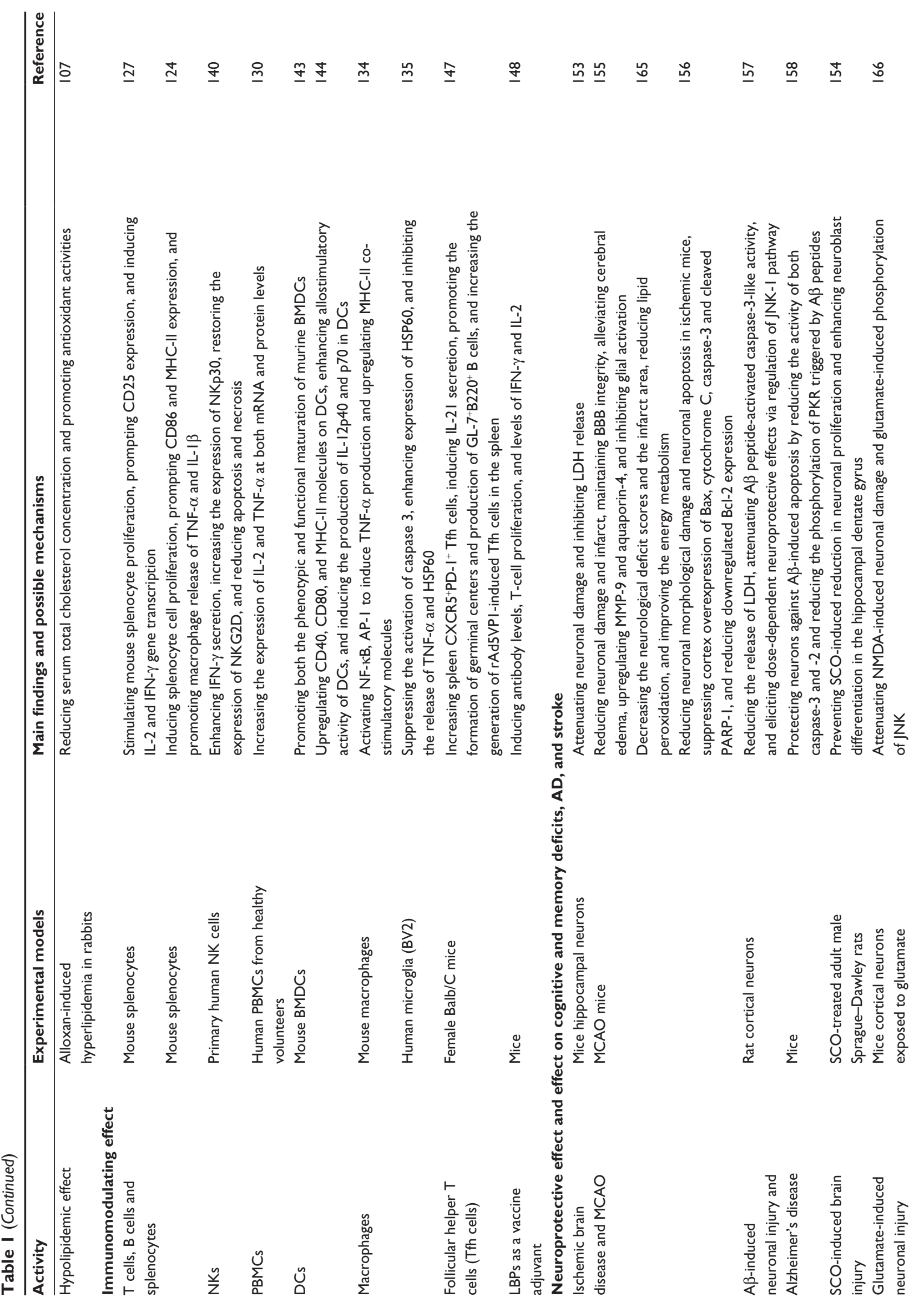




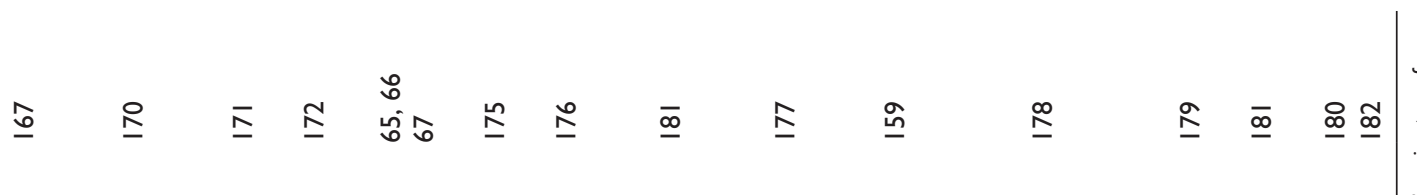

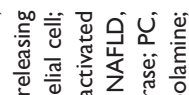

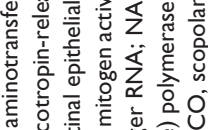

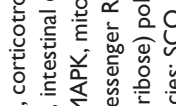

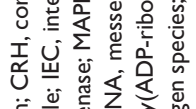

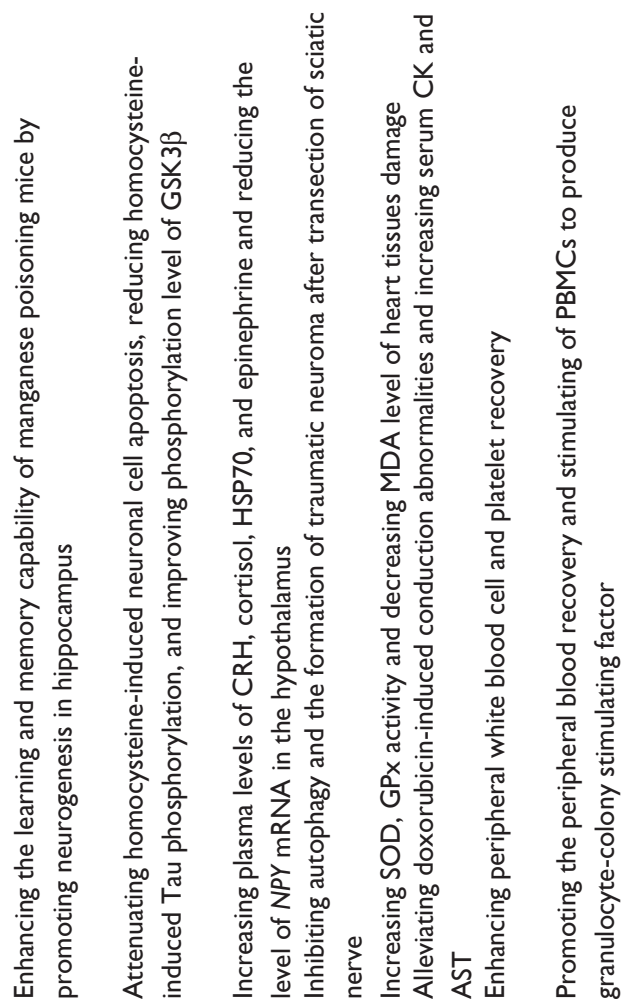

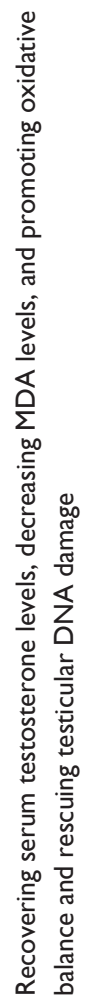

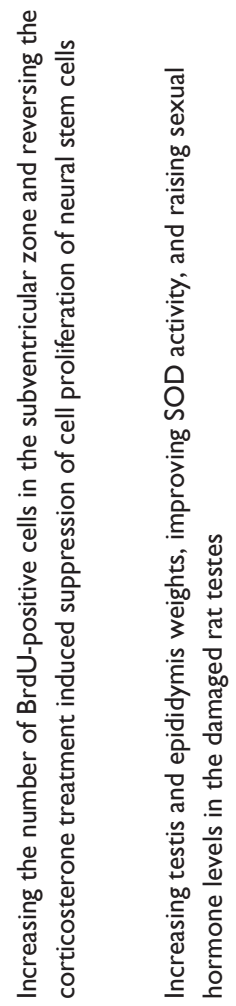

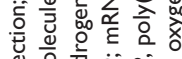

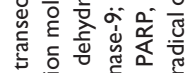

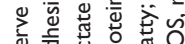

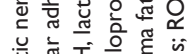

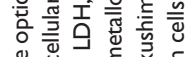

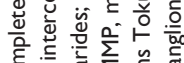

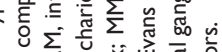

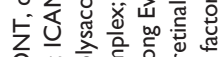
U $\stackrel{\circ}{\frac{0}{5}}$ 竞 这 : ָั

$$
\text { 总 }
$$

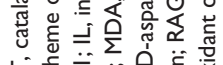

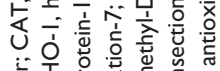

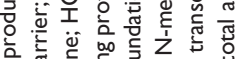

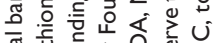

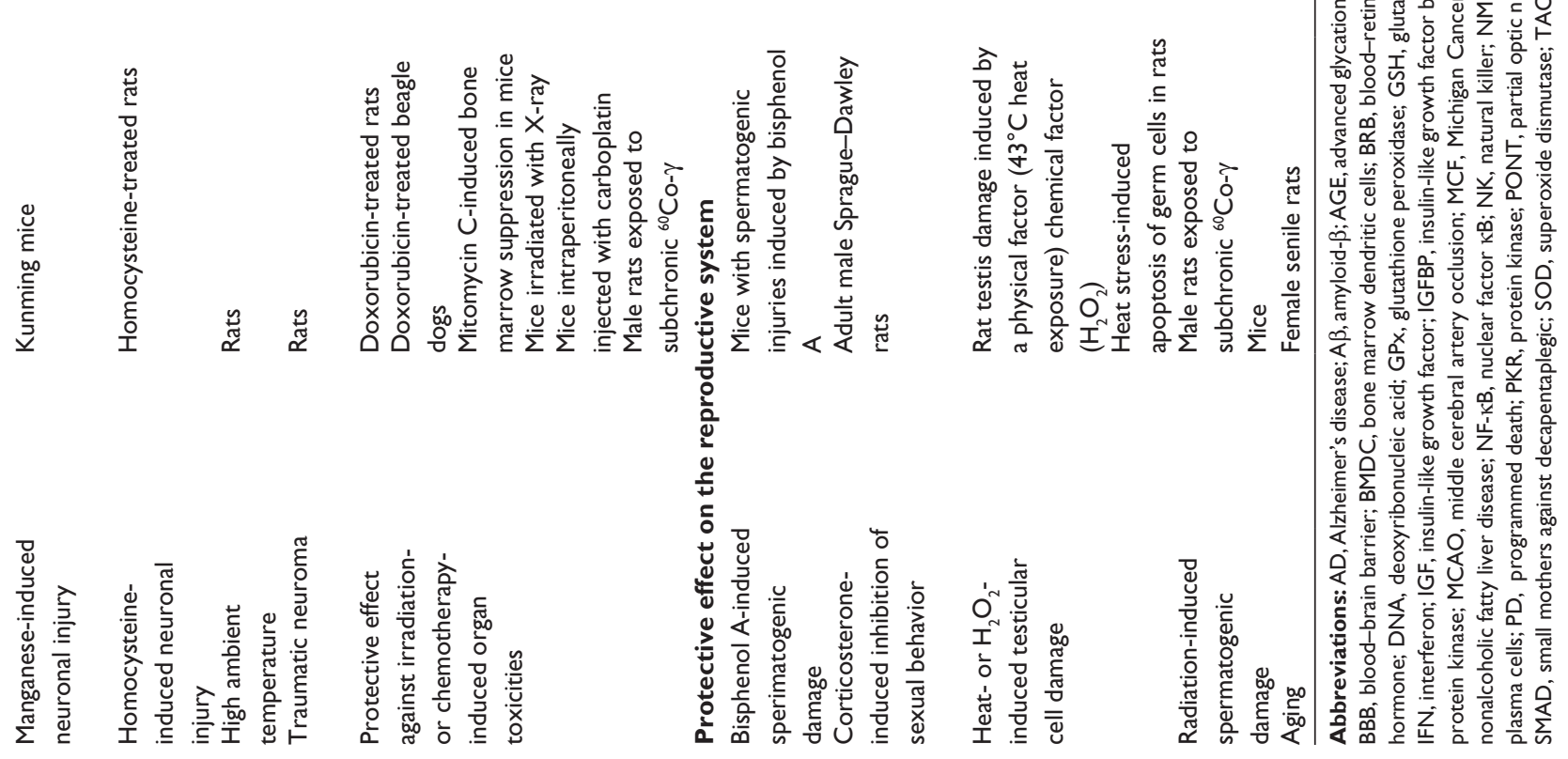




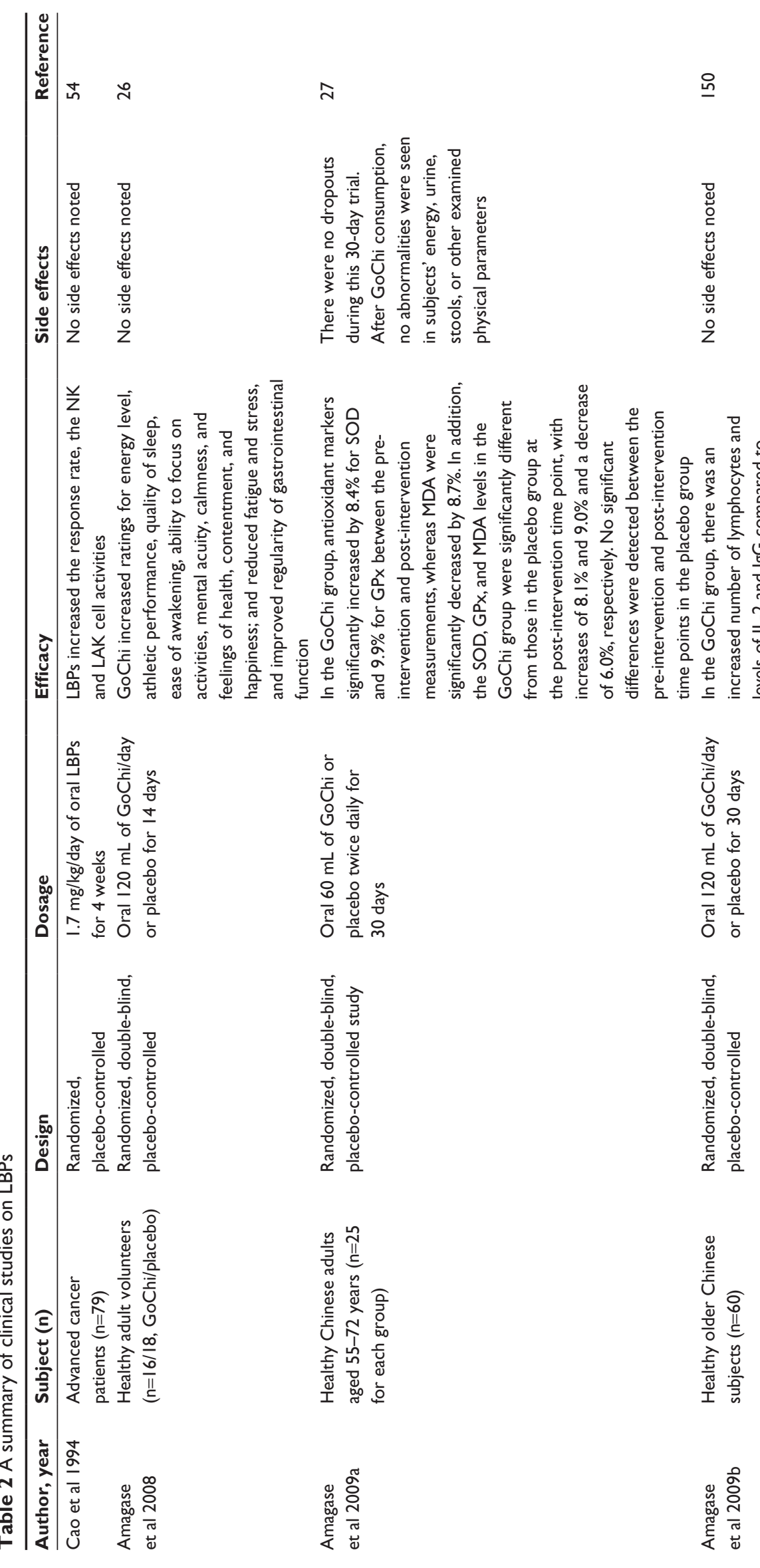




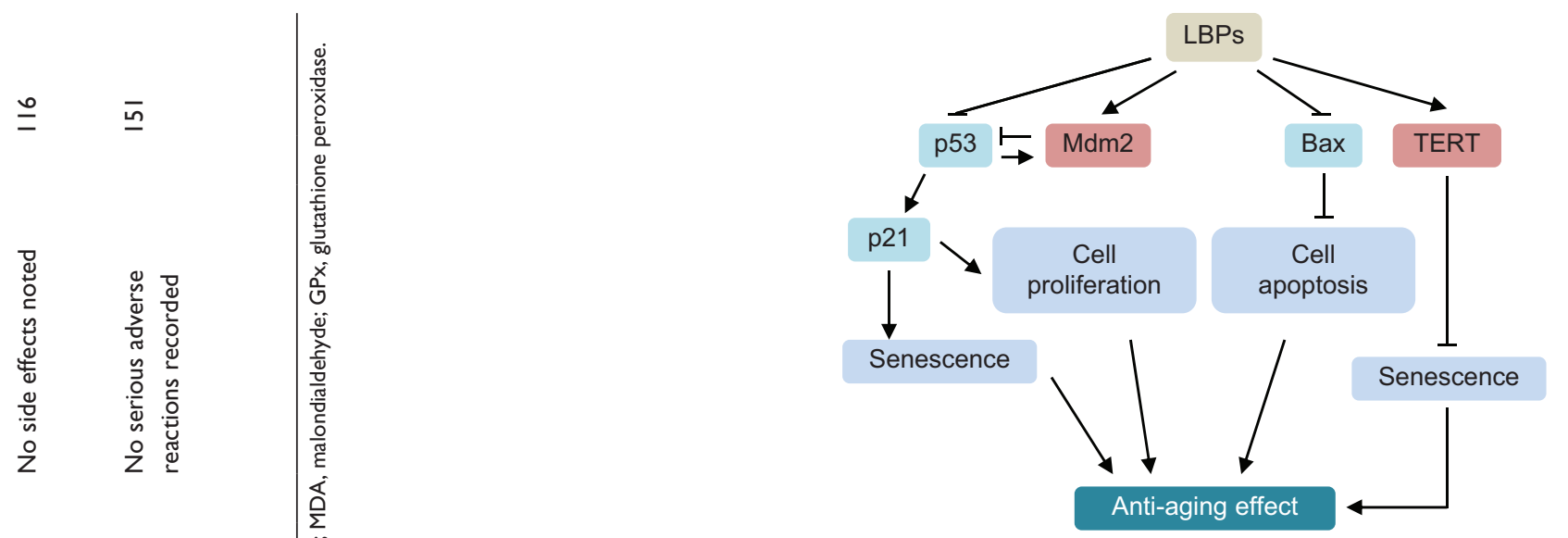

Figure 2 Possible mechanisms for the anti-aging effect of LBPs in zebrafish. Notes: LBPs show marked anti-aging effect through the inhibition of cell apoptosis and senescence. LBPs decrease the expression of p53, p2I, and Bax; whereas increase the expression of $M d m 2$ and TERT in zebrafish. During aging, p53 is activated, triggering expression of pro-senescence targets such as $\mathrm{p} 2 \mathrm{I}$, responsible for GI cell-cycle arrest and E2F7, pivotal in repression of mitotic genes. Mdm2 acts both as an $\mathrm{E} 3$ ubiquitin ligase that recognizes the $\mathrm{N}$-terminal trans-activation domain of $\mathrm{p} 53$ and as an inhibitor of $\mathrm{p} 53$ transcriptional activation.

Abbreviations: LBPs, Lycium barbarum polysaccharides; TERT, telomerase reverse transcriptase.

Li et al. ${ }^{16}$ LBPs were extracted from Goji fruits purchased from Jinghe County herb market, Xinjiang, People's Republic of China, and the amount of the polysaccharides was found to be $97.54 \%$ by phenol-sulfuric acid method. The mice were treated with $200 \mathrm{mg} / \mathrm{kg}$, $350 \mathrm{mg} / \mathrm{kg}$, or $500 \mathrm{mg} / \mathrm{kg}$ body weight LBPs by gastric gavage for 30 days. The study showed that increased endogenous lipid peroxidation, and decreased antioxidant activities in the lungs, liver, brain, and heart, as assessed by superoxide dismutase (SOD), catalase (CAT), glutathione peroxidase (GPx), and total antioxidant capacity (TAOC), and immune function as determined by measuring thymus and spleen index, phagocytic index, and phagocytic activity were observed in aged mice and restored to normal levels in LBP-treated mice. ${ }^{16}$ The level of lipofuscin, an important marker for oxidative damage, in various organs was increased in aged mice and suppressed by LBPs. In contrast, the level of malondialdehyde (MDA) in blood and other organs was significantly increased in aged mice compared to young mice, and the high level of MDA was brought down by LBP treatment. ${ }^{16}$ The inhibitory effect of LBPs on lipid peroxidation in aged mice might be, at least in part, attributed to the influence on the antioxidant enzymes and non-enzymatic system. These findings demonstrate that LBPs can promote the antioxidative enzymes and immune functions that are suppressed in aging and thereby decrease the risk of lipid peroxidation accelerated by age-induced generation of free radicals.

$\mathrm{Li}^{17}$ also reported that administration of $50 \mathrm{mg} / \mathrm{kg}$, $100 \mathrm{mg} / \mathrm{kg}$, or $200 \mathrm{mg} / \mathrm{kg}$ body weight LBPs by oral gavage 
for 30 days restored abnormal oxidative capacity to almost normal levels in streptozotocin-induced diabetic Wistar rats. LBPs were extracted from dry fruits of Goji berries in boiling water. The polysaccharides consisted of D-rhamnose, D-xylose, D-arabinose, D-fucose, D-glucose, and D-galactose with molar ratio of 1:1.07:2.14:2.29:3.59:10.06 and linked together by $\beta$-glycosidic linkages. Diabetes was induced by a single intraperitoneal injection of $50 \mathrm{mg} / \mathrm{kg}$ body weight streptozotocin. Results showed that the activities of blood and liver antioxidant enzymes (SOD, GPx, CAT, and glutathione reductase [GR]) and glutathione (GSH) level in diabetic rats were significantly decreased, and MDA level significantly increased compared to normal control rats. Administration of 50-200 mg/kg LBPs for 30 days significantly increased the activities of these antioxidant enzymes and decreased MDA level in diabetic rats compared to the model group. ${ }^{17}$

The modulatory effect of LBPs on oxidative stress was also investigated, in Kunming mice fed with high-fat diet for 2 months, by Wu et al. ${ }^{18}$ Mice were treated orally with $50 \mathrm{mg} / \mathrm{kg}, 100 \mathrm{mg} / \mathrm{kg}$, or $150 \mathrm{mg} / \mathrm{kg}$ body weight of LBPs once every day for 2 months. The results showed that the activities of blood and hepatic antioxidant enzymes (SOD, GPx, and CAT) and the GSH level in model mice significantly decreased, and blood and hepatic MDA and nitric oxide (NO) levels significantly increased compared to normal control mice. Administration of LBPs dose-dependently and significantly increased the activities of antioxidant enzymes and decreased MDA level in mice compared to the model group. ${ }^{18}$

Niu et $\mathrm{l}^{19}$ explored the modulatory effect of LBPs on exercise-induced oxidative stress in skeletal muscles in male Wistar rats. The exhaustive exercise experimental rats underwent a 30-day exhaustive exercise program. Rats were also treated orally with $100 \mathrm{mg} / \mathrm{kg}, 200 \mathrm{mg} / \mathrm{kg}$, or $300 \mathrm{mg} / \mathrm{kg}$ body weight LBPs once per day for 1 month. This model of experimental exhaustive exercise promoted oxidative stress in skeletal muscle tissues of rats, with decreased muscle glycogen content, decreased SOD and GPx activity, and increased MDA level and creatine kinase (CK) activity in skeletal muscle tissues of exhaustive exercise animals. ${ }^{19}$ The results showed that LBPs administration dose-dependently decreased the oxidative stress induced by the exhaustive exercise with increased SOD and GPx activity and reduced MDA level in skeletal muscles. ${ }^{19}$

Some metabolic products that can damage cell member lipid are generated during the process in which galactose is reduced into galactitol, such as the increases of lipid peroxidation and lipofuscin, finally leading to body aging. ${ }^{20}$
Continuous injection of D-galactose in animals will inevitably cause glucose metabolism disorder, thereby causing abnormal metabolism of heart, liver, kidney, brain, and other important organs. D-galactose-induced mouse-aging model has been used to test the anti-aging capacity of LBPs. Results showed that LBPs increased SOD, CAT, and GPx levels in blood and reduced MDA level. They also improved SOD activity of skin and reduced MDA content of skin. ${ }^{21}$ A similar effect was observed with LBPs in another study. ${ }^{22}$ Their mechanism may be related to the alleviation of glucose metabolism disorder and the resistance of the generation of lipid peroxide and other substances, which damage cell membrane lipids. Another study investigated the inhibiting effects of LBPs on non-enzymatical glycation in D-galactose-induced mouseaging model. ${ }^{23}$ The lymphocyte proliferation and interleukin (IL)-2 activity, learning and memory abilities, and SOD activity of erythrocytes were enhanced by LBPs. ${ }^{23}$

\section{Human umbilical vein endothelial cells}

Liu et $\mathrm{al}^{24}$ examined the effects of LBPs on angiotensin II-induced senescence of human umbilical vein endothelial cells (HUVECs) and the role of p53 and p16 in such effects. HUVECs were treated with $1 \times 10^{6} \mathrm{mM}$ angiotensin II to induce cell senescence, which was identified using SA- $\beta$-gal staining. Flow cytometry was used for analyzing the cell cycle changes, and the cell viability was assessed. LBPs treatment of angiotensin II-exposed cells resulted in decreased $\beta$-gal-positive cells with a reduction in $\mathrm{G}_{0} / \mathrm{G}_{1}$ phase cells and an increase in $\mathrm{S}$ phase cells. ${ }^{24}$ It also increased the cell viability and significantly decreased the expression levels of p53 and p16 (both tumor suppressors and senescence regulators) in HUVECs. These results demonstrate that LBPs can delay angiotensin II-induced aging of HUVECs possibly by downregulating the expression of p53 and p16. The p16-mediated senescence acts through the retinoblastoma pathway inhibiting the action of the cyclin-dependent kinases leading to G1 cell cycle arrest. ${ }^{25}$ Retinoblastoma is maintained in a hypophosphorylated state resulting in the inhibition of transcription factor E2F1.

\section{Clinical studies in healthy volunteers}

Amagase and $\mathrm{Nance}^{26}$ performed a randomized, double-blind, placebo-controlled, clinical study to investigate the general effects of use of a standardized L. barbarum juice (GoChi) for 14 days in healthy Chinese subjects. GoChi was produced from fresh ripe LBFs grown in the People's Republic of China. As a finished product, the juice contains 1,632 mg/ day serving (120 mL, ie, $13.6 \mathrm{mg} / \mathrm{mL})$ of LBPs. The placebo 
matched the color, flavor, and taste of GoChi in a formulation of sucralose (10 mg), artificial fruit flavor (30 mg), citric acid (60 mg), and caramel color (12 mg) in $30 \mathrm{~mL}$ of purified water. The effects of GoChi were examined by questionnaire subjective ratings (0-5) of general feelings of well-being, neurologic/psychologic traits, gastrointestinal, musculoskeletal, and cardiovascular complaints as well as any adverse effects. Body weight, body mass index, blood pressure, pulse rate, and visual acuity were also measured before and after consuming $120 \mathrm{~mL}$ of GoChi/day or placebo control solution. ${ }^{26}$ Significant differences between day 1 and day 15 were found in the GoChi group ( $n=16)$ with increased ratings for energy level, athletic performance, quality of sleep, ease of awakening, ability to focus on activities, mental acuity, calmness, and feelings of health, contentment, and happiness. GoChi also significantly reduced fatigue and stress, and improved regularity of gastrointestinal function. In contrast, the placebo group ( $n=18)$ showed only two significant changes (heartburn and happiness). ${ }^{26}$ No significant changes in musculoskeletal or cardiovascular complaints were observed in either group. All parametric data (body weight, etc) were not significantly different between groups or between day 1 and day 15 for either group. These results clearly indicate that daily consumption of GoChi for 14 days increases subjective feelings of general well-being and improves neurologic/psychologic performance and gastrointestinal functions.

Amagase et $\mathrm{al}^{27}$ further conducted a randomized, doubleblind, placebo-controlled clinical study to examine the antioxidant effects of GoChi in healthy Chinese adults living in Hunan province, People's Republic of China. In the study, 50 Chinese healthy adults aged 55-72 years were recruited and treated with Goji juice containing $13.6 \mathrm{mg} / \mathrm{mL} \mathrm{LBPs}$ at a dose of $120 \mathrm{~mL} /$ day or placebo ( $\mathrm{n}=25$ each group) ${ }^{27}$ In vivo antioxidant markers including serum levels of SOD, GPx, and lipid peroxidation (indicated by the level of MDA) were determined before and after GoChi or placebo consumption for 30 days. The results showed that GoChi consumption significantly increased serum SOD level by $8.4 \%$ and GPx by $9.9 \%$, whereas MDA was significantly decreased by $8.7 \% .{ }^{27}$ There were no dropouts during this 30-day trial. After GoChi or placebo consumption, no abnormalities were seen in subjects' energy, urine, stools, or other examined physical parameters. These data indicate that chronic GoChi is well tolerated in humans and can promote antioxidant capacity in humans via upregulating antioxidative enzymes.

Four randomized, blind, placebo-controlled clinical trials were pooled to identify the general effects of oral consumption of $120 \mathrm{~mL} /$ day GoChi. ${ }^{28}$ A questionnaire consisting of symptoms graded $0-5$ was given to the participants. For each question, the score changes in the questionnaire between pre- and post-intervention were summarized by the standardized mean difference and associated standard error of the mean to perform the meta-analysis. The change was also characterized into a binary outcome, improved or not, to derive odds ratio (OR) and associated standard error of the mean derived by a binary outcome using the Mantel-Haenszel method. The meta-analysis and heterogeneity were evaluated with the R program using the rmeta package. In total, 161 participants (18-72 years old) were included in the meta-analysis. Compared with the placebo group ( $\mathrm{n}=80)$, the GoChi-treated group $(\mathrm{n}=81)$ showed significant improvements in weakness, stress, mental acuity, ease of awakening, shortness of breath, focus on activity, sleep quality, daydreaming, and overall feelings of health and well-being under a random effects model. ${ }^{28}$ A fixed effects model showed additional improvements in fatigue, depression, circulation, and calmness. The OR indicated significantly higher chance to improve fatigue, dizziness, and sleep quality. ${ }^{28}$ Three studies had statistically significant heterogeneity in procrastination, shoulder stiffness, energy, and calmness. The meta-analysis confirmed the various health-promoting effects of GoChi in humans.

\section{Summary of the anti-aging and antioxidative effects of LBPs}

In summary, LBPs have shown potent anti-aging and antioxidant activities (Figure 3). They increase SOD, GPx, CAT, and GR activities, thereby inhibiting oxidative stress-induced damage. LBPs ameliorate oxidative stress-induced cellular apoptosis. They can delay angiotensin II-induced aging of HUVECs by downregulating the expression of p53 and p16. In the ischemia/reperfusion (I/R) injuries to heart, LBPs significantly decreased the myocardium lactate dehydrogenase (LDH) level and increased $\mathrm{Na}^{+} / \mathrm{K}^{+}$-ATPase and $\mathrm{Ca}^{2+}$-ATPase activities. LBPs ameliorate oxidative stress-induced cellular apoptosis by downregulating Bax and upregulating Bcl-2.

\section{Anticancer effects}

According to GLOBOCAN 2012, ${ }^{29}$ an estimated 14.1 million new cancer cases and 8.2 million cancer-related deaths occurred in 2012 worldwide, compared with 12.7 million and 7.6 million, respectively, in 2008. The most commonly diagnosed cancers worldwide were those of the lung (1.8 million, $13.0 \%$ of the total), breast ( 1.7 million, $11.9 \%$ ), and colorectum (1.4 million, 9.7\%). ${ }^{29}$ The most common causes of cancer death were cancers of the lung (1.6 million, $19.4 \%$ of the total), liver 


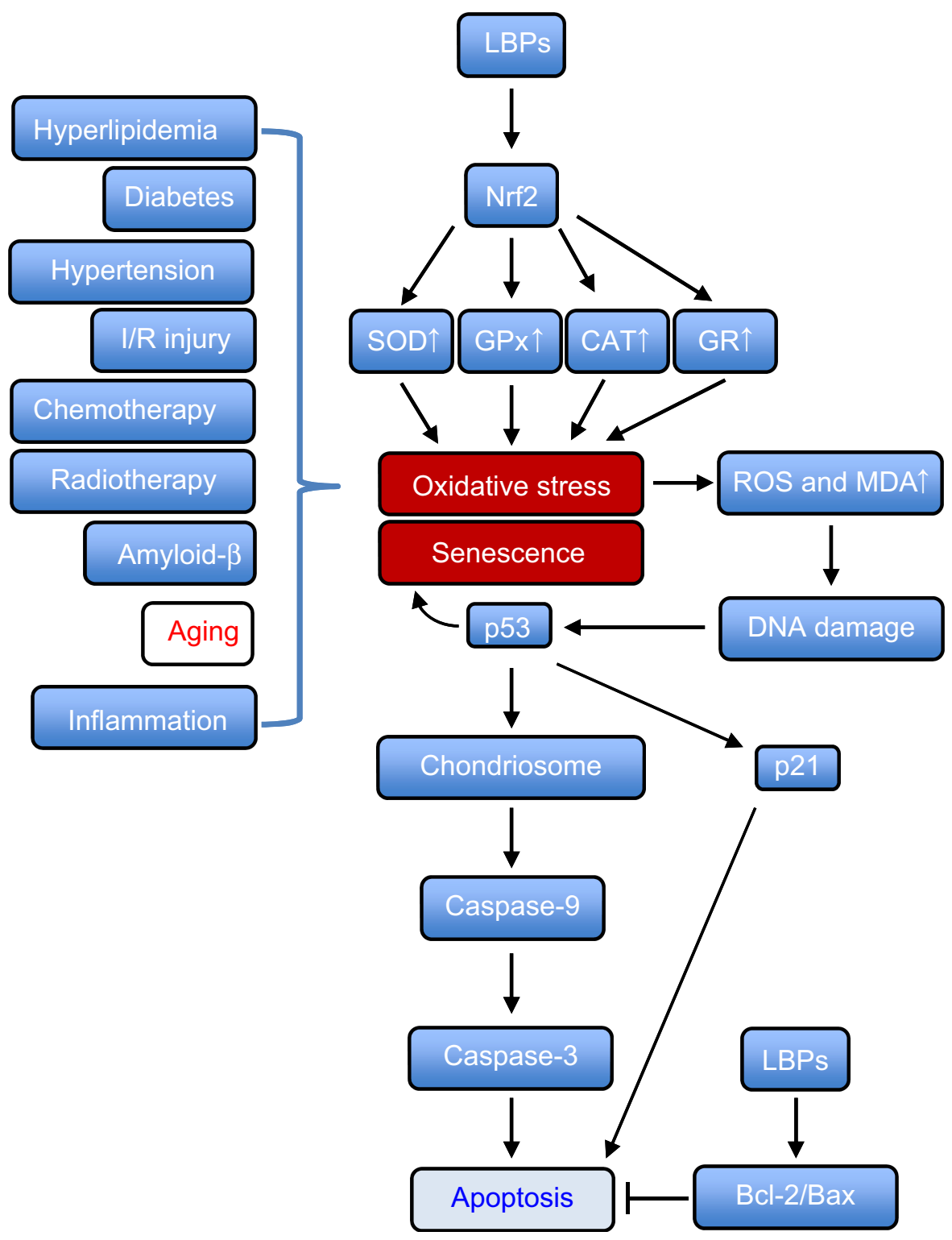

Figure 3 Possible mechanisms for the antioxidant activities of LBPs.

Notes: LBPs increase SOD, GPx, CAT, and GR activities, thereby inhibiting oxidative stress-induced damage. LBPs ameliorate oxidative stress-induced cellular apoptosis. LBPs can delay angiotensin II-induced aging of HUVECs by downregulating the expression of p 53 and pl6. In the I/R heart, LBPs significantly decrease the myocardium LDH level, increase $\mathrm{Na}^{+} / \mathrm{K}^{+}$-ATPase and $\mathrm{Ca}^{2+}$-ATPase activities. LBPs ameliorate oxidative stress-induced cellular apoptosis by downregulating Bax and upregulating Bcl-2.

Abbreviations: LBPs, Lycium barbarum polysaccharides; SOD, superoxide dismutase; CAT, catalase; GPx, glutathione peroxidase; GR, glutathione reductase; I/R, ischemia/ reperfusion; HUVECs, human umbilical vein endothelial cells; Nrf2, nuclear factor erythroid 2-related factor; ROS, reactive oxygen species; MDA, malondialdehyde.

(0.8 million, 9.1\%), and stomach (0.7 million, $8.8 \%$ ). Projections based on the GLOBOCAN 2012 estimates predict a substantive increase to 19.3 million new cancer cases per year by 2025 , due to growth and aging of the global population. ${ }^{29}$ Cancer cells contain genetic mutations and have dysregulation of cell cycle, apoptosis, autophagy, and other critical processes. Presently, main cancer therapy modalities include surgery, radiation, hormone therapy, chemotherapy, and immunotherapy. The effect of radiotherapy, chemotherapy, immunotherapy, and hormone therapy is often compromised due to development of drug resistance and severe side effects. In this regard, there is a strong need to identify safe and potent anticancer compounds from natural resources. LBPs have been found to have apoptotic and anti-proliferative effects on cancer cells in vitro and in vivo, and LBPs may enhance the effects and reduce the side effects of other cancer therapies. ${ }^{30}$

\section{Breast cancer}

Breast cancer is the most common cancer in women worldwide. In 2012, 1.7 million women were diagnosed with 
breast cancer and 522,000 women died from breast cancer. ${ }^{29}$ In 2010, 206,966 women and 2,039 men in the US were diagnosed with breast cancer, and 40,996 women and 439 men died from this disease. ${ }^{31}$ Current chemotherapy for advanced breast cancer often fails due to tumor resistance and adverse drug effects. Natural medicines have become an important complementary approach for breast cancer treatment.

Li et $\mathrm{a}^{32}$ first reported that LBPs inhibited the growth of Michigan Cancer Foundation-7 (MCF-7) cells by changing the metabolic pathways of estradiol. LBPs exhibited a dosedependent growth inhibition of MCF-7 cells by $9.5 \%-42.8 \%$ at day 3 and by $33.9 \%-83.9 \%$ at day 7 . The 3-day inhibitory response to $1 \%$ LBPs (maximum cytostatic concentration) exhibited $84.8 \%$ increase in estrone $\left(\mathrm{E}_{1}\right), 3.6$-fold increase in $2-\mathrm{OH}-\mathrm{E}_{1}, 33.3 \%$ decrease in $16 \alpha-\mathrm{OH}-\mathrm{E}_{1}$, and 9.2 -fold increase in estriol $\left(\mathrm{E}_{3}\right)$ formation. ${ }^{32}$ Notably, LBPs appear to inhibit the proliferation of estrogen receptor-positive MCF-7 cells via modulation of estrogen metabolism and switch of metabolic pathways.

Shen and $\mathrm{Du}^{33}$ investigated the mechanisms for the antiproliferative effects of LBPs on MCF-7 cells. These cells were treated with 10-300 $\mathrm{mg} / \mathrm{L}$ LBPs for 24 hours. LBP treatment arrested MCF-7 cell cycle in S phase. ${ }^{33}$ LBPs dosedependently activated extracellular signal-regulated kinase $1 / 2$ (Erk1/2), which was associated with the expression of p53. These results indicated that LBPs inhibit the growth of $\mathrm{MCF}-7$ cells through activation of Erk1/2.

Telang et $\mathrm{al}^{34}$ compared the efficacy of aqueous extracts from L. barbarum bark (LBB) and LBF on MCF-7 cells. LBB exhibited greater potency than LBF $(95 \%$ reduction in the half maximal inhibitory concentration). LBB produced a 6.8 -fold increase, $40 \%$ decrease, and a 3.7 -fold increase in $2-\mathrm{OH}-\mathrm{E}_{1}$, $16 \alpha-\mathrm{OH}-\mathrm{E}_{1}$, and $\mathrm{E}_{3}$ formation. The corresponding values for LBF were 3.9, 33, and 10.5. LBB produced a 16.3-fold and twofold increase in 2-OH- $\mathrm{E}_{1}: 16 \alpha-\mathrm{OH}-\mathrm{E}_{1}$ and $\mathrm{E}_{3}: 16 \alpha-\mathrm{OH}-\mathrm{E}_{1}$ ratios, whereas $\mathrm{LBF}$ produced a six- and 2.9-fold increase, respectively. The efficacy of LBB is due to increased 2-OH-E formation, whereas that of $\mathrm{LBF}$ is due to accelerated conversion of $16 \alpha-O H-E_{1}$ to $E_{3}$. Specific growth inhibitory profiles of LBB and LBF may be due to their distinct chemical composition and their complementary actions on estrogen metabolism.

\section{Cervical carcinoma}

Cervical carcinoma is the third most common cancer in women, accounting for $9 \%$ of all female cancers and $9 \%$ of all cancer deaths in women. ${ }^{29}$ It is the seventh most common cancer in the world, with an estimated 528,000 new cases in 2012. Cervical carcinoma is the fourth most common cancer in women worldwide, after breast, colorectal, and lung cancers. There were an estimated 266,000 deaths from cervical cancer worldwide in 2012, accounting for 7.5\% of all female cancer deaths. ${ }^{29}$ In 2010, 11,818 women in the US were diagnosed with cervical cancer and 3,939 women died from this disease. Cervical cancer is the sixth most common cancer in Europe for women, with around 58,400 new cases diagnosed in 2012. In 2011, there were 3,064 new cases of cervical cancer and 972 deaths from cervical cancer in the UK. Cervical cancer is predominantly a disease of lowincome countries, with overall rates nearly twice as high in less developed regions compared to more developed regions. Cervical cancer incidence rates are highest in Eastern Africa and lowest in Western Asia. There is increased interest in seeking new therapies for cervical carcinoma from natural compounds.

$\mathrm{Hu}$ et $\mathrm{al}^{35}$ used LBPs in combination with garlic to treat mice bearing human cervical U14 cancer. Examination of ascitic fluid revealed damage of the cancer cells by LBPs plus garlic, blanching of fluorescence staining of DNA and RNA, and the cancer cells besieged by large numbers of macrophages and leukocytes. ${ }^{35}$ Flow cytometric analysis found accumulation of cells in $\mathrm{G}_{1}$ phase. The number of $\mathrm{S}$ phase cells decreased from $56 \%$ to $49 \%$, and the number of $\mathrm{G}_{0} / \mathrm{G}_{1}$ phase cells increased from $16 \%$ to $33 \%$. LBPs plus garlic also resulted in swelling of mitochondria in cytoplasm, damage of mitochondrial crests with cavity formation, and enlargement and degranulation of rough endoplasmic reticulum. ${ }^{35}$

Zhu and $Z_{\text {hang }}{ }^{36}$ investigated the mechanisms for the anti-proliferative effects of LBPs in human cervical cancer HeLa cells. LBPs were extracted from dried fruits of L. barbarum harvested in Ningxia, People's Republic of China. Incubation of HeLa cells with $6.25 \mathrm{mg} / \mathrm{mL}$ LBPs for 4 days resulted in a $35 \%$ inhibition of cell growth. A significant accumulation of cells in the $\mathrm{S}$ phase $(46.9 \%-59.4 \%)$ and sub- $\mathrm{G}_{1}$ phase $(3.1 \%-5.0 \%$, indicating cellular apoptosis) was observed when treated with 6.25-100 mg/L LBPs for 4 days, together with significantly decreased proportions of cells in the $\mathrm{G}_{0} / \mathrm{G}_{1}$ phase (from $56.8 \%$ to $31.4 \%$ ). ${ }^{36}$ The loss of mitochondrial transmembrane potential $\left(\Delta \psi_{\mathrm{m}}\right)$ was observed by flow cytometer; and the percentage of $\Delta \psi_{\mathrm{m}}$ collapse was $6.78 \%$ following treatment with $6.25 \mathrm{mg} / \mathrm{L}$ LBPs. LBPs also dose-dependently increased intracellular $\mathrm{Ca}^{2+}$ concentration as detected by laser scanning confocal microscope in apoptotic cells. About 6.25-100 mg/L LBPs increased the NO content in the medium from $33.67 \mu \mathrm{M}$ at the basal level to $79.17-101.03 \mu \mathrm{M}$ in HeLa cells. ${ }^{36}$ The NO synthase and inducible NO synthase activities in the culture 
medium were also significantly increased in HeLa cells treated with $100 \mathrm{mg} / \mathrm{L}$ LBPs. These findings indicate that LBPs inhibit the growth of HeLa cells through induction of mitochondria-mediated apoptosis.

\section{Colorectal cancer}

Colorectal cancer is the third most common cancer in the world, with nearly 1.4 million new cases diagnosed in $2012 .{ }^{29}$ Colorectal cancer is the second leading cause of cancerrelated deaths in the US and the third most common cancer in men and women. ${ }^{37}$ In 2010, 131,607 people in the US were diagnosed with colorectal cancer, including 67,700 men and 63,907 women; 52,045 people died from this disease, including 27,073 men and 24,972 women. ${ }^{37}$ In 2011, 41,581 people in the UK were diagnosed with colorectal cancer and 15,659 people died from this disease. As a result of the relatively poor prognosis and response to conventional chemo- and radiotherapy, there is a great need for the discovery of new effective agents for colorectal cancer.

When human colon cancer cell lines SW480 and Caco-2 cells were treated with 100-1,000 mg/L LBPs for 1-8 days, LBPs inhibited the proliferation of both cell lines in a dosedependent manner. ${ }^{38}$ At concentrations from $400 \mathrm{mg} / \mathrm{L}$ to $1,000 \mathrm{mg} / \mathrm{L}, \mathrm{LBPs}$ significantly inhibited the growth of SW480 cells; while at concentrations from $200 \mathrm{mg} / \mathrm{L}$ to $1,000 \mathrm{mg} / \mathrm{L}$, they significantly inhibited the growth of Caco- 2 cells. ${ }^{38}$ The crystal violet assay showed that the number of adherent cancer cells was decreased by treatment with $100-1,000 \mathrm{mg} / \mathrm{L}$ LBPs for 8 days. Cells were arrested at the $\mathrm{G}_{0} / \mathrm{G}_{1}$ phase with a decrease in $\mathrm{S}$ phase when treated with LBPs. ${ }^{38}$ About 100-1,000 mg/L LBPs downregulated the expression of cyclin D, cyclin E, and cyclin-dependent kinase 2 (CDK2) in colon cancer cells. Cyclin E/CDK2 regulates multiple cellular processes by phosphorylating numerous downstream proteins. There is deregulated expression of cyclin D, cyclin $\mathrm{E}$, and CDK2 in colorectal cancer. These data demonstrate the antiproliferative effects of LBPs against colorectal cancer cells via modulation of critical cell cycle regulators.

\section{Gastric cancer}

Gastric cancer is the fifth most common cancer and the third leading cause of death from cancer globally with approximately 952,000 new cases and 723,000 deaths making up 7\% of all cancer cases and $9 \%$ of deaths. ${ }^{29,39}$ Almost two-thirds of gastric cancer cases occur in developing countries and $42 \%$ in People's Republic of China accounting for $3.99 \%$ of all deaths. ${ }^{40}$ There are about 22,220 new cases of gastric cancer and 10,990 deaths every year in the US. In the UK,
7,089 people were diagnosed with gastric cancer and 4,830 deaths due to this disease were recorded in $2011 . .^{40}$ The 5-year relative survival rate of gastric cancer is as low as $<10 \%$. ${ }^{39-42}$ Therefore, there is an urgent need to identify novel therapeutic strategies for later stage gastric cancer.

When human gastric cancer MGC-803 and SGC-7901 cells were treated at various concentrations of LBPs for 1-5 days, LBP treatment inhibited the growth of MGC-803 and SGC-7901 cells, with cell cycle arrest at the $\mathrm{G}_{0} / \mathrm{G}_{1}$ and S phases, respectively. ${ }^{43}$ The changes in cell cycle-associated proteins, such as cyclins and CDKs, were consistent with the changes in cell cycle distribution. The results suggested that induction of cell cycle arrest contributes to the anticancer activity of LBPs in gastric cancer cells.

\section{Leukemia}

Leukemia is a cancer of the white blood cells and bone marrow. Worldwide, around 352,000 people were estimated to have been diagnosed with leukemia in $2012 .{ }^{29}$ In 2014, it is estimated that there will be 52,380 new cases of leukemia and an estimated 24,090 people will die of this disease in the US. ${ }^{40}$ In 2011, 8,616 people in the UK were diagnosed with leukemia (all subtypes combined) and there were 4,603 deaths from leukemia. In Europe, around 82,300 new cases of leukemia were estimated to have been diagnosed in 2012. There are four main subtypes of leukemia: acute myeloid leukemia, acute lymphoblastic leukemia, chronic myeloid leukemia, and chronic lymphocytic leukemia. About 20-1,000 mg/L LBPs inhibited the growth of human promyelocytic leukemia HL-60 cells in a dose-dependent manner. ${ }^{44}$ LBPs also induced the apoptosis of HL-60 cells as determined by DNA ladder and terminal deoxynucleotidyl transferase dUTP nick end labeling assays.

\section{Liver cancer}

Liver cancer is the sixth most common cancer in the world, with 782,000 new cases diagnosed in 2012. ${ }^{29}$ Worldwide, it is the third leading cause of cancer deaths. The estimated number of new cases with liver cancer in 2014 in the US is 33,190 , with estimated deaths of 23,000 due to liver cancer. ${ }^{40}$ In the UK, 4,348 people were diagnosed with liver cancer in 2011 and 4,106 people died from liver cancer in 2011. Hepatocellular carcinoma is the most common type of primary liver cancer, and factors that increase the risk of developing hepatocellular carcinoma include long-term, heavy alcohol use and chronic infection with hepatitis $\mathrm{B}$ or $\mathrm{C}$ viruses.

Zhang et $\mathrm{al}^{45}$ reported that $100 \mathrm{mg} / \mathrm{L}$ LBPs inhibited the proliferation of human hepatoma QGY7703 cells, induced 
cell cycle arrest, and significantly increased intracellular $\mathrm{Ca}^{2+}$ level. When rat H-4-II-E and human liver cancer HA22T/VGH cell lines were incubated with various concentrations of crude L. barbarum extract (mainly LBPs), the extract at $\geq 5 \mathrm{~g} / \mathrm{L}$ inhibited the cellular proliferation, promoted $\mathrm{G}_{2} / \mathrm{M}$ phase arrest, and stimulated p53-mediated apoptosis in $\mathrm{H}-4$ II-E and HA22T/VGH cells. ${ }^{46}$ The effect may be due to inhibition of nuclear factor (NF)- $\mathrm{\kappa B}$ that alters the expression of regulatory cell cycle proteins such as cyclin $\mathrm{B}$ and p21WAF1/Cip1.

Zhang et $\mathrm{al}{ }^{47}$ found that different fractions of LBPs at the dose of 50-400 mg/L for 2 days, 4 days, and 6 days showed distinct effects on the proliferation, cell cycle distribution, and apoptosis in human liver cancer SMMC-7721 cells. LBP-a4 had the highest inhibition activity of $36.5 \% \pm 2.6 \%$ at the dose of $400 \mathrm{mg} / \mathrm{L}$ for 2 days. LBPs were extracted from fruits of Chinese wolfberry obtained from Xinjiang province, People's Republic of China, and LBP fractions were isolated by ultrafiltration membranes with molecular weight cutoff (MWCO) of $80 \mathrm{kDa}, 30 \mathrm{kDa}, 10 \mathrm{kDa}$, and $4 \mathrm{kDa}$ successively. Polysaccharides fractions LBP-a8, LBP-p8, LBP-a3, LBP-a1, and LBP-a4 were obtained by freeze-drying the retentates of ultrafiltration with MWCO of $80 \mathrm{kDa}, 30 \mathrm{kDa}$, and $10 \mathrm{kDa}$ and permeates of ultrafiltration with $\mathrm{MWCO}$ of $4 \mathrm{kDa}$. The results showed that LBP-a8, LBP-a3, LBP-a1, and LBP-a4 inhibited the growth of SMMC-7721 cells in a concentration- and time-dependent manner. ${ }^{47}$ In contrast, LBP-p8 promoted the proliferation of SMMC-7721 cells to $183.5 \% \pm 4.7 \%$ of the control group at the concentration of $200 \mathrm{mg} / \mathrm{L}$ for 4 days. Treatment of SMMC-7721 cells with $400 \mathrm{mg} / \mathrm{L}$ LBP-a4 for 4 days arrested the cells at $\mathrm{G}_{0} / \mathrm{G}_{1}$ phase and increased the intracellular $\mathrm{Ca}^{2+}$ concentration. ${ }^{47}$ Cells treated with LBP-a4 at $\mathrm{G}_{0} / \mathrm{G}_{1}$ phase increased from $49.21 \%$ to $69.65 \%$, while cells at $\mathrm{S}$ phase and $\mathrm{G}_{2} / \mathrm{M}$ phase decreased from $40.53 \%$ and $10.26 \%$ to $24.79 \%$ and $5.56 \%$, respectively. However, incubation of cells with $200 \mathrm{mg} / \mathrm{L}$ LBP-p8 for 4 days only slightly increased the cell ratio of $\mathrm{G}_{0} / \mathrm{G}_{1}(52.84 \%)$ and $\mathrm{S}(42.13)$ phase. The intracellular $\mathrm{Ca}^{2+}$ concentration of SMMC-7721 cells treated with $400 \mathrm{mg} / \mathrm{L}$ LBP-a4 for 4 days was 1.59-fold higher than that of control cells, while that of LBP-p8-treated cells was only 1.07 times higher than that of control cells. ${ }^{47} \mathrm{LBP}-\mathrm{a} 4$ consisted of $11.5 \%$ uronic acid, $0.34 \%$ protein, and $39.02 \%$ neutral sugar, while LBP-p8 consisted of $13.4 \%$ uronic acid, $4.77 \%$ protein, and $26.26 \%$ neutral sugar. LBP-p8 consisted of seven kinds of monosaccharides including fucose, rhamnose, arabinose, xylose, glucose, mannose, and galactose, and LBP-a4 was composed of six kinds of monosaccharides including fucose, arabinose, xylose, glucose, mannose, and galactose (Figure 1C). The average molecular weight of LBP-a4 and LBP-p8 were $10.20 \mathrm{kDa}$ and $6.50 \times 10^{3} \mathrm{kDa}$, respectively. These findings demonstrate a clear impact of LBP components and structures on the activities of LBPs.

\section{Sarcoma}

Sarcoma is a type of cancer that develops from certain tissues such as bone or muscle. ${ }^{48}$ There are two main types of sarcoma: bone sarcomas and soft tissue sarcomas. Soft tissue sarcomas can develop from soft tissues like fat, muscle, nerves, fibrous tissues, blood vessels, or deep skin tissues. The most common types of sarcoma in adults are malignant fibrous histiocytoma, liposarcoma, and leiomyosarcoma. About 12,020 people (6,550 males and 5,470 females) will be diagnosed with soft-tissue sarcoma in the US and an estimated 4,740 people will die of the disease in 2014. ${ }^{40}$ Around 3,300 people were diagnosed with soft tissue sarcoma in 2010 in the UK. For sarcomas that have spread to distant parts of the body, the five-year survival is $16 \%$. The effect of a polysaccharide-protein complex from L. barbarum (LBP3p) on the immune system in S180-bearing mice was investigated by Gan et al. ${ }^{49}$ The mice inoculated with $\mathrm{S} 180$ cell suspension were treated orally with $5 \mathrm{mg} / \mathrm{kg}, 10 \mathrm{mg} / \mathrm{kg}$, and $20 \mathrm{mg} / \mathrm{kg}$ LBP3p for 10 days. The effects of LBP3p on transplantable tumors and macrophage phagocytosis, quantitative hemolysis of mouse red blood cells, lymphocyte proliferation, cytotoxic T lymphocyte (CTL) activity, IL-2 gene expression, and lipid peroxidation were determined. LBP3p significantly inhibited the growth of transplantable sarcoma S180 and increased macrophage phagocytosis, the form of antibody secreted by spleen cells, spleen lymphocyte proliferation, CTL activity, $I L-2$ messenger (m) RNA expression level and reduced the lipid peroxidation in S180-bearing mice. ${ }^{49}$ The dose of $10 \mathrm{mg} /$ $\mathrm{kg} \mathrm{LBP3}$ p was more effective than that of $5 \mathrm{mg} / \mathrm{kg}$ and $20 \mathrm{mg} /$ $\mathrm{kg} \mathrm{LBP3p}$. These data suggest that LBP3p inhibited sarcoma growth in vivo via enhanced immune activities.

\section{Prostate cancer}

Prostate cancer is the second most common cancer in men worldwide, after lung cancer. ${ }^{50}$ There were over 903,500 new prostate cancer cases reported worldwide and an estimated 258,400 men died from this disease in 2008. ${ }^{29} \mathrm{In}$ the US, 196,038 men were diagnosed with prostate cancer, and 28,560 men died from this disease in $2010 .^{51}$ In the UK, 40,975 men were diagnosed with prostate cancer in 2010, and 10,793 men died from this disease in $2011 .{ }^{52}$ Chemotherapy for prostate cancer usually brings drug resistance and severe 
adverse reactions in patients. Therefore, new anticancer drugs that can prevent the progression of prostate cancer and execute prostate cancer cells with improved efficacy and reduced side effects are urgently needed.

The effects of LBPs on the growth of human prostate cancer cells were examined in vitro and in vivo by Luo et al. ${ }^{53}$ LBPs inhibited the growth of both PC-3 and DU-145 cells in a dose- and time-dependent manner, by breaking their DNA strands and inducing the apoptosis of these cells. The Bcl-2/Bax expression decreased significantly after LBP treatments and the ratio of $\mathrm{Bcl}-2 / \mathrm{Bax}$ expression following LBP treatment also decreased significantly with a doseeffect relationship, ${ }^{53}$ which suggested that LBPs regulated the expression of $\mathrm{Bcl}-2$ and $\mathrm{Bax}$ to induce apoptosis of PC-3 and DU-145 cells. The animal study showed that LBPs significantly inhibited PC-3 xenograft growth in nude mice with significant reduction of the tumor volume and weight in the LBP-treated group than in those of the control group. ${ }^{53}$

\section{Clinical study of LBPs in cancer patients}

In a clinical trial, 79 patients with advanced cancer were treated with lymphokine-activated killer (LAK)/IL-2 in combination with LBPs. ${ }^{54}$ Initial results indicated that objective regression of cancer was achieved in patients with malignant melanoma, renal cell carcinoma, colorectal carcinoma, lung cancer, nasopharyngeal carcinoma, and malignant hydrothorax. The response rate of patients treated with LAK/IL-2 plus LBPs was higher than that of patients treated with LAK/IL-2 alone. ${ }^{54}$ The mean remission in patients treated with LAK/IL-2 plus LBPs also lasted significantly longer. LAK/IL-2 plus LBP treatment led to more marked increase in natural killer (NK) and LAK cell activity than LAK/IL-2 alone. ${ }^{54}$ LBPs may be used as an adjuvant in the biotherapy of cancer.

\section{Summary of the anticancer activities of LBPs}

LBPs inhibit the proliferation of various types of cancer cells and induce cell cycle arrest at the $\mathrm{G}_{0} / \mathrm{G}_{1}, \mathrm{~S}$, or $\mathrm{G}_{2} / \mathrm{M}$ phase (Figure 4). They inhibit the growth of cancer xenografts in nude mice. In cancer patients, LAK/IL-2 plus LBP treatment leads to more marked increase in NK and LAK cell activity than LAK/IL-2 alone (Figure 5). LBPs regulate the expressions of Bcl-2 and Bax to induce tumor cell apoptosis by increasing intracellular $\mathrm{Ca}^{2+}$ concentration and mitochondrial pathway. Furthermore, LBPs inhibit the growth of MCF-7 cells through activation of Erk $1 / 2$ and modulation of estrogen metabolism. LBPs downregulate the expression of cyclin D, cyclin E, and CDK2 in colon cancer cells. Moreover, LBPs stimulate $\mathrm{p} 53$-mediated apoptosis in liver cancer cells due to inhibition of NF- $\mathrm{KB}$.

\section{Antifatigue effects}

Chronic fatigue syndrome (CFS) is a complicated disorder characterized by persistent fatigue that lasts for at least 6 months for adults and 3 months for children or adolescents, with at least four additional symptoms: impaired memory or concentration, sore throat, tender cervical or axillary lymph nodes, muscle pain, multi-joint pain, new headaches, unrefreshing sleep, or post-exertion malaise. ${ }^{55-58}$ The fatigue is not due to exertion, not significantly relieved by rest, and is not caused by other medical conditions. The Centers for Disease Control report that more than 1 million Americans have CFS and approximately $80 \%$ of the cases are undiagnosed. Approximately 250,000 people in the UK are affected with the illness according to the National Health Service. Pharmacotherapy plays a minor role in CFS management, but herbal medicines may produce some benefits for CFS. The antifatigue effect of LBPs was tested with five different doses $(5 \mathrm{mg} / \mathrm{kg} /$ day, $10 \mathrm{mg} / \mathrm{kg} /$ day, $20 \mathrm{mg} / \mathrm{kg} /$ day, $50 \mathrm{mg} / \mathrm{kg} / \mathrm{day}$, and $100 \mathrm{mg} / \mathrm{kg} /$ day) in mice. ${ }^{59}$ The results showed that LBPs induced remarkable adaptability to exercise load, enhanced resistance, and accelerated elimination of fatigue. LBPs could enhance the storage of muscle and liver glycogen, increase the activity of LDH before and after swimming, decrease the increase of blood urea nitrogen after strenuous exercise, and accelerate the clearance of blood urea nitrogen after exercise. The dosage of $10 \mathrm{mg} / \mathrm{kg} /$ day LBPs was the most effective among the five tested doses..$^{59}$

\section{Antiviral effects}

Wang et $\mathrm{a}^{60}$ prepared four sulfated $L$. barbarum polysaccharides (sLBPs), sLBPS(0.7), sLBPS(1.1), sLBPS(1.5), and sLBPS(1.9), and compared their effects on the cellular infectivity of Newcastle disease viruses (NDVs) in chick embryo fibroblasts. Four sLBPSs at five concentrations, within the safety concentration scope, and NDVs were added into the cultivating system of chick embryo fibroblasts in three modes, pre- and post-adding polysaccharide, and simultaneous adding of polysaccharide and viruses after being mixed. The effects of sLBPSs on cellular infectivity of NDVs were assayed by MTT method taking the nonmodified LBPS as the control ${ }^{60}$ The results showed that sLBPS(1.5), sLBPS(1.9), and sLBPS(1.1) in three sample-adding modes, $\operatorname{sLBPS}(0.7)$ in simultaneous adding after being mixed, significantly inhibited the infectivity of NDVs. The viral inhibitory rate of sLBPS(1.5) in pre-adding and simultaneous adding, and 


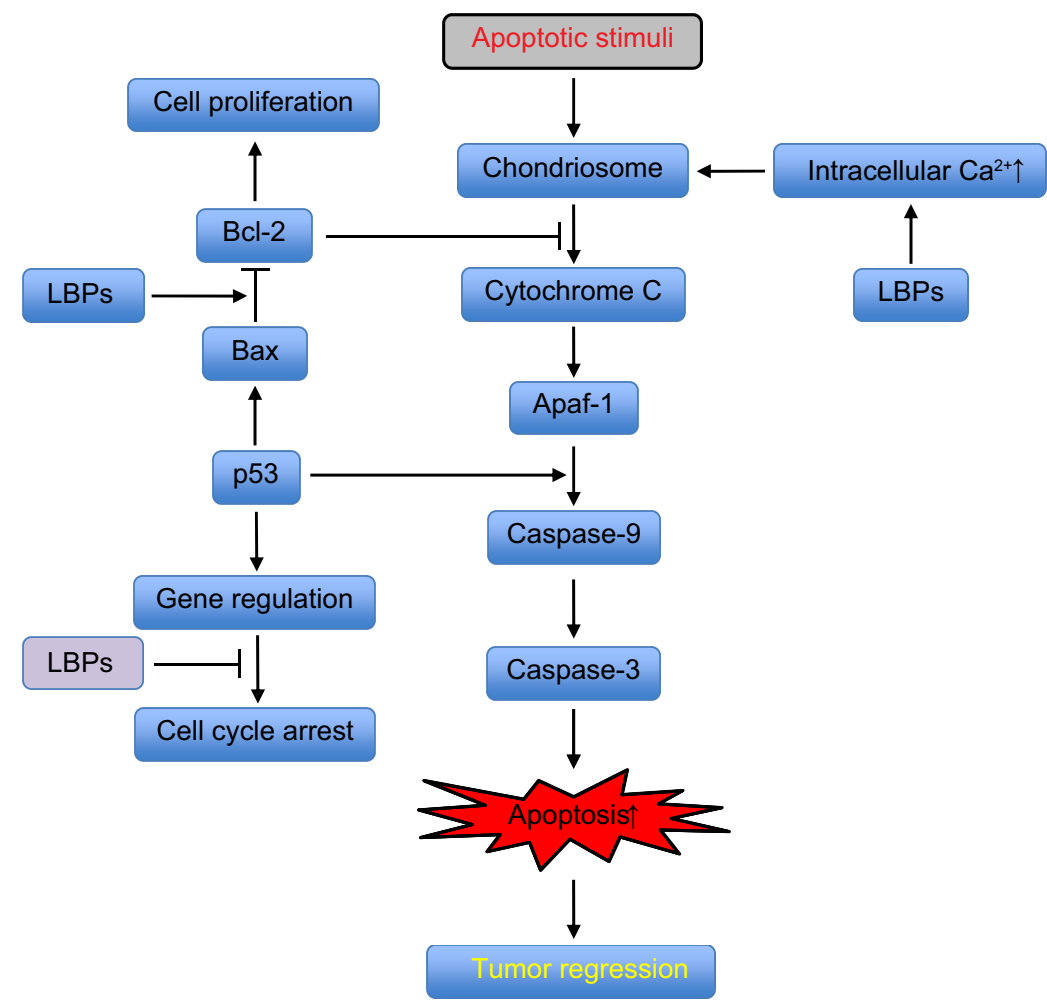

Figure 4 Possible mechanisms for the anticancer activities of LBPs.

Notes: LBPs inhibit the proliferation of various types of cancer cells and induce cell cycle arrest at the $G_{0} / G_{1}, S$, or $G_{2} / M$ phase. LBPs inhibit the growth of cancer xenografts in nude mice. In cancer patients, LAK/IL-2 plus LBP treatment leads to more marked increase in NK and LAK cell activity than LAK/LL-2 alone. LBPs regulate the expression of $\mathrm{Bcl}-2$ and Bax to induce tumor cell apoptosis via increasing intracellular $\mathrm{Ca}^{2+}$ concentration and mitochondrial pathway. LBPs inhibit the growth of MCF-7 cells through activation of ErkI/2 and modulation of estrogen metabolism. LBPs downregulate the expression of cyclin D, cyclin E, and CDK2 in colon cancer cells. LBPs stimulate p53mediated apoptosis in liver cancer cells due to inhibition of NF-KB.

Abbreviations: LBPs, Lycium barbarum polysaccharides; IL-2, interleukin-2; NK, natural killer; LAK, lymphokine activated killer; MCF-7, Michigan Cancer Foundation-7; CDK2, cyclin-dependent kinase 2; NF- $\mathrm{kB}$, nuclear factor $\mathrm{\kappa B}$.
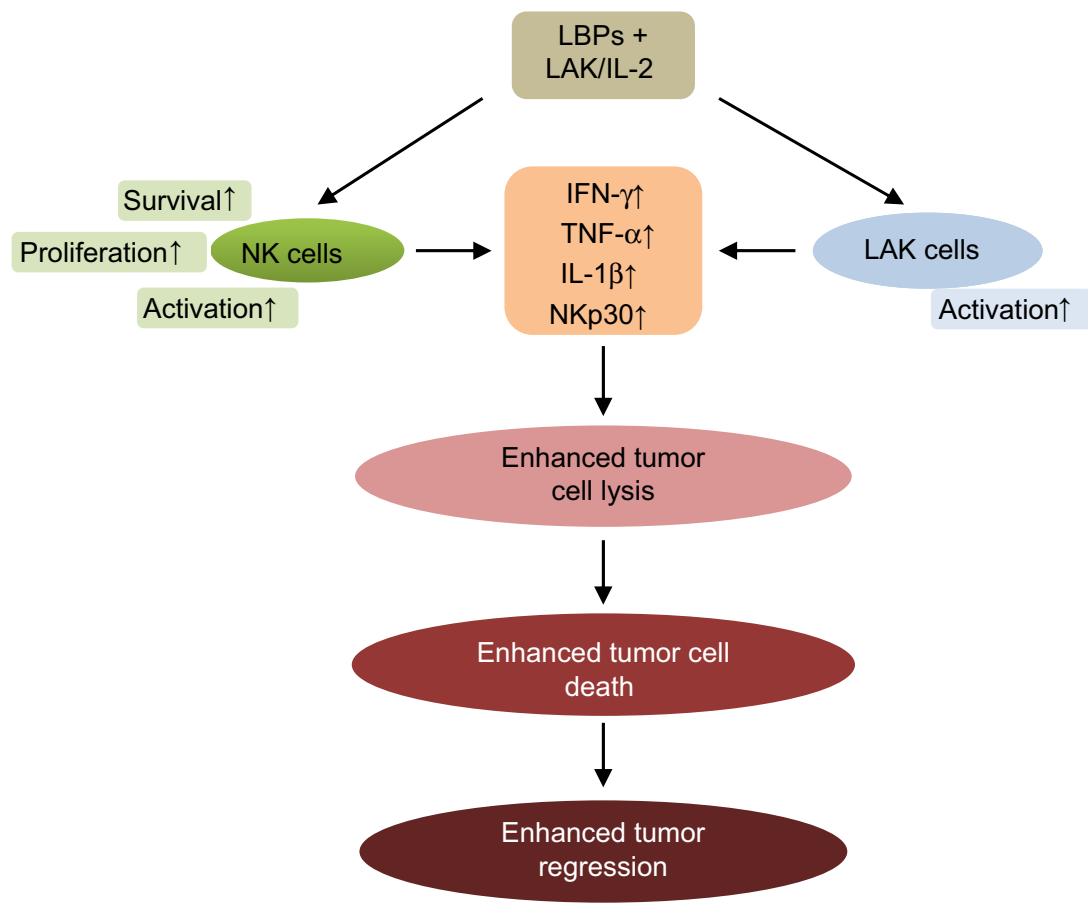

Figure 5 LBPs potentiate the immune-enhancing activity of LAK/IL-2 therapy in cancer patients.

Notes: LBPs enhance NK and LAK cell activities in cancer patients treated with LAK/IL-2, resulting in an increase in tumor cell lysis and death.

Abbreviations: LBPs, Lycium barbarum polysaccharides; IFN, interferon; IL-2, interleukin-2; NK, natural killer; LAK, lymphokine activated killer; TNF, tumor necrosis factor. 
sLBPS(1.9) in post-adding, was the highest. Nonmodified LBPS did not present significant effect in any sample-adding mode. ${ }^{60}$ These results indicated that sulfated modification significantly enhanced the antiviral activity of LBPs, which was correlated with the degree of sulfation of LBPs. The mechanisms for the antiviral activity of LBPs are unknown.

\section{Cardioprotective effects}

\section{Ischemic heart disease and I/R injury}

Ischemic heart disease is the leading cause of death worldwide, causing 7,249,000 deaths in 2008, $12.7 \%$ of total global mortality. ${ }^{61}$ From 2006 to 2010 , age-adjusted ischemic heart disease prevalence in the US declined overall from $6.7 \%$ to $6.0 \%{ }^{62}$ The myocardial protective effects of LBPs have been studied in rats and beagle dogs. ${ }^{63-66}$

$\mathrm{Lu}$ and $\mathrm{Zhao}^{63}$ investigated the protective effects of LBPs on myocardial I/R damage in Wistar adult male rats. Dry Goji fruits were purchased from the herbs market in Xi'an city, Shaanxi, People's Republic of China, and LBPs were extracted with methanol, acetone, ethanol, and boiling water. Rat hearts were rapidly excised from anesthetized rats and perfused retrogradely in Krebs-Henseleit solution at $15 \mathrm{~mL} / \mathrm{min}$ at $37^{\circ} \mathrm{C}$ and aerated with $95 \% \mathrm{O}_{2}$ plus $5 \% \mathrm{CO}_{2}$ to maintain normal $\mathrm{pH}, \mathrm{pO}_{2}$, and $\mathrm{pCO}_{2}$ levels. Surgical rats were treated with $150 \mathrm{mg} / \mathrm{kg}$ or $300 \mathrm{mg} / \mathrm{kg}$ body weight LBPs and subject to myocardial I/R injury. LBPs significantly decreased the myocardium LDH level and increased $\mathrm{Na}^{+} / \mathrm{K}^{+}$-ATPase and $\mathrm{Ca}^{2+}$-ATPase activities. ${ }^{63}$ In addition, LBPs dose-dependently decreased myocardium
Bax-positive cell rate and myocardial cell apoptosis and increased Bcl-2-positive cell rate. ${ }^{63}$ These results suggest that LBPs protected rat heart from I/R injury via upregulation of heart $\mathrm{Na}^{+} / \mathrm{K}^{+}$-ATPase and inhibition of cardiomyocyte apoptosis. In summary, the cardioprotective effect of LBPs against I/R injury is mainly due to the antioxidative, anti-inflammatory, and anti-apoptotic activities of LBPs (Figure 6).

\section{Doxorubicin-induced cardiotoxicity}

Doxorubicin (DOX) is a potent antitumor agent, but its dosedependent cardiotoxicity limits its clinical use. DOX-induced cardiotoxicity involves the formation of free radicals and amplification of mitochondrial dysfunction. Due to relatively lower levels of CAT and the readily deactivated GPx in the cardiomyocytes, the heart is more susceptible to oxidative damage than other tissues. As an antioxidant, the cardioprotective effect of LBPs has been demonstrated in acute DOXinduced cardiotoxicity in rats ${ }^{66}$ and beagle dogs. ${ }^{65}$ Inhibition of oxidative stress is thought to be the main mechanism of the cardioprotective effects of LBPs. Xin et a ${ }^{66}$ suggested that LBPs might protect against DOX-induced cardiotoxicity through antioxidant-mediated mechanisms.

Xin et $a 1^{65}$ conducted a mechanistic study in male Sprague-Dawley rats to explore the protective effect of LBPs on DOX-induced cardiotoxicity. Rats were administered orally with $200 \mathrm{mg} / \mathrm{kg}$ /day LBPs for 10 continuous days. About $10 \mathrm{mg} / \mathrm{kg}$ DOX was administered to rats via intravenous injection at day 7 . At the end of the experiment,

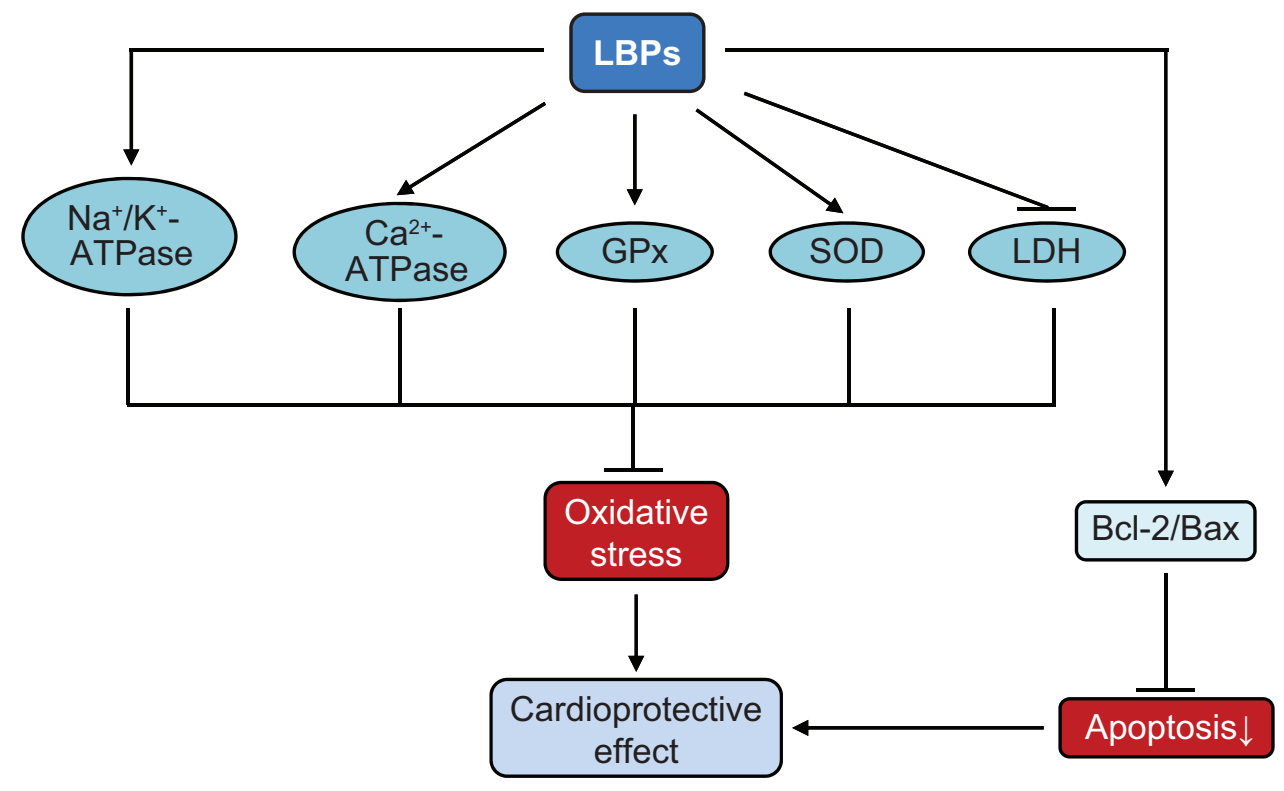

Figure 6 Possible mechanisms for the cardioprotective effects of LBPs.

Notes: LBPs exert a remarkable cardioprotective effect in in vitro and in vivo models. LBPs increase the activity of $\mathrm{Na}^{+} / \mathrm{K}^{+}-\mathrm{ATPase}$ and $\mathrm{Ca}^{2+}-\mathrm{ATPase}$, enhance the expression of GPx, SOD, and reduce the production of LDH, resulting in a marked reduction in oxidative stress. Also, LBPs increase the ratio of anti-apoptotic factor (Bcl-2) and decrease the pro-apoptotic factor (Bax), protecting the myocardial cells from apoptotic cell death.

Abbreviations: LBPs, Lycium barbarum polysaccharides; SOD, superoxide dismutase; GPx, glutathione peroxidase; LDH, lactate dehydrogenase. 
the rats were sacrificed with hearts promptly removed for biochemical and histological analysis. The results showed that pretreatment with $200 \mathrm{mg} / \mathrm{kg}$ LBPs for 10 days significantly reduced DOX-induced oxidative injury in cardiac tissue and significantly attenuated DOX-induced cardiac cytoplasmic vacuolization and myofibrillar disarrangement. ${ }^{65}$ LBP pretreatment decreased heart MDA level and increased heart SOD and GPX activities in DOX-treated rats. LBPs decreased the levels of serum CK and partially reversed DOX-induced bradycardia and prolonged QT interval as determined by electrocardiography. ${ }^{65}$ Furthermore, the cytotoxic study in vitro showed that $100 \mu \mathrm{g} / \mathrm{mL}$ LBPs protected against cytotoxicity of DOX in cardiac myoblasts H9c2. Incubation of human lung carcinoma A549 cells with $200 \mu \mathrm{g} / \mathrm{mL}$ LBPs did not alter the antiproliferative activity of DOX. These data indicated that LBPs elicit a potent protective effect on DOX-induced cardiomyocyte damages mainly via antioxidative and free radical-scavenging pathways.

Xin et $\mathrm{al}^{64}$ carried out a further study in beagle dogs to examine if LBPs alleviated DOX-induced cardiotoxicity. Intravenous administration of $15 \mathrm{mg} / \mathrm{kg}$ DOX significantly induced acute cardiotoxicity in beagle dogs characterized by conduction abnormalities including decreased heart rate, ST segment elevation, QT intervals prolongation, inverted $\mathrm{T}$ wave, arrhythmia, and myocardial ischemia and increased serum CK and aspartate aminotransferase (AST). ${ }^{64}$ Oral pretreatment with $20 \mathrm{mg} / \mathrm{kg}$ body weight LBPs daily for 7 days effectively alleviated both DOX-induced conduction abnormalities and increased serum CK and AST. ${ }^{64}$ All these results confirm and extend previous observations in rats concerning the protective effect of LBPs against DOXinduced cardiotoxicity.

\section{Effects of LBPs on experimental colitis}

Inflammatory bowel disease (IBD) is a broad term that describes conditions with chronic or recurring immune response and inflammation of the gastrointestinal tract. ${ }^{67-70}$ The two most common IBDs are ulcerative colitis and Crohn's disease. In contrast to Crohn's disease, ulcerative colitis is restricted to the colon and the inflammation is limited to the mucosal layer. ${ }^{71}$ Patients affected by these diseases experience abdominal symptoms, including diarrhea, abdominal pain, bloody stools, and vomiting. The data that does exist suggest that the worldwide incidence rate of ulcerative colitis varies greatly between 0.5 and 24.5/100,000 persons, while that of Crohn's disease varies between 0.1 and $16 / 100,000$ persons worldwide, with the prevalence rate of IBD reaching up to $396 / 100,000$ persons. ${ }^{72}$ The major classes of drugs used today to treat IBD include aminosalicylates, steroids, immune modifiers (azathioprine, 6-mercaptopurine, and methotrexate), antibiotics (metronidazole, ampicillin, ciprofloxin, others), and biologic therapy (inflixamab). ${ }^{70}$ All these drugs may produce side effects.

Zhao et $\mathrm{al}^{73}$ investigated the prophylactic and curative effects of crude polysaccharides (QHPS) extracted from a two-herb formula composed of LBPs and Astragalus (Huangqi) at a ratio of 2:3 in colitis rats. An acetic acidinduced ulcerative colitis rat model was used in the study. The results showed that QHPS treatments effectively reduced the ulcerative colitis-associated weight loss and diarrhea and attenuated the colonic mucosal damage associated with inducible colitis. The significant increase in serum levels of diamine oxidase, D-lactate, and endotoxin was induced by acetic acid and inhibited by QHPS treatment. ${ }^{73}$ Furthermore, QHPS significantly stimulated rat intestinal epithelial cell-6 proliferation in a dose-dependent manner. This study indicated that polysaccharides extracted from this two-herb formula could protect against experimental ulcerative colitis, presumably by promoting the recovery of the intestinal barrier.

\section{Effects of LBPs on intestinal I/R injury}

Intestinal $\mathrm{I} / \mathrm{R}$ is a frequently occurring condition during abdominal and thoracic vascular surgery, small bowel transplantation, hemorrhagic shock, and surgery using cardiopulmonary bypass, with high morbidity and mortality. ${ }^{74}$ Intestinal $\mathrm{I} / \mathrm{R}$ is associated with intestinal barrier function loss, which facilitates bacterial translocation into the circulation, thereby triggering systemic inflammation. Moreover, reperfusion of ischemically damaged intestinal tissue further aggravates tissue damage and is considered to be an effector of local as well as distant inflammation and multiple organ failure, which remains the leading cause of death in critically ill patients. ${ }^{74}$

In a recent study, Yang et $\mathrm{al}^{75}$ examined the effects and potential mechanisms of LBPs on intestinal $\mathrm{I} / \mathrm{R}$ injury in rats. A common $\mathrm{I} / \mathrm{R}$ model was used to induce intestinal injury by clamping and unclamping the superior mesenteric artery in rats. Changes in the MDA, tumor necrosis factors (TNF)- $\alpha$, activated NF- $\kappa \mathrm{B}$, intercellular adhesion molecule (ICAM)-1, E-selectin, and related antioxidant enzyme levels, polymorphonuclear neutrophil accumulation, intestinal permeability, and intestinal histology were monitored. LBPs showed marked inhibitory effect against free radicals and lipid peroxidation in vitro. ${ }^{75}$ LBPs increased the levels of antioxidant enzymes and reduced intestinal oxidative injury in animal models of intestinal I/R. In addition, LBPs inhibited polymorphonuclear neutrophil accumulation 
and ICAM-1 expression, and ameliorated changes in the TNF- $\alpha$ level, NF- $\kappa$ B activation, intestinal permeability, and histology. ${ }^{75}$ These results indicate that LBPs protect against I/R-induced intestinal injuries, possibly through inhibiting I/R-induced oxidative stress, cytokine production, and inflammation.

\section{Effects of LBPs on experimental glaucoma and $\mathrm{I} / \mathrm{R}$-induced retinal injury}

Retinal I/R injury is associated with many ocular diseases, including glaucoma, amaurosis, fugax, and diabetic retinopathy. Oxidative injury is one of the complications after retinal I/R injuries accompanied by retinal swelling, disrupted blood-retinal barrier (BRB), neuronal cell death, and glial cell activation. ${ }^{76}$ The role of $\mathrm{BRB}$ is to maintain the homeostatic condition of retinal microenvironment and exclude harmful substance getting into the retina. The outer barrier is formed by the retinal pigment epithelium, separating the outer retina from the choroid; and the inner BRB is formed by the tight junctions of the vascular endothelial cells and sheathed by the Muller cell processes. In many ocular diseases including ischemic retinal vein/artery occlusion and diabetic retinopathy, breakdown of the inner BRB increases retinal vascular permeability, resulting in retinal edema and cell death. Glaucoma, the leading cause of vision loss in the world, is associated with the loss of retinal ganglion cells (RGCs) and their axons. The secondary damage is considered to be the major cause of RGC loss in glaucoma. High intraocular pressure-induced retinal $\mathrm{I} / \mathrm{R}$ is a commonly used model for retinal ischemic studies. This method produces global ischemia via the obstruction of both retinal and choroidal circulation, contributing to pathological features that are nearly identical to those observed in patients after a central retinal artery occlusion or ophthalmic artery occlusion. LBPs have shown protective effects against I/R-induced retinal injury in animal studies, and they protect RGCs, retinal vasculature, and BRB in animal models. ${ }^{77-85}$

\section{Experimental glaucoma: acute ocular hypertension}

Acute ocular hypertension ( $\mathrm{AOH})$ is a well-established animal model for producing retinal degeneration, which has been used to investigate the pathogenesis of RGC death and possible therapeutic interventions for neuroprotection. Several animal studies have shown the protective effects of LBPs against $\mathrm{AOH}$-induced retinal injury. ${ }^{78,79}$

Mi et $\mathrm{al}^{79}$ evaluated the protective effect of LBPs on retinal $\mathrm{I} / \mathrm{R}$ injury in male $\mathrm{C} 57 \mathrm{BL} / 6 \mathrm{~N}$ mice. The mice were treated in unilateral eye for 1 hour by introducing $90 \mathrm{mmHg}$ ocular pressure to induce AOH. The animals were administered with $1 \mathrm{mg} / \mathrm{kg}$ LBPs daily from 7 days before the I/R insult till sacrifice at either day 4 or day 7 post-insult. The neuroprotective effects of LBPs on RGCs and BRB were assessed. In control $\mathrm{AOH}$ retina, loss of RGCs, thinning of inner retinal layer thickness, increased immunoglobulin $\mathrm{G}$ (IgG) leakage, broken tight junctions, and decreased density of retinal blood vessels were observed. However, in LBP-treated $\mathrm{AOH}$ retina, there was less loss of RGCs with thinning of inner retinal layer thickness, IgG leakage, more continued structure of tight junctions associated with higher level of occludin protein, and the recovery of the blood vessel density when compared with vehicle-treated AOH retina. ${ }^{79}$ Moreover, LBPs provide neuroprotection by downregulating advanced glycation end products and their receptors, endothelin-1, and amyloid- $\beta(\mathrm{A} \beta)$ in the retina, as well as their related signaling pathways, which was related to inhibiting vascular damages and the neuronal degeneration in $\mathrm{AOH}$ insults. These data suggest that LBPs could prevent damage to RGCs from $\mathrm{AOH}$-induced ischemic injury and that LBPs may be a potential treatment for vascular-related retinopathy.

He et $\mathrm{al}^{78}$ further explored the mechanisms for LBPmediated protective effects on $\mathrm{AOH}$-induced retinal injury in eight-week-old male Sprague-Dawley rats. The left eye of rats was subject to increased intraocular pressure of $130 \mathrm{mmHg}$ for 60 minutes using a physiological saline reservoir to induce $\mathrm{AOH}$. Successful achievement of retinal ischemia was confirmed by the collapse of the central retinal artery and the whitening of the iris during the elevation of intraocular pressure. About $1 \mathrm{mg} / \mathrm{kg} /$ day LBPs was administered by gavage for 7 days before $\mathrm{AOH}$ procedure. The protective effects of LBPs were evaluated by quantifying ganglion cell and amacrine cell survival and by measuring cellular apoptosis in the retinal layers. In addition, the expression of heme oxygenase-1 (HO-1) was examined using Western blotting and immunofluorescence analyses. The redox-sensitive transcription nuclear factor erythroid 2-related factor (Nrf2) in cytosol and nucleus was measured using immunofluorescent staining. HO-1 is the rate-limiting enzyme that catalyzes the degradation of heme into biliverdin, carbon monoxide, and iron, and is one of the phase II detoxifying enzymes and antioxidants that are closely regulated by Nrf2. Increased apoptosis and decreased number of viable cells were observed in the ganglion cell layer (GCL) and inner nuclear layer (INL) in the I/R retina, which were reversed by LBP treatment. ${ }^{78}$ In LBP-pretreated rats, the rate of RGC loss was delayed and more than $50 \%$ of 
RGCs remained viable in the retina 7 days after the ischemic insult. When compared with the vehicle-treated I/R retina, the LBP-treated I/R retina had an increase in the number of choline acetyltransferase-positive retinal amacrine cells. The retinal level of radical oxygen species (ROS) was decreased by LBP pretreatment in I/R mice. Similar to the specific Nrf2 activator, sulforaphane, LBP pretreatment significantly increased the number of RGCs with nuclear translocation of Nrf2 in I/R retina. ${ }^{78}$ Retinal HO-1 expression determined by immunofluorescent staining and immunoblotting was also upregulated by LBPs. Inhibition of HO-1 activity by zinc protoporphyrin at $20 \mathrm{mg} / \mathrm{kg}$ abolished LBP-induced protective effects in the retina after I/R. ${ }^{78}$ The data demonstrate that LBPs elicit retino- and neuro-protective effects via the activation of $\mathrm{Nrf} 2$ and upregulation of HO-1 expression.

\section{Experimental glaucoma: chronic ocular hypertension}

LBPs have shown potent neuroprotective effects by reducing the loss of RGCs in chronic ocular hypertension $(\mathrm{COH})$ models. ${ }^{82-84}$ Chan et $\mathrm{al}^{82}$ investigated whether oral administration of LBPs protected RGCs against $\mathrm{COH}$ in Sprague-Dawley rats. $\mathrm{COH}$ in rats was induced by laser photocoagulation of episcleral and limbal veins. LBPs significantly decreased the loss of RGCs, although elevated intraocular pressure was not significantly altered. Around $70 \%$ of RGC death in $\mathrm{COH}$ rats was retarded with a shortterm feeding of LBPs and this neuroprotective effect was maintained for up to 4 weeks. $^{82}$ Rats treated with $1 \mathrm{mg} / \mathrm{kg}$ LBPs almost abolished COH-induced loss of RGCs. These results show the therapeutic benefits of $L$. barbarum against neurodegeneration in the retina of rat $\mathrm{COH}$ model.

It is believed that the neuroprotective effect of LBPs in $\mathrm{COH}$ rats is partly due to modulating the activation of microglia, as manipulating the activation state of microglia is beneficial for neuron protection. This effect has been observed by Chiu et al ${ }^{83}$ who used multiphoton confocal microscopy to investigate morphological changes of microglia in whole-mounted retinas of $\mathrm{COH}$ rats. Retinas under $\mathrm{COH}$ displayed slightly activated microglia. Administration of $1-100 \mathrm{mg} / \mathrm{kg}$ LBPs elicited moderately activated microglia in the inner retina with ramified appearance but thicker and focally enlarged processes. When activation of microglia was reduced by intravitreal injection of macrophage/microglia inhibitory factor, the neuroprotective effect of $10 \mathrm{mg} / \mathrm{kg}$ LBP was decreased. ${ }^{83}$ There is evidence from a proteomic study $^{84}$ that the prosurvival effect of LBPs on rat RGCs in $\mathrm{COH}$ may be mediated by an increase in upregulation of $\beta \mathrm{B} 2$ crystalline, which is a neuroprotective agent.

\section{Retinal degeneration}

In outer retina, LBPs have been shown to decrease apoptosis in photoreceptors of $\mathrm{rd} 1$ mice with photoreceptor degeneration. ${ }^{85}$ Mice homozygous for the $r d 1$ mutation have an early onset severe retinal degeneration due to a murine viral insert and a second nonsense mutation in exon 7 of the $P d e 6 b$ gene in all mouse strains with the $r d 1$ mutation. LBP treatment increased GPx activity and GSH levels and decreased cysteine concentrations in rd1 retinas. ${ }^{85}$ These data suggest that the prosurvival effects of LBPs on photoreceptors in $r d 1$ mouse retina are mainly via reduction of oxidative stress.

Middle cerebral artery occlusion-induced ischemic retinal injury

Li et $\mathrm{al}^{77}$ investigated the effects of intragastric LBP pretreatment by gavage on the retinal injuries induced by middle cerebral artery occlusion (MCAO) in $\mathrm{C} 57 \mathrm{BL} / 6 \mathrm{~N}$ male mice. Prior to induction of MCAO, mice were treated orally with $1 \mathrm{mg} / \mathrm{kg}$ LBPs once a day for 1 week. Retinal ischemia was maintained for 2 hours, after which the filament was pulled out to allow reperfusion for 22 hours. Viable cells in GCL of the central and peripheral retina were counted and retinal swelling was evaluated by measuring the inner retinal thickness from the inner limiting membrane to INL. Expression levels of glial fibrillary acidic protein (GFAP), aquaporin-4 (AQP4), poly(ADP-ribose) (PAR), and nitrotyrosine (NT) in mouse retina were determined by immunohistochemistry. The integrity of BRB was assessed by measuring IgG extravasation. The study showed that the number of viable cells in GCL in the central and the peripheral retina was significantly higher in the LBP-treated I/R mice compared with that in the vehicletreated $\mathrm{I} / \mathrm{R}$ mice. ${ }^{77}$ There was a decrease in inner retinal thickness of the central retina in the LBP-treated I/R mice when compared with the vehicle-treated I/R mice. Fewer apoptotic cells were found in GCL and INL of the LBP-treated I/R retina when compared with that of the vehicle-treated $\mathrm{I} / \mathrm{R}$ retina. Protein kinase $\mathrm{C}$-alpha expression (a marker for rod bipolar cells) in the LBP-treated I/R retina was more when compared with that in the vehicle-treated $\mathrm{I} / \mathrm{R}$ retina. ${ }^{77}$ The expression of calretinin by amacrine cells was higher in LBP-treated I/R retina compared with that of the vehicle-treated $\mathrm{I} / \mathrm{R}$ retina. There were more neuronal NO synthase-expressing amacrine cells found in the LBP-treated I/R retina compared with the vehicle-treated I/R retina. Disruption of BRB leads to swelling of astrocytes and Muller cells processes associated with the activation of GFAP and AQP4 under ischemic conditions. The immunoreactivity of GFAP in astrocytes in GCL was reduced in LBP-treated I/R retina compared with that of the 
vehicle-treated $I / R$ retina. The immunoreactivity of AQP4 expressed in the astrocytes of inner limiting membrane and INL was significantly lower in LBP-treated I/R retina compared with the vehicle-treated I/R retina. LBP treatment also reduced the number of retinal blood vessels with IgG leakage, nuclear translocation of PAR expression, and NT expression. ${ }^{77}$ The breakdown of DNA strands activates the nuclear enzyme poly(ADP-ribose) polymerase (PARP) to produce PAR. Free radical formation facilitates $\mathrm{NO}$ production, which reacts with superoxide to from peroxynitrite, a strong oxidant that leads to nitration of tyrosine residues of cells to form NT. These results show that pretreatment of mice with LBPs effectively protected the retina from RGC apoptosis, retinal swelling, glial cell activation, BRB disruption, and oxidative stress.

\section{Complete or partial optic nerve transection}

The partial optic nerve transection (PONT) model allows good separation of secondary degeneration from the directly injured RGCs. Li et al ${ }^{80}$ investigated the protective effects of LBPs on RGCs in Sprague-Dawley rats subject to complete or partial optic nerve transection (CONT or PONT). Rats were administered with $1 \mathrm{mg} / \mathrm{kg} /$ day LBPs for 7 days before surgery until sacrificed at different time points. The expression levels of several proteins related to inflammation, oxidative stress, and Jun N-terminal kinases (JNK)/c-Jun pathway were determined using Western blotting assay. LBPs did not delay primary degeneration of RGCs after either CONT or PONT, but delayed secondary degeneration of RGCs after PONT ${ }^{80}$ These results demonstrate that LBPs decrease secondary degeneration of RGCs by inhibiting oxidative stress and the JNK/c-Jun pathway and by transiently increasing the expression of insulin-like growth factor-1 (IGF-1).

Chu et al also investigated the retinal protective effects of LBPs in rat PONT model when the multifocal electroretinograms (mfERGs) were recorded in SpragueDawley rats. ${ }^{81}$ The $\mathrm{mfERG}$ allows for recording multiple local retinal responses within a short time period, and it is widely used in glaucoma investigation in animal and human studies. The rats were administered $1 \mathrm{mg} / \mathrm{kg} \mathrm{LBP}$ via a nasogastric tube every day until euthanization. The PONT surgery was performed at day 7 after start of LBP dosing. As with the primate $\mathrm{mfERG}$ response, the waveform in rats contains a trough (N1) at around 25 milliseconds, followed by a major positive component (P1) at around 55 milliseconds, and a photopic negative response (PhNR) that can be observed at around 75 milliseconds. ${ }^{81}$ The topographical mfERG response demonstrated a stronger retinal function along the visual streak with a peak in the nasal field in both conditions with and without PONT. After administering $1 \mathrm{mg} / \mathrm{kg} \mathrm{LBP}$ a week prior to PONT surgery, the rats showed increased N1 responses, P1 responses, and PhNRs, especially in the inferior retina when compared with the control group. The N1 amplitudes were significantly increased at week 4 after PONT except in the superior regions. ${ }^{81}$ The P1 amplitude in the far superior region showed a significant reduction 1 week after PONT, but then returned to the normal range. $\mathrm{P} 1$ amplitudes remained normal in other regions after PONT but were significantly increased in the inferior retina 4 weeks after PONT. The PhNR amplitude reduced significantly in the superior retina 1 week after PONT and then gradually returned to the normal range. The PhNR amplitude in the inferior retina appeared to be increased after PONT with prolonged feeding with LBPs, but this effect was not statistically significant. These results show that LBPs reduce the deterioration of retinal function after PONT through unknown mechanisms.

\section{Hepatoprotective effects}

Alcoholic liver disease or alcoholic fatty liver disease

Alcohol use was the third leading risk factor contributing to the global burden of disease after high blood pressure and tobacco smoking. According to a WHO 2008 report, alcohol causes 1.8 million annual deaths globally and accounts for $4.0 \%$ of the total disease burden. ${ }^{86}$ Alcoholic liver disease or alcoholic fatty liver disease (AFLD) is a chronic multistep disease with fatty accumulation in the liver due to chronic alcohol overconsumption, which typically progresses through the stages of fatty liver or simple steatosis, alcoholic hepatitis, and chronic hepatitis with hepatic fibrosis or cirrhosis. ${ }^{87,88}$ Chronic consumption of alcohol results in the secretion of proinflammatory cytokines such as TNF- $\alpha$, IL-6 and IL-8, oxidative stress, lipid peroxidation, and acetaldehyde toxicity. ${ }^{87,88}$ These factors cause inflammation, apoptosis, and eventually, fibrosis and cirrhosis of the liver. As one of the most prevalent liver diseases caused by alcohol overconsumption, AFLD affects over 2 million people in the US. In the People's Republic of China, it is estimated that $2.8 \%$ of population has AFLD or suspected AFLD. There is no cure for alcoholic liver disease, ${ }^{89}$ and natural compounds with potent antioxidative effects have been used to treat alcoholic liver disease.

Cheng and Kong ${ }^{90}$ investigated the protective effect of LBPs on alcohol-induced liver injury in rats. Rats were fed with $7 \mathrm{~g}$ ethanol/ $\mathrm{kg}$ body weight by gastric infusion three times a day, for 30 consecutive days, to make the liver injury model. Ethanol treatment significantly increased 
serum alanine aminotransferase and AST, triglycerides, total cholesterol, low-density lipoprotein cholesterol (LDL-C), and MDA levels but decreased serum high-density lipoprotein cholesterol (HDL-C) and hepatic SOD, CAT, GPx, and GSH. ${ }^{90}$ Administration of $300 \mathrm{mg} / \mathrm{kg}$ LBPs for 30 days significantly reversed these ethanol-induced effects, reduced liver injury, prevented the progression of alcohol-induced fatty liver, and improved the antioxidant function when compared with the ethanol group. The results indicate that LBPs protect the liver from ethanol-induced injuries via antioxidation.

Xiao et $\mathrm{al}^{91}$ investigated whether thioredoxin-interacting protein (TXNIP) and NOD-like receptor 3 (NLRP3) inflammasome mediated the attenuation of ethanol-induced hepatic injury by LBPs using the rat normal hepatocyte line BRL-3A cells. Cells were pretreated with LBPs prior to ethanol incubation. Hepatic damages including apoptosis, inflammation, and oxidative stress were monitored. TXNIP was knocked down using specific small interfering RNA. The study showed that $50 \mu \mathrm{g} / \mathrm{mL}$ LBP pretreatment significantly alleviated 24-hour ethanol-induced overexpression of TXNIP, increased cellular apoptosis, secretion of inflammatory cytokines, activation of NLRP3 inflammasome, production of ROS, and reduced antioxidant enzyme expression. ${ }^{91}$ Silence of TXNIP suppressed the activated NLRP3 inflammasome, increased oxidative stress, and worsened apoptosis in the cells. Further addition of LBPs did not affect the effects of TXNIP inhibition on BRL-3A cells..$^{91}$ These results indicate that inhibition of hepatic TXNIP by LBPs contributes to the reduction of cellular apoptosis, oxidative stress, and NLRP3 inflammasome-mediated inflammation.

\section{Nonalcoholic fatty liver disease}

Nonalcoholic fatty liver disease (NAFLD) is a chronic metabolic liver disease that histologically resembles the alcoholinduced hepatic injury, but is not caused by alcohol abuse. ${ }^{92,93}$ It is a spectrum of disease ranging from simple steatosis, to non-alcoholic steatohepatitis, through to advanced fibrosis and cirrhosis. NAFLD is associated with other medical conditions such as metabolic syndrome, obesity, cardiovascular disease, and diabetes. ${ }^{92,93}$ Mechanisms involved in the pathogenesis are associated with diet and lifestyle, influx of free fatty acids to the liver from adipose tissue due to insulin resistance, hepatic oxidative stress, cytokines production, reduced very low-density lipoprotein secretion, and intestinal microbiome. ${ }^{94}$ In Western countries, NAFLD affects $20 \%-40 \%$ of the adult populations. Weight loss through improved diet and increased physical activity has been the cornerstone therapy of NAFLD, but no drugs are approved for use in NAFLD. ${ }^{93,95}$

In a study conducted by Xiao et $\mathrm{al}^{96,97}$ female rats were fed with a high-fat diet (HD) to induce nonalcoholic steatohepatitis, with or without an oral $1 \mathrm{mg} / \mathrm{kg}$ LBP feeding, daily for 8 weeks. LBP-treated rats showed improved histology and free fatty acid levels, rebalance of lipid metabolism, reduction in profibrogenic factors through the transforming growth factor (TGF)- $\beta$ /small mothers against decapentaplegic pathway, improved oxidative stress through cytochrome P450 2E1-dependent pathway, reduction in hepatic proinflammatory mediators and chemokine production, and amelioration of hepatic apoptosis through the p53-dependent intrinsic and extrinsic pathways. ${ }^{96}$

A mouse study by Li et al ${ }^{98}$ investigated whether LBPs prevented fatty liver through activation of adenosine monophosphate-activated protein kinase (AMPK) and suppression of sterol regulatory element-binding protein-1c (SREBP-1c). ${ }^{98}$ Male C57BL/6J mice were fed a low-fat diet, $\mathrm{HD}$, or $100 \mathrm{mg} / \mathrm{kg}$ LBP-treatment diet for 24 weeks. The results showed that LBPs improved body compositions and lipid metabolic profiles in high-fat diet-fed mice. Oil Red O staining showed that LBPs significantly reduced hepatic intracellular triacylglycerol accumulation. Hepatic genes expression profiles demonstrated that LBPs activated the phosphorylation of AMPK, suppressed nuclear expression of SREBP-1c, and decreased protein and $\mathrm{mRNA}$ expression of lipogenic genes. ${ }^{98}$

Lin et $\mathrm{al}^{99}$ investigated whether AMPK $\alpha 2$ is essential for the protective effects of wolfberries on mitochondrial dysfunction and subsequent hepatic steatosis in mice. Six-weekold male AMPK $\alpha 2$ knockout mice and genetic background C57BL/6J mice were fed a control, HD (45\% [kilocalorie] fat), and/or HD with 5\% (kilocalorie) wolfberry diets for 18 weeks. HD feeding for 18 weeks lowered hepatic lutein and zeaxanthin contents, inhibited protein expression of $\beta, \beta$-carotene $9^{\prime}, 10^{\prime}$-oxygenase 2 and heat shock protein 60 (HSP60) in mitochondria, increased reactive oxygen species level, suppressed mitophagy and mitochondrial biogenesis as determined by accumulation of $\mathrm{p} 62$, inhibited phosphorylation of Unc-51-like kinase 1 on Ser555, and decreased expression of peroxisome proliferator-activated receptor- $\gamma$ coactivator $1 \alpha$, resulting in hepatic steatosis in AMPK $\alpha 2$ knockout and C57BL/6J mice. ${ }^{99}$ Dietary wolfberry elevated the xanthophyll concentrations and enhanced expression of $\beta, \beta$-carotene $9^{\prime}, 10^{\prime}$-oxygenase 2 and HSP60, attenuated mitochondrial oxidative stress, activated AMPK $\alpha 2$, potentiated mitophagy and mitochondrial biogenesis, and enhanced 
lipid oxidation and secretion in the liver of C57BL/6J mice. ${ }^{99}$ Dietary wolfberry selectively activated AMPK $\alpha 2$, enhanced mitochondrial biogenesis, and potentiated mitophagy, leading to the prevention of hepatic steatosis in obese mice.

\section{Carbon tetrachloride-induced acute liver injury}

A mouse study ${ }^{100}$ on the protective effect of LBPs was conducted in carbon tetrachloride $\left(\mathrm{CCl}_{4}\right)$-induced acute liver injury. Mice were intraperitoneally injected with $\mathrm{CCl}_{4}$ to induce acute hepatotoxicity and were orally fed with LBPs 2 hours before the $\mathrm{CCl}_{4}$ injection. The results showed that LBPs reduced necroinflammation and oxidative stress induced by $\mathrm{CCl}_{4}$. The protective effects of LBPs against $\mathrm{CCl}_{4}$-induced hepatotoxicity were partly through the downregulation of NF- $\kappa B$ activity. ${ }^{100} \mathrm{NF}-\kappa \mathrm{B}$ plays a key role in regulating the immune response to stimuli such as stress, cytokines, free radicals, ultraviolet irradiation, and infection. ${ }^{101}$ While in an inactivated state, NF- $\mathrm{KB}$ is located in the cytosol complexed with the inhibitory protein I $\kappa \mathrm{B} \alpha$. The activated NF- $\kappa \mathrm{B}$ will be translocated into the nucleus where it binds to specific sequences of DNA called response elements. The DNA/NF- $\kappa B$ complex then recruits other proteins such as coactivators and RNA polymerase to trigger gene expression. ${ }^{101}$

Ahn et $\mathrm{a}^{102}$ investigated whether Lycium chinense (LC) fruit extract and its component betaine could affect $\mathrm{CCl}_{4}$-induced hepatotoxicity in rats. The treatment of L. chinense fruit extract significantly suppressed the increase of serum alanine aminotransferase and $\mathrm{AST}$ in $\mathrm{CCl}_{4}$-injured rats; restored the decreased levels of anti-oxidant enzymes, such as total antioxidant capacity, SOD, CAT, and GPx; and suppressed the expression of inflammatory mediators including inducible nitric oxide synthase and cyclooxygenases. ${ }^{102}$ Betaine showed hepatoprotective effects as that of L. chinense fruit extract. These findings imply that LC fruit extract reduced $\mathrm{CCl}_{4}$-induced hepatic injury via increasing antioxidative activity and decreasing inflammatory mediators including inducible nitric oxide synthase and cyclooxygenases.

\section{Summary on the hepatoprotective effects of LBPs}

Taken together, LBPs can substantially reduce oxidative stress, suppress inflammatory responses, and inhibit apoptosis to protect liver from injuries due to various insults. LBPs increase the levels and activities of GPx, SOD, CAT, GSH, HDL-C, and AMPK, but reduce the levels of LDL-C and MDA via modulation of p53-, SREBP-1c-, and NF-KBmediated pathways (Figure 7).

\section{Hypoglycemic effects}

Diabetes mellitus is a group of complicated metabolic disorders characterized by high blood glucose level and inappropriate insulin secreting capacity due to decreased glucose metabolism and pancreatic cell mass or dysfunction of cells. Based on the data from the 2011 National Diabetes Fact Sheet in the US, 25.8 million children and adults (ie, 8.3\% of the population) have diabetes and 1.9 million new cases of diabetes were diagnosed in people aged 20 years and older in 2010. A total of 25.6 million or $11.3 \%$ of US people aged 20 years and older have diabetes. In adults, type 2 diabetes (previously called non-insulin-dependent diabetes mellitus or adult-onset diabetes; T2DM) accounts for about $90 \%-95 \%$ of all diagnosed cases of diabetes. T2DM is a chronic metabolic disorder characterized by progressive hyperglycemia secondary to declining $\beta$-cell function, and usually accompanied by a reduced sensitivity to insulin in peripheral tissues, such as liver and muscle. ${ }^{103}$ If untreated or not well managed, longterm hyperglycemia can lead to increased risk of macrovasulcar (cardiovascular, cerebrovascular, and peripheral vascular disease) and microvasulcar (nephropathy, neuropathy, and retinopathy) complications. Improving glucose metabolism and preserving $\beta$-cell mass and function represent the major strategies for the treatment of T2DM. High glucose concentrations and fatty acid levels stimulate excessive accumulation of ROS, which can cause tissue injury and insulin resistance in peripheral metabolic tissues. ${ }^{104}$ Several studies have showed that LBPs had significant hypoglycemic effects and insulin-sensitizing activity by increasing antioxidation, glucose metabolism, and insulin secretion and by promoting pancreatic $\beta$-cell proliferation. ${ }^{17,105-110}$

\section{Streptozotocin- or alloxan-induced diabetes}

Luo et a ${ }^{107}$ compared the hypoglycemic effects of LBF water decoction, crude polysaccharide extracts (crude LBPs), and purified polysaccharide fractions (LBPs) in alloxan-induced diabetic rabbits. All the three LBF extracts/fractions significantly reduced blood glucose levels in rabbits. ${ }^{107}$ The hypoglycemic effect of LBPs was more significant than those of water decoction and crude LBPs, but water and methanolic fruit extracts and crude polysaccharide extracts exhibited stronger antioxidant activity than purified polysaccharide fractions.

Zhao et al ${ }^{108}$ conducted an animal study to examine the hypoglycemic activity of LBPs in male Wistar rats with experimental diabetes. Rats were fed with HD for 3 weeks and administered intraperitoneal injection of $50 \mathrm{mg} / \mathrm{kg}$ streptozotocin to induce diabetes. Fasting plasma levels of glucose, lipids, and insulin were monitored. The content 


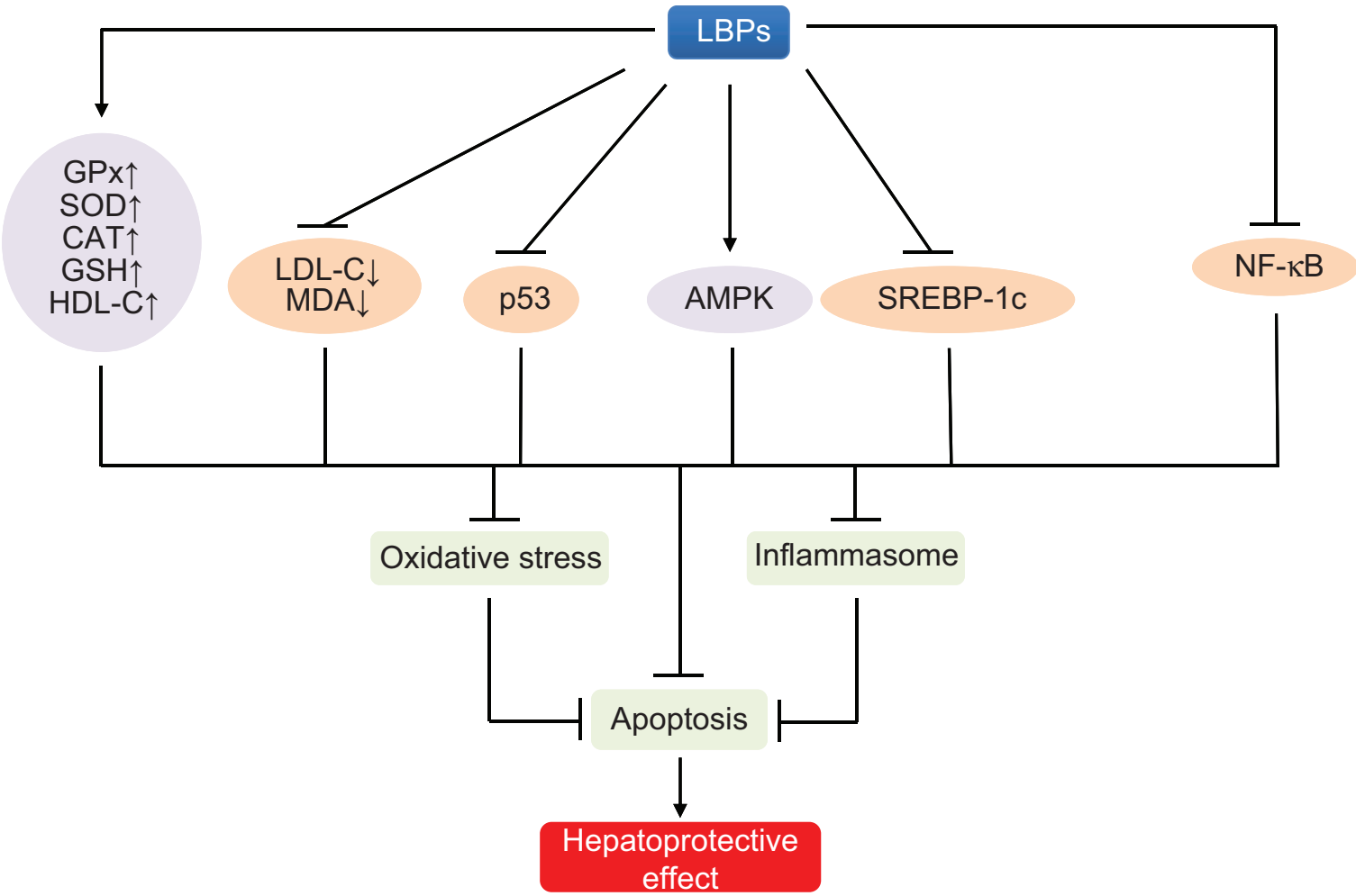

Figure 7 Possible mechanisms for the hepatoprotective effects of LBPs.

Notes: LBPs showed significant hepatoprotective effect in in vivo models via suppression of oxidative stress, inflammatory response, and apoptosis. LBPs increase the levels and activities of GPx, SOD, CAT, GSH, HDL-C, and AMPK, but reduce the levels and activities of LDL-C, MDA, P53, SREBP-Ic, and NF-KB in vivo.

Abbreviations: LBPs, Lycium barbarum polysaccharides; SOD, superoxide dismutase; CAT, catalase; GPx, glutathione peroxidase; GSH, glutathione; HDL-C, high-density lipoprotein cholesterol; AMPK, monophosphate-activated protein kinase; LDL-C, low-density lipoprotein cholesterol; MDA, malondialdehyde; SREBP-Ic, sterol regulatory element-binding protein-Ic; NF- $\kappa B$, nuclear factor $\kappa B$.

of glucose transporter type-4 (GLUT4) in gastrocnemius skeletal muscle was determined. Under anabolic condition, GLUT4 is the main carrier that transports blood glucose into muscle and adipose cells. ${ }^{111,112}$ In the nonstimulated state, GLUT4 is efficiently sequestered intracellularly. This retention prevents GLUT4 from reaching the cell surface and transporting glucose into muscle and fat cells when blood glucose levels are low. ${ }^{112}$ After a meal, when blood glucose levels rise, insulin is secreted by the pancreas, which triggers an intracellular signaling cascade, leading to the translocation of GLUT4 from intracellular compartments to the cell surface, resulting in glucose uptake and normalization of the blood glucose levels. ${ }^{111,112}$ Oral treatment of $10 \mathrm{mg} / \mathrm{kg} /$ day LBP for 3 weeks resulted in a significant decrease in the concentration of plasma triglyceride and weight in diabetic rats. ${ }^{108}$ Furthermore, LBPs markedly decreased the plasma cholesterol levels, fasting plasma insulin levels, and the postprandial glucose level at 30 minutes during oral glucose tolerance test and significantly increased the insulin sensitivity index in diabetic rats. ${ }^{108}$ Moreover, LBPs increased the level of GLUT4 in skeletal muscle under insulin stimulation. LBPs can alleviate abnormal glucose and lipid metabolism and ameliorate insulin resistance, and the mechanism may be involved in upregulation of GLUT4 and improved GLUT4 trafficking and intracellular insulin signaling.

The effect of oral LBP treatment on blood glucose, oxidative stress, and DNA damage was examined by $\mathrm{Wu}$ et al ${ }^{106}$ in male Wistar rats with experimental diabetes. Rats were fed with HD for 3 weeks and administered intraperitoneal injection of $50 \mathrm{mg} / \mathrm{kg}$ streptozotocin to induce diabetes. Oral administration of $10 \mathrm{mg} / \mathrm{kg} /$ day LBP for 4 weeks led to decreased levels of blood glucose. ${ }^{106}$ Serum MDA and NO levels were decreased by LBPs in fasting diabetic rats, and the serum level of SOD was increased by LBPs in diabetic rats. ${ }^{106}$ LBPs reduced cellular DNA damage in peripheral lymphocytes of the diabetic rats as determined by the single cell gel assay. These results suggest that LBPs can improve glucose metabolism via inhibition of oxidative stress in diabetes.

$\mathrm{Li}^{17}$ reported that in streptozotocin-induced diabetic rats, treatment of $50-200 \mathrm{mg} / \mathrm{kg}$ LBP for 30 days significantly decreased blood glucose level and increased blood plasma insulin level. The hypoglycemic effects of LBPs are strongly related to their antioxidative effects. 


\section{HD-induced insulin resistance}

$\mathrm{Nrf2}$ is a master regulator for the expression of Phase II detoxifying enzymes such as HO-1, SOD, and CAT. ${ }^{113}$ Upon stimulation by oxidative stress, Nrf2 is translocated into the nucleus and induces the expression of antioxidant enzymes by binding antioxidant response element. JNK activation is a crucial mediator of ROS-induced insulin resistance. ${ }^{114}$ Suppression of JNK activation prevents insulin receptor substrate-1 (IRS-1) degradation and promotes insulin signaling and insulin-dependent glucose uptake.

Yang et $\mathrm{al}^{110}$ investigated the mechanisms involved in LBP-mediated phosphatidylinositol 3-kinase (PI3K)/Akt/Nrf2 pathway against high-fat-induced insulin resistance in human hepatoma HepG2 cells and male C57BL/6J mice. HepG2 cells were incubated with LBPs for 12 hours in the presence of palmitate. C57BL/6J mice were fed an HD together with $100 \mathrm{mg} / \mathrm{kg}$ LBPs for 24 weeks. Liver glucokinase (GCK) and pyruvate kinase $(\mathrm{PK})$ activities were monitored. The mRNA levels of $G C K, P K$, phosphoenolpyruvate carboxykinase (PEPCK), glucose 6-phosphatase (G6Pase), IL-6, TNF- $\alpha$, and monocyte chemotactic protein 1 (MCP-1) were determined using quantitative real-time PCR. The protein expression levels of Nrf2 and phosphorylated (p)-Nrf2 at Ser40; HO-1, SOD, CAT, JNK, glycogen synthase kinase $3 \beta$ (GSK3 $\beta$ ), and p-GSK3 $\beta$ at Ser9; IRS-1, p-IRS-1 at Ser307; PI3K and p-PI3K at Tyr458/199; Akt and p-Akt at Ser473; and JNK and p-JNK at Thr183/Tyr were determined by Western blotting assay. ${ }^{110}$ The results showed that oral treatment with $100 \mathrm{mg} / \mathrm{kg}$ LBPs for 24 weeks lowered blood glucose and insulin concentrations and increased pyruvate concentration compared with high fat-fed mice. In the liver, LBPs increased hepatic $G C K$ and $P K$ mRNA levels but decreased liver PEPCK and G6Pase mRNA levels. LBPs treatment of mice significantly enhanced the phosphorylation of IRS-1, PI3K, and Akt in liver. In HepG2 cells, incubation of 100-600 $\mu \mathrm{g} / \mathrm{mL}$ LBPs for 12 hours significantly promoted the phosphorylation of IRS-1, PI3K, and Akt. In in vivo experiment, administration of LBPs effectively inhibited the phosphorylation of JNK but increased the phosphorylation of GSK3 $\beta$ in the liver of highfat diet-fed mice. LBPs also lowered the mRNA levels of liver $M C P-1, I L-6$, and $T N F-\alpha$. In HepG2 cells, LBPs significantly increased the phosphorylation of GSK3 $\beta$ but reduced the phosphorylation of JNK. When HepG2 cells were pretreated with $10 \mu \mathrm{M}$ LY294002 and $2 \mu \mathrm{M}$ wortmannin (both PI3K/ Akt inhibitors) for 2 hours, and then treated with $300 \mu \mathrm{g} / \mathrm{mL}$ LBPs for 12 hours, the inhibitor-induced p-JNK level was suppressed by LBPs, and inhibitor-suppressed p-GSK3 $\beta$ level was reversed by LBPs. ${ }^{110}$ LBPs regulated phosphorylation levels of GSK3 $\beta$ and JNK through PI3K/Akt signaling. In HepG2 cells, $300 \mu \mathrm{g} / \mathrm{mL}$ LBPs caused the nuclear translocation of p-Nrf2. LBPs significantly induced the phosphorylation of Nrf2 through PI3K/Akt signaling in vitro and in vivo. ${ }^{110}$ LBPs increased the expression of hepatic HO-1, SOD, and CAT and reduced intracellular ROS level via PI3K/Akt/Nrf2 axis in mice. ${ }^{110}$ These data indicate that LBPs significantly reversed glycolytic and gluconeogenic gene expression via the activation of Nrf2-mediated cytoprotective effects and that LBPs reverse insulin resistance induced by $\mathrm{HD}$ via activation of PI3K/Akt/Nrf2-mediated antioxidative pathway.

\section{Spontaneous diabetes}

Several spontaneous or genetically derived diabetic rat models are commonly used in pharmacological and pathological studies, including Zucker fatty rats, ZDF rats, SHR/N-cp rats, JCR/LA-cp rats, and Otsuka Long Evans Tokushima fatty (OLETF) rats. ${ }^{115}$ The OLETF rats show typical symptoms of T2DM, including hyperinsulinemia, hyperglycemia, insulin resistance, hypertriglycemia, and mild obesity. A recent study by Zhao et $\mathrm{al}^{109}$ further reported that LBPs improved insulin resistance via translocation and activation of GLUT4 in OLETF rats. The results showed that LBPs caused translocation of the GLUT4 to the cell surface, which in turn stimulated glucose uptake, and the effect was sensitive to wortmannin, an inhibitor of PI3K, and SB203580, an inhibitor of p38 mitogen-activated protein kinase (p38 MAPK). ${ }^{109}$ Furthermore, the effects of LBPs on p38 MAPK activities were abrogated by pretreatment of rat adipocytes using SB203580. LBPs improved insulin resistance via translocation and activation of GLUT4 in OLETF rats, and the activation of PI3K and p38 MAPK contributed to these effects. ${ }^{109}$

\section{Clinical study}

Amagase and Nance ${ }^{116}$ investigated the effect of GoChi consumption on caloric expenditure and changes in morphometric parameters (waist circumference) in healthy adults. Two separate randomized, double-blind, placebo-controlled, small clinical studies were conducted using GoChi and assessing its effects on resting metabolic rate and postprandial energy expenditure as measured by indirect calorimetry after single-bolus intake of three doses of GoChi $(30 \mathrm{~mL}, 60 \mathrm{~mL}$, and $120 \mathrm{~mL}$ ) and placebo; and waist circumference and other morphometric changes in a 14-day intervention trial (120-mL daily intake) in the subjects (age $=34$ years, body mass index $=29 \mathrm{~kg} / \mathrm{m}^{2}$ ). ${ }^{116}$ A single bolus of GoChi intake increased postprandial energy expenditure 1-4 hours postintake over the baseline level in a dose-dependent manner and 
was significantly higher than the placebo group by $10 \%$ at 1 hour post-intake of $120 \mathrm{~mL}$. In a 14-day intervention trial, GoChi was found to significantly decrease waist circumference by $5.5 \pm 0.8 \mathrm{~cm}(\mathrm{n}=15)$ compared with the preintervention measurements and placebo group at postintervention day $15 .{ }^{116}$ In contrast, the changes in the placebo group $(\mathrm{n}=14)$ from preinterventions was $0.9 \pm 0.8 \mathrm{~cm}$, which was not statistically significant. These results show that GoChi consumption can increase metabolic rate and reduce the waist circumference.

\section{Summary of the hypoglycemic activities of LBPs}

LBPs significantly promote glucose uptake involving several signaling pathways in the liver and muscle (Figure 8). LBPs increase the content of GLUT4 and promote the translocation of GLUT4 from cytosol to cell membrane, enhancing glucose uptake in Wistar rats muscle. LBPs also increase the phosphorylation of $\mathrm{PI} 3 \mathrm{~K} / \mathrm{Akt} / \mathrm{Nrf} 2$ and repress the activation of JNK, promoting insulin-signaling pathway and insulin-dependent glucose uptake in $\mathrm{C} 57 \mathrm{BL} / 6 \mathrm{~J}$ mice liver. Furthermore, LBPs activate PI3K- and p38MAPK-mediated signaling pathway, improving insulin sensitivity in rats. Moreover, consumption of GoChi, a standardized Goji juice containing $13.6 \mathrm{mg} / \mathrm{mL}$ LBPs, promotes caloric expenditure and reduces waist circumference in healthy subjects.

\section{Hypolipidemic effects}

Based on data from the 2005-2008 National Health and Nutrition Examination Survey, an estimated 71 million (33.5\%) US adults aged $\geq 20$ years had high LDL-C, but only 34 million (48.1\%) were treated and 23 million (33.2\%) had their LDL-C controlled. ${ }^{117}$ Control of high LDL-C can reduce cardiovascular morbidity and mortality substantially. Luo et $\mathrm{al}^{107}$ investigated the hypolipidemic effect of LBPs on alloxan-induced hyperlipidemic rabbits. LBPs significantly reduced serum total cholesterol and triglyceride concentrations and markedly increased HDL-C levels after treatment with LBPs for 10 days in rabbits. ${ }^{107}$ LBPs also showed potent antioxidant activities in hyperlipidemic rabbits. These data demonstrate that the hypolipidemic effect of LBPs and antioxidation should contribute to this effect.

\section{Immunomodulating effects}

Many naturally occurring polysaccharides have been reported to be potent immunomodulators. ${ }^{118,119}$ These polymers can influence innate and cell-mediated immunity through interactions with $\mathrm{T}$ cells, monocytes, macrophages, and polymorphonuclear lymphocytes. LBPs have been found to have a variety of immune-modulatory activities in vitro and in vivo.

\section{T cells, B cells, and splenocytes}

Chen et al ${ }^{120}$ compared the immunomodulating effects of different LBP fractions in mice. Crude LBPs isolated from L. barbarum were separated to obtain five homogeneous fractions, namely LBPF1, LBPF2, LBPF3, LBPF4, and LBPF5. The study showed that LBP, LBPF4, and LBPF5 significantly stimulated mouse splenocyte proliferation. The proliferation proved to be of T cells, but not B cells. Cell cycle analysis indicated that LBP, LBPF4, and LBPF5 markedly reduced sub- $\mathrm{G}_{1}$ cells. ${ }^{120} \mathrm{LBP}, \mathrm{LBPF} 4$, and LBPF5 activated the transcription factors nuclear factor of activated T-cells (NFAT) and activator protein-1 (AP-1), prompted CD25 (ie, IL-2 receptor- $\alpha$ ) expression, and induced IL-2 and interferon (IFN) $-\gamma$ expressions. NFAT proteins (NFATs $1-5$ ) have crucial roles in the development and function of the immune system. In T cells, NFAT proteins not only regulate activation but are also involved in the control of thymocyte development, T-cell differentiation, and self-tolerance. ${ }^{121}$ AP-1 regulates gene expression in response to a variety of stimuli, including cytokines, growth factors, stress, and bacterial and viral infections. IL-2 is important for the growth and activation of $\mathrm{T}$ cells, and IFN- $\gamma$ is an important activator of macrophages and inducer of class II major histocompatibility complex (MHC-II) molecule expression. IL-2 is mainly produced by $\mathrm{T}$ cells ${ }^{122}$ and IFN- $\gamma$ is produced predominantly by NK and NK $\mathrm{T}$ cells as part of the innate immune response, and by $\mathrm{CD}^{+} \mathrm{T}$ helper cells $\left(\mathrm{Th}_{1}\right)$ and $\mathrm{CD} 8^{+} \mathrm{CTLs}$ once antigenspecific immune response is triggered. ${ }^{123}$ Administration of LBPs to mice (intraperitoneal [ip] or oral administration [po]) significantly induced T-cell proliferation. ${ }^{120}$ These results suggest that activation of T lymphocytes by LBPs may contribute to one of their immuno-enhancement functions.

The in vitro and in vivo immunomodulating effects of LBPF4-OL on mouse splenocytes, T cells, B cells, and macrophages were investigated by Zhang et al. ${ }^{124}$ LBPF4-OL was the glycan part of $L$. barbarum polysaccharide-protein complex fraction 4 (LBPF4). Splenocytes were stimulated with LBPF4-OL and cytokine concentrations in the supernatants were determined. In the in vivo study, mice were intraperitoneally injected with $100 \mu \mathrm{g} / \mathrm{mL}$ LBPF4-OL daily for 6 days. The results showed that LBPF4-OL markedly induced the splenocyte proliferation, but could not induce proliferation of purified T- and B-lymphocytes. ${ }^{124} \mathrm{~B}$-cell proliferation occurred in the presence of activated macrophages or lipopolysaccharide (LPS). LBPs obviously induced 


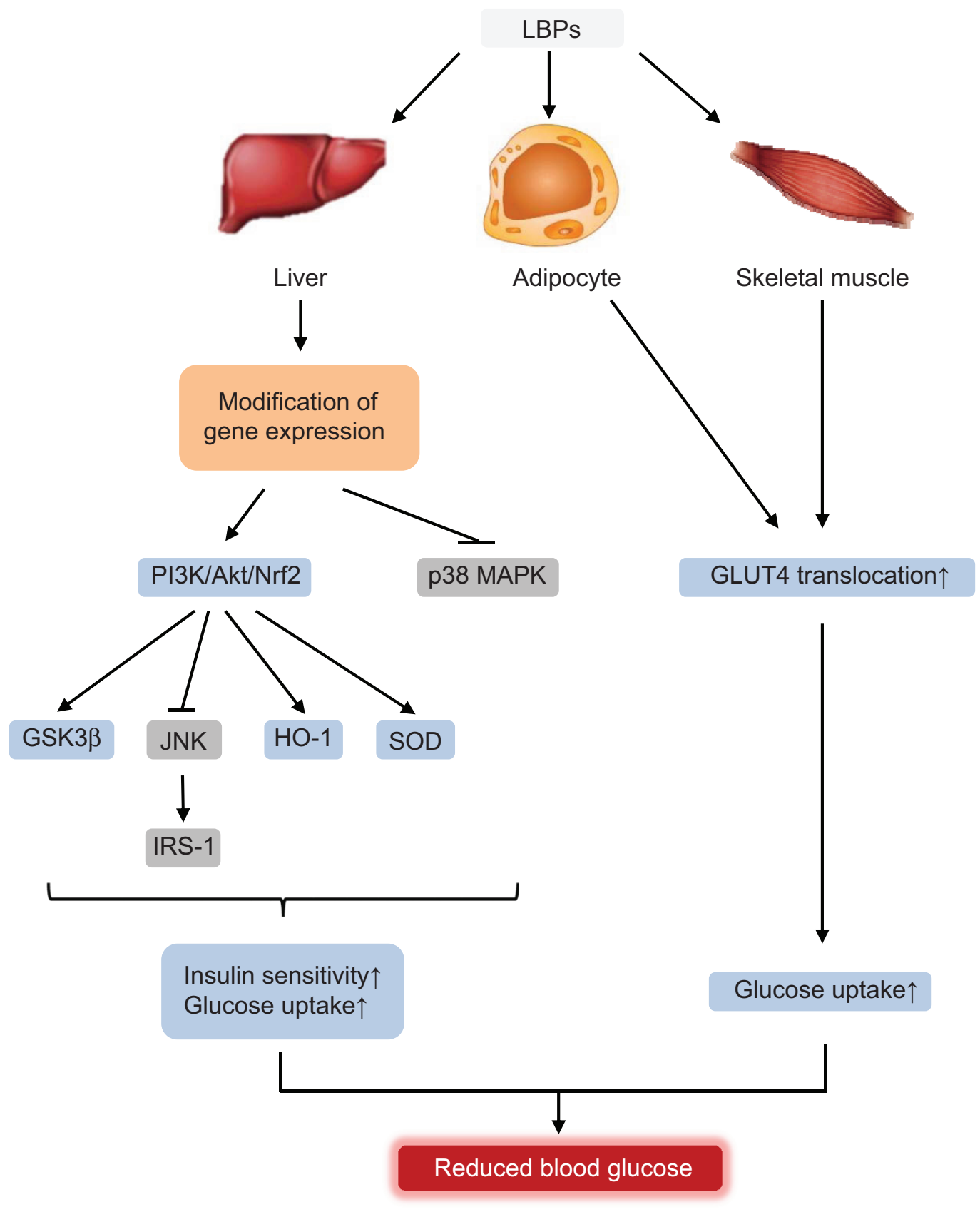

Figure 8 Possible mechanisms for the hypoglycemic effects of LBPs.

Notes: LBPs significantly promote glucose uptake involving several signaling pathways in the liver and muscle. LBPs increase the content of GLUT4 and promote the translocation of GLUT4 from cytosol to cell membrane, enhancing glucose uptake in Wistar rats muscle. LBPs also increase the phosphorylation of PI3K/Akt/Nrf2 and repress the activation of JNK, promoting insulin-signaling pathway and insulin-dependent glucose uptake in C57BL/6] mice liver. Furthermore, LBPs activate PI3K- and p38MAPKmediated signaling pathway, improving insulin sensitivity in rats. Moreover, consumption of GoChi, a standardized Goji juice containing $13.6 \mathrm{mg} / \mathrm{mL}$ LBPs promotes caloric expenditure and reduces waist circumference in healthy subjects.

Abbreviations: LBPs, Lycium barbarum polysaccharides; JNK, Jun N-terminal kinases; Nrf2, nuclear factor erythroid 2-related factor; PI3K, phosphatidylinositol 3-kinase; P38 MAPK, P38 mitogen activated protein kinase; GLUT4, glucose transporter type-4; IRS-I, insulin receptor substrate-I; HO-I, heme oxygenase- I; SOD, superoxide dismutase; GSK3 $\beta$, glycogen synthase kinase $3 \beta$.

IL-6, IL-8, IL-10, and TNF- $\alpha$ production in splenocytes in a concentration-dependent manner. ${ }^{124}$ IL-6 is secreted by $\mathrm{T}$ cells and macrophages to stimulate immune response during infection and after trauma (especially burns or other tissue damage) leading to inflammation. IL-8 (also called CXCL8 and neutrophil chemotactic factor) is a chemokine produced by macrophages and other cell types such as epithelial cells, airway smooth muscle cells, and endothelial cells. IL-8 induces chemotaxis in target cells (primarily neutrophils but also other granulocytes) toward the site of infection and induces phagocytosis. IL-10 inhibits the production of IFN- $\gamma$, IL-2, IL-3, TNF- $\alpha$, 
and granulocyte-macrophage colony-stimulating factor (GM-CSF) by activated macrophages and helper T cells. TNF- $\alpha$ is mainly produced by activated macrophages $\left(M_{1}\right)$, although it can be produced by many other cell types such as CD4 ${ }^{+} \mathrm{T}$ lymphocytes, monocytes, NK cells, neutrophils, mast cells, eosinophils, and neurons. ${ }^{125}$ The primary role of TNF- $\alpha$ is in the regulation of immune cells. TNF- $\alpha$ induces fever, apoptotic cell death, cachexia, and inflammation; inhibits tumorigenesis and viral replication; and responds to sepsis via IL-1 and IL-6 producing cells. ${ }^{125}$ Flow cytometer analysis showed that LBPF4-OL prompted CD86 (B7-2) and MHC-II molecule expression on macrophages and greatly promoted release of TNF- $\alpha$ and IL- $1 \beta$ from macrophages. ${ }^{124}$ IL- $1 \beta$ is produced by activated macrophages as a proprotein, which is proteolytically processed to its active form by caspase 1 . This cytokine is an important mediator of the inflammatory response and is involved in a variety of cellular activities, including cell proliferation, differentiation, and apoptosis.

Vidal et al ${ }^{126}$ revealed that dietary wolfberry supplementation enhanced both in vivo (delayed-type hypersensitivity) and ex vivo (T-cell proliferation) $\mathrm{T}$-cell response to specific antigens, but it did not affect mitogen-induced T-cell or B-cell proliferation in young and aged mice. Over 44 days, young-adult (2 months) and aged (21 months) C57BL/6J mice were fed ad libitum with a controlled diet and received drinking water supplemented or not with $0.5 \%$ (wt/vol) Lacto-Wolfberry. All mice were immunized on day 15 and challenged on day 22 with a T-cell-dependent antigen, keyhole limpet hemocyanin. The study showed that LactoWolfberry supplementation significantly increased in vivo systemic immune markers. ${ }^{126}$ Both antigen-specific humoral response and cell-mediated immune responses in young-adult and aged mice were enhanced. However, no significant effect of Lacto-Wolfberry supplementation was observed on ex vivo splenocyte proliferative response to mitogens and on splenocyte T-cell subsets. ${ }^{126}$ These data suggest that dietary intake of Lacto-Wolfberry may favorably modulate the poor responsiveness to antigenic challenge observed with aging.

Zhang et $\mathrm{al}^{127}$ further compared the effect of LBPF4 and LBPF4-OL on the proliferation of splenocytes and mitogeninduced $\mathrm{B}$ and $\mathrm{T}$ lymphocytes in female Balb/C mice. LBPF4 and LBPF4-OL were isolated in the fruit bodies of L. barbarum through a series of diethylaminoethyl anion exchange cellulose and gel-permeation chromatography. The molecular weight of LBPF4 was $214.8 \mathrm{kDa}$, and consisting of 17 amino acids and four kinds of monosaccharides. The molecular weight of LBPF4-OL was $181 \mathrm{kDa}$, consisting of three types of monosaccharides. ${ }^{127}$ The effects on cytokine secretion, the phagocytic potential of macrophages, and the expression level of intracellular signaling molecules including NF- $\mathrm{B}$ and B-cell-specific activator protein (BSAP, also named Pax5) were also determined. BSAP/Pax5 is essential for commitment of lymphoid progenitors to the B lymphocyte lineage. ${ }^{128}$ Spleen cells $\left(5 \times 10^{5}\right)$ were stimulated with $10 \mu \mathrm{g} / \mathrm{mL}$, $50 \mu \mathrm{g} / \mathrm{mL}$, and $100 \mu \mathrm{g} / \mathrm{mL}$ LBPF4-OL. Concanavalin A (Con A, $0.5 \mu \mathrm{g} / \mathrm{mL}$ ) and LPS $(5 \mu \mathrm{g} / \mathrm{mL})$ were included as positive controls for the proliferation of $\mathrm{T}$ and $\mathrm{B}$ cells, respectively. The results showed that $50 \mu \mathrm{g} / \mathrm{mL} \mathrm{LBPF} 4$ significantly enhanced spleen cell proliferation $\sim 3.2$ fold, while LBPF4-OL enhanced proliferation 7.2 fold. Administration of $10 \mu \mathrm{g} / \mathrm{mL}, 50 \mu \mathrm{g} / \mathrm{mL}$, or $100 \mu \mathrm{g} / \mathrm{mL}$ LBPF4 but not LBPF4-OL, significantly enhanced the Con A-induced T lymphocyte proliferation. ${ }^{127}$ However, LPS-induced B-cell proliferation was enhanced by $10 \mu \mathrm{g} / \mathrm{mL}, 50 \mu \mathrm{g} / \mathrm{mL}$, or $100 \mu \mathrm{g} / \mathrm{mL}$ of both LBPF4 and LBPF4-OL. Administration of $50 \mu \mathrm{g} / \mathrm{mL}$ LBPF4-OL was more effective on inducing the proliferation of splenocytes and LPS-stimulated B cells than $100 \mu \mathrm{g} / \mathrm{mL}$ LBPF4. LBPF4 appeared to induce lymphocyte proliferation predominantly depending on both $\mathrm{B}$ and $\mathrm{T}$ cells, and LBPF4-OL induced lymphocytes proliferation only depending on B cells. The stimulation of murine peritoneal macrophages with LBPF4 and LBPF4-OL resulted in a comparable dose-dependent increase of the production of TNF- $\alpha$ and IL-1 $\beta \cdot{ }^{127}$ In addition, both LBPF4 and LBPF4-OL at concentrations of $10 \mu \mathrm{g} / \mathrm{mL}, 50 \mu \mathrm{g} / \mathrm{mL}$, and $100 \mu \mathrm{g} / \mathrm{mL}$ increased the secretion of NO to comparable levels. Administration of $10 \mu \mathrm{g} / \mathrm{mL}$ LBPF4 and LBPF4-OL showed no significant effects on the phagocytic activity of resting macrophages in mice, but the macrophage chicken erythrocyte phagocytic activity was significantly increased by low concentrations of LBPF4 and LBPF4-OL. About $50 \mu \mathrm{g} / \mathrm{mL}$ (but not $10 \mu \mathrm{g} / \mathrm{mL}$ ) LBPF4 and LBPF4-OL significantly promoted BSAP and NF- $\kappa \mathrm{B}$ activity. ${ }^{127}$ These data suggest that LBPF4-OL can only enhance B cell and macrophage functions, but polysaccharide-protein complex LBPF4 can enhance the function of both $\mathrm{T}$ and $\mathrm{B}$ cells and macrophages.

Recently, Zhang et al $^{129}$ found that LBPF4-OL acted as an activator of the Toll-like receptor 4 (TLR4)/p38 MAPK signaling pathway using TLR4 knockout mice. LBPF4-OL significantly induced TNF- $\alpha$ and IL- $1 \beta$ production in peritoneal macrophages isolated from wild type $(\mathrm{C} 3 \mathrm{H} / \mathrm{HeN})$ but not TLR4-deficient mice $(\mathrm{C} 3 \mathrm{H} / \mathrm{HeJ})$. The proliferation of LBPF4-OL-stimulated lymphocytes from $\mathrm{C} 3 \mathrm{H} / \mathrm{HeJ}$ mice was significantly lower than that of lymphocytes from $\mathrm{C} 3 \mathrm{H} /$ HeN mice. ${ }^{129}$ Furthermore, through a bio-layer interferometry assay, LPS but not LBPF4-OL directly associated with the 
TLR4/MD2 molecular complex. Flow cytometry analysis indicated that LBPF4-OL markedly upregulated TLR4/MD2 expression in both peritoneal macrophages and Raw264.7 cells. ${ }^{129}$ LBPF4-OL also increased the phosphorylation of p38-MAPK and inhibited the phosphorylation of JNK and Erk1/2. These data suggest that LBPF4-OL can activate TLR4/p38 MAPK signaling pathway.

\section{Peripheral blood mononuclear cells}

IL-2 is necessary for the growth, proliferation, and differentiation of $\mathrm{T}$ lymphocytes to become functional T cells. ${ }^{122}$ Antigen binding to the T-cell receptor stimulates the secretion of IL-2 by T cells and the expression of IL-2 receptors (IL-2Rs). The IL-2/IL-2R interaction stimulates the growth, differentiation, and survival of antigen-specific $\mathrm{CD}^{+}$and $\mathrm{CD}^{+} \mathrm{T}$ cells. IL-2 plays an important role for the development of T-cell-dependent immune memory. An in vitro study reported the effects of LBPs on the expression of IL-2 and TNF- $\alpha$ in human peripheral blood mononuclear cells (PBMCs) from healthy volunteers. ${ }^{130}$ The LBPs used in this study were the third fraction of LBPs extracted with hot water from L. barbarum planted in Zhongning, Ningxia, People's Republic of China and isolated by anionic exchange chromatography and gel-filtration chromatography. Administration of $10 \mathrm{mg} / \mathrm{L}$ LBPs increased the expression of IL- 2 and TNF- $\alpha$ at both mRNA and protein levels in a dose-dependent manner. Treatment of human PBMCs with $5 \mathrm{mg} / \mathrm{L}, 10 \mathrm{mg} / \mathrm{L}, 20 \mathrm{mg} / \mathrm{L}$, and $40 \mathrm{mg} / \mathrm{L} \mathrm{LBPs}$ increased IL-2 mRNA 1.8-, 3.9-, 7.0-, and 7.4-fold, respectively. The activity of IL-2 was increased 4.3-, 7.7-, 14.2-, and 16.0-fold, respectively, compared to the negative control. ${ }^{130}$ Treatment of PBMCs with $5 \mathrm{mg} / \mathrm{L}, 10 \mathrm{mg} / \mathrm{L}, 20 \mathrm{mg} / \mathrm{L}$, and $40 \mathrm{mg} / \mathrm{L}$ LBPs increased TNF- $\alpha$ mRNA level 2.4-, 3.9-, 6.1-, and 15.4-fold, respectively. The activity of TNF- $\alpha$ after treatment with $5 \mathrm{mg} / \mathrm{L}, 10 \mathrm{mg} / \mathrm{L}, 20 \mathrm{mg} / \mathrm{L}$, and $40 \mathrm{mg} / \mathrm{L} \mathrm{LBPs}$ for 8 hours was increased 7.1-, 9.1-, 13.6-, and 15.2-fold, respectively, compared to the negative control. LBPs may induce immune responses that contribute to the therapeutic effect in cancer.

\section{Macrophages}

Macrophages play a crucial role in innate immunity and also help initiate adaptive immunity. ${ }^{131,132}$ Macrophages predominantly expressing the killer phenotype are called $M_{1}$ macrophages, whereas those involved in tissue repair are called $\mathrm{M}_{2}$ macrophages. ${ }^{133}$ The primary role of macrophages is to phagocytose or engulf and then digest cellular debris and pathogens; they also stimulate lymphocytes and other immune cells to respond to pathogens. $M_{1}$ macrophages are activated by LPS and IFN- $\gamma$ and secrete high levels of IL-12 and low levels of IL-10; and $\mathrm{M}_{2}$ macrophages produce high levels of IL-10, TGF- $\beta$, and low levels of IL-12. ${ }^{133}$ IL-12 is involved in the stimulation and maintenance of $\mathrm{Th}_{1}$ cellular immune responses and also has an important role in enhancing the cytotoxic function of NKs. Macrophages can be identified by specific expression of a number of proteins including CD14, CD40, CD11b, CD64, F4/80 (mice)/EMR1 (human), lysozyme M, MAC-1/MAC-3, and CD68. LBPs are able to activate macrophages. A study found that LBPs (50 mg/kg, ip) markedly upregulated the expressions of CD40, CD80 (B-lymphocyte activation antigen B7-1), CD86 (B-lymphocyte activation antigen B7-2), and MHC-II molecules on peritoneal macrophages. In vitro studies showed that LBPs activated transcription factors NF- $\kappa$ B and AP-1, induced TNF- $\alpha$, IL-1 $\beta$, and IL-12p40 mRNA expression, and enhanced TNF- $\alpha$ production in RAW264.7 macrophage cells in a dose-dependent manner. ${ }^{134}$ Furthermore, LBPs significantly enhanced macrophage endocytic and phagocytic capacities in vivo. These results indicated that LBPs enhance innate immunity by activating macrophages. The mechanism might be through activation of transcription factors NF- $\kappa \mathrm{B}$ and $\mathrm{AP}-1$ to induce TNF- $\alpha$ production and upregulation of MHC-II co-stimulatory molecules. ${ }^{134}$

An in vitro study by Teng et al ${ }^{135}$ investigated the inhibitory effects of LBPs on the production of LPS-induced proinflammatory mediators in BV2 microglia. The data showed that LPS induced the activation of NF- $\mathrm{\kappa B}$ and its upstream protein caspase 3 . NF- $\kappa \mathrm{B}$ plays a key role in inflammatory disease and may be involved in autophagy, while autophagy itself may also participate in the pathogenesis of inflammation and inflammatory disease. ${ }^{136}$ LPS also unregulated the expression of an additional apoptosis-inducing factor with a passive role in the maturation of caspase processing, HSP60, in BV2 microglial cells and increased the release of TNF- $\alpha$ and HSP60 in the culture media. Following treatment with LBPs, the activated caspase 3 were significantly suppressed. Furthermore, the enhanced expression of HSP60 was reduced and the LPS-induced release of TNF- $\alpha$ and HSP60 was inhibited. These results suggest that LBPs may have therapeutic potential for the treatment of neurodegenerative diseases that are accompanied by microglial activation.

Peng et $\mathrm{al}^{137}$ investigated the effect of Lycium ruthenicum polysaccharides (LRGP3) on inflammatory reactions induced by LPS in mouse macrophage RAW264.7 cells. The results showed that LRGP3 treatment significantly inhibited the LPS-induced NO production and the mRNA expression of 
iNOS, as well as the level of TLR4. Furthermore, LRGP3 treatment prevented IкB $\alpha$ degradation and reduced phosphoNF-KB p65 protein expression in LPS-stimulated RAW264.7 cells. ${ }^{137}$ Meanwhile, the levels of proinflammatory cytokines, such as IL- $1 \alpha$, IL-6, and TNF- $\alpha$, were suppressed by LRGP3 in LPS-stimulated RAW264.7 cells. LRGP3 attenuated LPSinduced inflammation via inhibiting TLR4/NF- $\mathrm{KB}$ signaling pathway.

\section{Natural killers}

NK cells are major effectors of the innate immunity, providing rapid responses to virally infected cells and respond to tumor formation. ${ }^{138,139}$ Cytokines involved in NK activation include IL-12, IL-15, IL-18, IL-2, and CCL5. NK cells are activated in response to IFNs or macrophage-derived cytokines. NK cells control viral infections by secreting IFN- $\gamma$ and TNF $\alpha .{ }^{138,139}$ IFN- $\gamma$ activates macrophages for phagocytosis and lysis, and TNF $\alpha$ acts to promote direct NK tumor cell killing. NKs express the surface markers CD16 (FcrRIII) and CD56 in humans. A recent study by Huyan et $\mathrm{al}^{140}$ reported the effects of LBPs on primary human NK cells under normal or simulated microgravity conditions. The results demonstrated that LBPs markedly promoted the cytotoxicity of NK cells by enhancing IFN- $\gamma$ and perforin secretion and increasing the expression of the activating receptor NKp30 under normal conditions. Meanwhile LBPs enhanced NK cell function under simulated microgravity conditions by restoring the expression of the activating receptor NKG2D and reducing the early apoptosis and late apoptosis/necrosis. ${ }^{140}$ In addition, the antibody neutralization test showed that the complement receptor CR3 may be the critical receptor involved in LBP-induced NK cells activation. These findings indicate that LBPs are potent immune regulators and can promote the immune functions of the public and astronauts during space missions.

\section{Dendritic cells}

Dendritic cells (DCs) are potent antigen-presenting cells that play pivotal roles in the initiation of the adaptive ( $\mathrm{T}$ and $\mathrm{B}$ cell) immune response. ${ }^{141,142}$ The principal function of DCs is to present antigens, and only DCs have the ability to induce a primary immune response in resting naïve $\mathrm{T}$ lymphocytes. DCs also play a role in the maintenance of $\mathrm{B}$ cell function and recall responses. DCs express a variety of adhesion molecules including CD11a (integrin lymphocyte function-associated antigen-1, namely LFA-1), CD11c/ CD18, CD50 (ICAM-2), CD54 (ICAM-1), CD58 (LFA-3), and CD102 (ICAM-3). ${ }^{141,142}$ CD11a/LFA-1 plays a central role in leukocyte intercellular adhesion through interactions with its ligands, ICAMs 1-3, and also functions in lymphocyte costimulatory signaling. DCs also express costimulatory molecules including CD80 (B7-1) and CD86 (B7-2), which are upregulated during DC activation. CD86 tends to be a marker of early DC maturation, while CD80 only appears in mature DC. ${ }^{141,142}$

The effects of LBPs on the phenotypic and functional maturation of murine bone marrow DCs (BMDCs) were investigated in vitro by Zhu et al. ${ }^{143}$ The co-expression of MHC-II, CD11c, and secretion of IL-12 p40 by BMDCs stimulated with $100 \mathrm{mg} / \mathrm{L}$ LBPs increased significantly. LBPs are capable of promoting both the phenotypic and functional maturation of murine BMDCs in vitro.

Chen et al ${ }^{144}$ reported that LBPs induced phenotypic and functional maturation of DCs with strong immunogenicity. LBPs can upregulate the expression of CD40, CD80, CD86, and MHC-II molecules on DCs, downregulate DC uptake of antigen, enhance allostimulatory activity of DCs, and induce the production of IL-12p40 and p70 in DCs. ${ }^{144}$ LBP-treated DCs can enhance both $\mathrm{Th}_{1}$ and $\mathrm{Th}_{2}$ responses in vitro and in vivo. LBPs may serve as a potent adjuvant for the design of DC-based vaccines.

Chen et a ${ }^{145}$ investigated the effect of LBPs on differentiation and maturation of healthy human peripheral bloodderived DCs cultured in different tumor microenvironment in vitro. Peripheral blood-derived DC precursor cells were obtained by the density-gradient centrifugation method, and the tumor-cell supernatants were used to prepare conditioned medium. The GM-CSF and IL-4-induced DC precursor cell differentiation to DCs, the TNF- $\alpha$ promoted the immature DCs developed to mature DCs. In LBP-treated groups, the molecular phenotype of DCs, their capacity to stimulate allogeneic lymphocyte proliferation, and the levels of IL-12p70 and IFN- $\gamma$ secretion were higher than the untreated group. ${ }^{145}$ Meanwhile, the expression of NF- $\mathrm{KB}$ of the DCs in the medium treated with LBPs was higher than the untreated group. ${ }^{145}$ Between the two different tumor microenvironment groups, the nuclear NF- $\kappa$ B expression was obviously different. LBP could increase the expression of the phenotype of DCs via NF- $\kappa B$ signaling pathway.

\section{Follicular helper $T$ cells}

Follicular helper $\mathrm{T}$ (Tfh) cells are recognized as a subset of helper $\mathrm{T}$ cells that regulate the multiple stages of B-cell maturation and function. ${ }^{146} \mathrm{Tfh}$ cells retain intense expression of CXCR5, which directs these cells toward CXCL13-rich areas within the germinal center. Tfh cells express a number 
of costimulatory molecules, such as inducible costimulator and CD40L that have the capacity to restrain their interaction with $\mathrm{B}$ cells and antigen-presenting cells, including CTLA-4 and PD-1, which may reflect their discriminating role in the germinal center. Tfh cells also express a number of cytokines that facilitate antibody production including IL-4, IL-10, and IL-21.

A recent study by $\mathrm{Su}$ et $\mathrm{al}^{147}$ reported that LBPs were able to activate $\mathrm{CXCR} 5^{+} / \mathrm{PD}-1^{+}$Tfh cells and induced IL-21 secretion in female Balb/C mice. Mice were immunized once with ip injection of $0.2 \mathrm{~mL}$ of $10^{8}$ TCID50 rAd5VP1. LBPs were given to mice daily for 7 days by gastric gavage at $5 \mathrm{mg} / \mathrm{kg}$, $25 \mathrm{mg} / \mathrm{kg}$, or $50 \mathrm{mg} / \mathrm{kg}$ body weight. After 7 days, mice were sacrificed, the splenocytes were harvested, and the number of $\mathrm{CXCR}^{+} / \mathrm{PD}-1^{+}$Tfh cells was determined by three-color flow cytometry. ${ }^{147}$ Mouse splenocytes were also analyzed by flow cytometry to determine the counts of B220 ${ }^{+} / \mathrm{GL}-7^{+}$ $\mathrm{B}$ cells. The study showed that LBP treatment increased the percentage of $\mathrm{CXCR}^{+} / \mathrm{PD}-1^{+} \mathrm{Tfh}$ cells within total $\mathrm{CD}^{+} \mathrm{T}$ cells; $5 \mathrm{mg} / \mathrm{kg}(2.17 \% \pm 0.07 \%), 25 \mathrm{mg} / \mathrm{kg}(3.93 \% \pm 0.74 \%)$, and $50 \mathrm{mg} / \mathrm{kg}(3.84 \% \pm 0.20 \%)$. Administration of $5 \mathrm{mg} / \mathrm{kg}$ LBP for 7 days exhibited a minor effect on the production of IL-21, whereas $25 \mathrm{mg} / \mathrm{kg}$ and $50 \mathrm{mg} / \mathrm{kg}$ LBPs significantly increased the production of IL-21 when compared with mice treated with phosphate buffered saline only. ${ }^{147}$ LBPs also promoted the formation of germinal centers and production of $\mathrm{B} 220^{+} / \mathrm{GL}-7^{+}$germinal center B cells in mice. The fraction of B220 $/ \mathrm{GL}-7^{+} \mathrm{B}$ cells was significantly increased with $25 \mathrm{mg} / \mathrm{kg}$ and $50 \mathrm{mg} / \mathrm{kg}$ LBPs compared with mice receiving phosphate buffered saline only $(1.80 \% \pm 0.49 \%)$. Moreover, LBPs as an adjuvant increased generation of rAd5VP1induced Tfh cells in mice. ${ }^{147}$ There was a marked increase in the number of $\mathrm{CXCR}^{+} / \mathrm{PD}-1^{+} / \mathrm{CD}^{+}{ }^{+}$Tfh cells and B220 2 GL- $7^{+}$germinal center B cells in mice immunized with $10^{8}$ TCID50 rAd5VP1 plus LBPs. These results indicate that LBPs may enhance T-cell-dependent antibody responses by acting as an adjuvant for the generation of Tfh cells.

\section{LBP as a vaccine adjuvant}

LBPs stimulated moderate immune responses, and therefore, could potentially be used as a substitute for oil adjuvants in vaccines. Subfractions of polysaccharides, $12.5 \mathrm{mg} / \mathrm{kg}$, $25 \mathrm{mg} / \mathrm{kg}$, or $50 \mathrm{mg} / \mathrm{kg} \mathrm{LBP3a}$, were mixed with a DNA vaccine encoding the major outer membrane protein of Chlamydophila abortus. ${ }^{148}$ Balb/C mice were inoculated at days 0,14 , and 28, and challenged on day 44. Serum antibody levels, in vitro lymphocyte proliferation, the levels of IL- 2 , IFN- $\gamma$, and TNF- $\alpha$, and Chlamydia clearance in the spleen were monitored. A combination of DNA vaccine plus LBP3a induced significantly higher antibody levels in mice, higher T-cell proliferation, and higher levels of IFN- $\gamma$ and IL-2. Mice immunized with DNA vaccine and LBPs showed significantly higher levels of $\mathrm{Th}_{1}$ immune response and Chlamydia clearance in mouse spleen. The immunoenhancing effect induced by $25 \mathrm{mg} / \mathrm{kg} \mathrm{LBP} 3 \mathrm{a}$ was more effective than that induced by $12.5 \mathrm{mg} / \mathrm{kg}$ and $50 \mathrm{mg} / \mathrm{kg}$ LBP3a. These results suggest that LBPs may be used as an effective adjuvant with a DNA vaccine against swine C. abortus.

Vaccination is the most efficient strategy to prevent influenza infection. However, vaccine efficacy is significantly diminished in the elderly due to the age-related impairment of both innate and adaptive immune responses. A recent study ${ }^{149}$ has examined whether dietary wolfberry supplementation enhanced the protective effect of influenza vaccine against influenza challenge in aged male C57BL/6J mice (20-22 months old). The mice were fed a 5\% milkbased preparation of wolfberry (Nestec) or fed with 5\% corn starch (control) for 30 days, then immunized with an influenza vaccine or saline (control) by ip injection on days 31 and 52 of the dietary intervention, and finally challenged with influenza A/Puerto Rico/8/34 virus (Sino Biological, Bejing, People's Republic of China) with an aluminum adjuvant at a ratio of $1: 1$. The milk-based preparation of wolfberry contained $530 \mathrm{mg} / \mathrm{g}$ of wolfberry fruit, $290 \mathrm{mg} / \mathrm{g}$ of skimmed milk, and $180 \mathrm{mg} / \mathrm{g}$ of maltodextrin. At day 73 , mice were infected with influenza A/Puerto Rico/8/34 virus and were monitored daily for weight loss and mortality. ${ }^{149}$ Mice fed with wolfberry diet had higher influenza IgG titers, less weight loss, and improved survival rate in influenzainfected mice when compared with the mice treated by influenza vaccine alone. ${ }^{149}$ Furthermore, an in vitro study showed that administration of $100 \mathrm{mg} / \mathrm{L}, 200 \mathrm{mg} / \mathrm{L}, 400 \mathrm{mg} / \mathrm{L}$, or $800 \mathrm{mg} / \mathrm{L}$ wolfberry supplementation enhanced maturation and activity of antigen-presenting DCs isolated from the bone marrow of aged mice. Wolfberry extract dosedependently increased the percentages of DCs expressing MHC-II and T-cell costimulatory molecules CD40, CD80, and CD86 and their expression. Wolfberry enhanced the production of proinflammatory IL-12 and TNF- $\alpha .{ }^{149}$ With improved maturation of DCs, the endocytic capability of DCs was significantly reduced when treated with wolfberry extract. Adoptive transfer of wolfberry-treated bone marrow

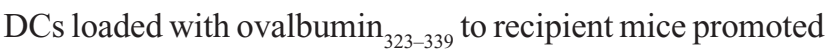
antigen-specific T-cell proliferation as well as IL-4 and IFN- $\gamma$ production in $\mathrm{CD}^{+} \mathrm{T}$ cells. ${ }^{149}$ Wolfberry may enhance 
the antigen-presenting function of DCs, leading to a higher level of antigen-specific T-cell effector function involving at least $\mathrm{Th}_{1}$ and $\mathrm{Th}_{2}$ responses. These data indicate that dietary wolfberry potentiates the efficacy of influenza vaccination, resulting in better host protection to prevent subsequent influenza infection via improved DC function.

\section{Clinical studies}

Amagase et al $^{150}$ investigated the systematic effects of consuming $120 \mathrm{~mL} /$ day GoChi for 30 days on immune function, general well-being, and safety in a randomized, double-blind, placebo-controlled clinical study in 60 older Chinese healthy adults (55-72 years old). The GoChi group showed a statistically significant increase in the number of lymphocytes and levels of IL-2 and IgG compared to preintervention and the placebo group, whereas the number of CD4, CD8, and NK cells or levels of IL-4 and IgA were not significantly altered. The placebo group showed no significant changes in any immune measures, whereas the GoChi group showed a significant increase in general feelings of well-being, such as fatigue and sleep, and showed a tendency for increased short-term memory and focus between pre- and post-intervention; the placebo group showed no significant positive changes in these measures. ${ }^{150}$ GoChi was well tolerated. No adverse reactions, abnormal symptoms, or changes in body weight, blood pressure, pulse, visual acuity, urine, stool, or blood biochemistry were noted in either group. ${ }^{150}$ Daily consumption of GoChi significantly increased several immunological responses and subjective feelings of general well-being without any adverse reactions in the elderly.

A recent study by Vidal et $\mathrm{al}^{151}$ reported that elderly persons who consumed Lacto-Wolfberry for 3 months $(13.7 \mathrm{~g} /$ day in the form of the same milk-based preparation of wolfberry) had higher serum influenza-specific IgG concentrations and seroconversion rate after receiving an influenza vaccine compared with age-matched elderly individuals in the placebo group. The study was conducted in 150 healthy community-dwelling Chinese elderly (65-70 years old) supplemented with Lacto-Wolfberry or placebo (13.7 g/day). No serious adverse reactions were reported during the trial, neither symptoms of influenza-like infection nor changes in body weight and blood pressure, blood chemistry or cells composition, and autoantibodies levels were observed. ${ }^{151}$ Lacto-Wolfberry supplementation had no significant effect on delayed-type hypersensitivity response and inflammatory markers. These data show that chronic dietary supplementation with Lacto-Wolfberry in the elderly enhances their capacity to respond to influenza vaccine challenge.

\section{Summary of immunomodulating effects of LBPs}

A number of in vitro and in vitro studies have revealed the immunomodulating activities of LBPs (Figure 9). LBPs promote the proliferation and activity of splenocytes, T cells, B cells, macrophages, and NK cells. LBPs induce IL-6, IL-8, IL-10, and TNF- $\alpha$ production in splenocytes. LBPs stimulate PBMCs to produce IL-2 and TNF- $\alpha$. IL-2 stimulates growth and differentiation of T cells. LBPs promote T lymphocytes and macrophages to release important cytokines such as IL-10 and TNF- $\alpha$. LBPs activate macrophages and upregulate the expressions of CD40, CD80, CD86, and MHC-II molecules. LBPs activate transcription factors NF- $\kappa \mathrm{B}$ and AP-1, induce TNF- $\alpha$, IL-1 $\beta$, and IL-12p40 expression in macrophages. LBPs significantly enhance macrophage endocytic and phagocytic capacities. LBPs promote the cytotoxicity of $\mathrm{NK}$ cells by enhancing IFN- $\gamma$ and perforin release and the expression of the activating receptors NKp30 and NKG2D. LBPs also stimulate macrophages and NK cells to release TNF- $\alpha$ and IL-1 $\beta$. LBPs activate the transcription factors NFAT and AP-1 and prompt CD25 (IL-2 receptor- $\alpha$ ) expressions. LBPs induce the maturation of DCs and improve their antigen-presenting function. LBPs can upregulate the expression of CD40, CD80, CD86, and MHC-II molecules in bone marrow- and peripheral blood-derived DCs, downregulate DC uptake of antigen (Ag), enhance allostimulatory activity of DCs, and induce the production of IL-12p40 and p70 in DCs. LBP-treated DCs can enhance both $\mathrm{Th}_{1}$ and $\mathrm{Th}_{2}$ responses. LBPs potentiate the immune responses of DNA vaccine against $C$. abortus in mice. LBPs activate CXCR5 ${ }^{+} \mathrm{PD}-1^{+}$Tfh cells and induce IL-21 secretion. Dietary wolfberry supplementation enhances both in vivo and ex vivo T-cell response to specific antigens. Elderly persons who consume Lacto-Wolfberry for 3 months show higher serum influenza-specific IgG concentrations and seroconversion rate after receiving an influenza vaccine.

\section{Neuroprotective effects and effects on cognitive and memory deficits, AD, and stroke}

As the aged population dramatically increases in these decades, there is a great increase in the prevalence of age-associated neurodegenerative diseases such as cognitive and memory deficits, AD, and Parkinson's disease. There is increased interest in seeking new therapeutic agents for these devastating diseases from herbal medicines. LBPs possess neuroprotective effects in various in vitro and in vivo models ${ }^{152-154}$ but the mechanisms have not yet been fully elucidated. In the nervous system, LBPs can protect against neuronal injury or loss induced by $\mathrm{I} / \mathrm{R},{ }^{155,156} \mathrm{~A} \beta$ peptide, ${ }^{157,158}$ glutamate 


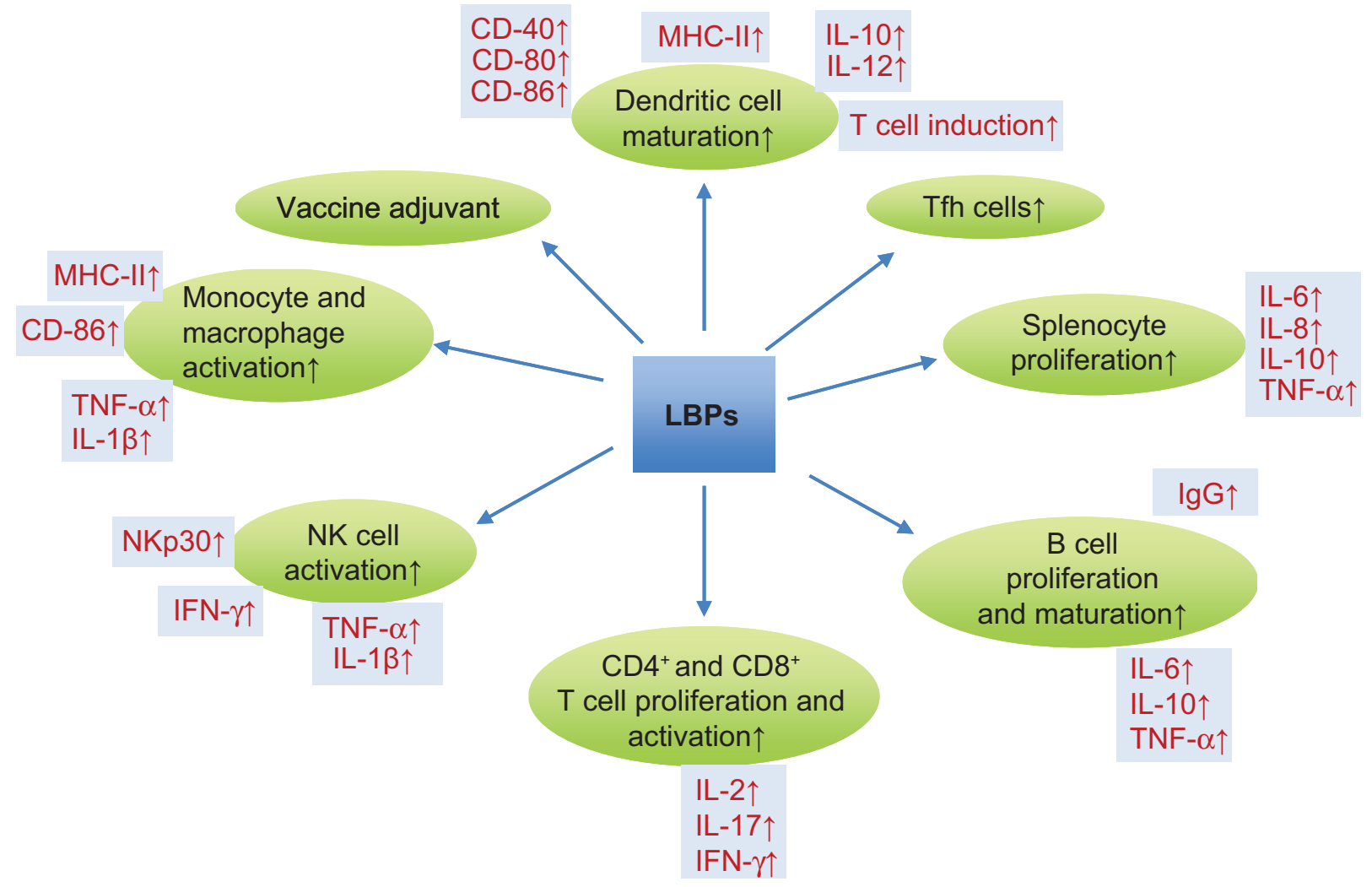

Figure 9 Possible mechanisms for the immunomodulating effects of LBPs.

Notes: LBPs have been found to have a variety of immune-modulatory activities in vitro and in vivo. LBPs promote the proliferation and activity of splenocytes, T cells, B cells, macrophages and NK cells. LBPs induce IL-6, IL-8, IL-I0, and TNF- $\alpha$ production in splenocytes. LBPs stimulate PBMCs to produce IL-2 and TNF- $\alpha$. IL-2 stimulates growth and differentiation of T cells. LBPs promote T lymphocytes and macrophages to release important cytokines such as IL-I0 and TNF- $\alpha$. IL-I 0 inhibits the production of IFN- $\gamma$, IL-2, IL-3, TNF- $\alpha$, and granulocyte-macrophage colony-stimulating factor (GM-CSF) by activated macrophages and by helper T cells. LBPs activate macrophages and upregulate the expressions of CD40, CD80, CD86, and MHC-II molecules. LBPs activate transcription factors NF-KB and AP-I, induce TNF- $\alpha$, IL-I $\beta$, and IL-I2p40 expression in macrophages. LBPs significantly enhance macrophage endocytic and phagocytic capacities. LBPs promote the cytotoxicity of NK cells by enhancing IFN- $\gamma$ and perforin release and the expression of the activating receptors NKp30 and NKG2D. LBPs also stimulate macrophages and NK cells to release TNF- $\alpha$ and IL-I $\beta$. LBPs activate the transcription factors NFAT and AP-I and prompt CD25 (IL-2 receptor- $\alpha$ ) expression. LBPs induce the maturation of DCs and improve their antigen-presenting function. LBPs can upregulate the expression of CD40, CD80, CD86, and MHC-II molecules in bone marrow- and peripheral blood-derived DCs, downregulate DC uptake of Ag, enhance allostimulatory activity of DCs, and induce the production of IL- 12 p40 and p70 in DCs. IL- 12 is involved in the stimulation and maintenance of Th, cellular immune responses and also has an important role in enhancing the cytotoxic function of NKs. LBP-treated DCs can enhance both Th, and Th, responses. LBPs potentiate the immune responses of DNA vaccine against Chlamydophila abortus in mice. LBPs also activate CXCR5+PD-I+ Tfh cells and induce IL-2I secretion. Dietary wolfberry supplementation enhances both in vivo and ex vivo T-cell response to specific antigens. Elderly persons who consume Lacto-Wolfberry for 3 months show higher serum influenza-specific lgG concentrations and seroconversion rate after receiving an influenza vaccine.

Abbreviations: Ag, antigen; AP-I, activator protein-I; GM-CSF, granulocyte-macrophage colony-stimulating factor; DCs, dendritic cells; IFN- $\gamma$, interferon- $\gamma$; IL, interleukin; LBP, Lycium barbarum polysaccharide; MHC-II, class II major histocompatibility complex; NF- $\kappa B$, nuclear factor $\kappa B$; NFAT, nuclear factor of activated T-cells; NK, natural killer; PD, programmed death; TNF, tumor necrosis factor; JNK, Jun N-terminal kinases; Nrf2, nuclear factor erythroid 2-related factor; PI3K, phosphatidylinositol 3-kinase; p38 MAPK, p38 mitogen activated protein kinase; GLUT4, glucose transporter type-4; IRS-I, insulin receptor substrate-I; HO-I, heme oxygenase-I; SOD, superoxide dismutase; GSK3 $\beta$, glycogen synthase kinase $3 \beta$; Tfh, T follicular helper.

excitotoxicity, and other neurotoxic insults. ${ }^{154}$ LBPs also enhance neurogenesis. ${ }^{154,159}$

\section{Ischemic brain disease and MCAO}

Ischemic stroke has become one of the most devastating diseases, which cause high rates of disability and mortality in aged people. ${ }^{160-162}$ Acute excitotoxicity, oxidative stress, and inflammation are the three primary mechanisms involved in cell death during ischemic stroke. ${ }^{163}$ Cerebral edema is a detrimental feature after ischemic stroke and is one of the impact factors of clinical deterioration within the first 24 hours after stroke onset. Cerebral ischemia and reperfusion triggers a cascade of cellular events including cell death, oxidative stress, and inflammation, which all contribute to the breakdown of blood-brain barrier (BBB). ${ }^{160-162}$ Neuronal cell apoptosis plays an important role in the development of ischemic injury in the brain tissue. Mitochondrial apoptotic pathway is a major apoptotic pathway, and a large number of apoptosis-related proteins in mitochondria play an important role in the initiation and development of neuronal apoptosis. ${ }^{164}$ Pro-apoptotic and anti-apoptotic Bcl-2 family proteins play important roles 
in mitochondrial apoptotic pathway. Bax is a pro-apoptotic and Bcl-2 is an anti-apoptotic protein in the Bcl-2 family. Cytochrome $\mathrm{C}$ binds and activates apoptotic proteaseactivating factor-1 as well as procaspase-9, forming an apoptosome together with ATP. Apoptosome then activates caspase-9, leading to caspase- 3 activation and eventually cellular apoptosis. Caspase- 3 has been identified as a key mediator of apoptosis and cleaves the substrate PARP-1, which is a multifunctional nuclear enzyme whose activity is rapidly stimulated by DNA breaks.

The protective effect of LBPs was investigated in primary cultured rat hippocampal neurons subject to oxygen-glucose deprivation/reperfusion by Rui et al. ${ }^{153}$ Cultured hippocampal neurons were exposed to oxygen-glucose deprivation for 2 hours followed by a 24-hour re-oxygenation. Treatment with LBPs (10-40 mg/L) significantly attenuated neuronal damage and inhibited LDH release in a dose-dependent manner. ${ }^{153}$

Yang et $\mathrm{al}^{155}$ investigated the protective effect of LBP pre-treatment in an experimental stroke (MCAO) model in male C57BL/6N mice. To gain LBPs, dry L. barbarum residues were dissolved in water at $70^{\circ} \mathrm{C}$, and the supernatant was concentrated, precipitated with $95 \%$ ethanol, and then vacuum dried to produce the extracts. The mice were administered $1 \mathrm{mg} / \mathrm{kg}$ or $10 \mathrm{mg} / \mathrm{kg}$ LBPs daily for 7 days, and then subjected to 2-hour transient MCAO by the intraluminal method followed by 22-hour reperfusion upon filament removal. LBP pre-treatment dose-dependently improved neurological deficits; decreased infarct size, apoptotic neurons in ischemic penumbra area, and cerebral edema; and protected the brain from $\mathrm{BBB}$ disruption as indicated by reduced Evans Blue dye leakage into the ipsilateral hemispheres and an upregulation of occludin expression. ${ }^{155}$ Occludin, one of the proteins located at tight junctions, plays an important role in maintaining the integrity of BBB. Pretreatment with $10 \mathrm{mg} / \mathrm{kg}$ LBPs for 7 days also profoundly suppressed the upregulation of AQP4 expression in ipsilateral penumbral areas. ${ }^{155}$ Furthermore, $10 \mathrm{mg} / \mathrm{kg}$ LBPs suppressed GFAP activation in ipsilateral penumbral areas. Pre-treatment with $10 \mathrm{mg} / \mathrm{kg}$ LBPs reduced both nitrosative stress and lipid peroxidation in cerebral ischemic penumbra after MCAO. LBPs at both doses attenuated the expression of matrix metalloproteinase-9 (MMP-9) in ipsilateral penumbral areas. ${ }^{155}$ These findings clearly demonstrate the beneficial prophylactic effects of LBPs against ischemic damage and cerebral edema in a murine experimental stroke model. The neuroprotective effects of LBPs on ischemic stroke include reduction of neuronal damage and infarct, maintenance of BBB integrity, and alleviation of cerebral edema through antioxidation, suppression of upregulated MMP-9 and AQP4, anti-apoptosis, and inhibition of glial activation.

In a study using male Kunming mice, Wang et al ${ }^{165}$ examined the effect of intragastric administration with LBPs on brain injuries in MCAO mice. The study demonstrated that LBPs at doses of $20 \mathrm{mg} / \mathrm{kg}$ and $40 \mathrm{mg} / \mathrm{kg}$ significantly decreased the neurological deficit scores and the infarct area in MCAO mice. LBPs also significantly decreased MDA content, and increased SOD, GPx, CAT, and LDH activities in the ischemic brain. ${ }^{165}$ These findings suggest that LBPs might act as potential neuroprotective agent against the cerebral reperfusion-induced brain injury through reducing lipid peroxides, scavenging free radicals, and improving the energy metabolism.

In a similar study, Wang et al ${ }^{156}$ used male Imprinting Control Region mice to make the model of MCAO and investigated the protective effect of intragastric administration of $10 \mathrm{mg} / \mathrm{kg}, 20 \mathrm{mg} / \mathrm{kg}$, and $40 \mathrm{mg} / \mathrm{kg}$ body weight LBPs or $0.4 \mathrm{mg} / \mathrm{kg}$ nimodipine for 7 days on MCAO-induced brain injuries. The results showed that intragastric administration of $20 \mathrm{mg} / \mathrm{kg}$ and $40 \mathrm{mg} / \mathrm{kg}$ LBPs markedly decreased the neurological deficit scores and the infarct volume in MCAO mice. ${ }^{156}$ Administration of $10-40 \mathrm{mg} / \mathrm{kg}$ LBPs also reduced neuronal morphological damage and neuronal apoptosis in ischemic penumbra of the left cortex. About $40 \mathrm{mg} / \mathrm{kg}$ LBPs significantly suppressed cortex overexpression of Bax, cytochrome C, caspase-3, -9, and cleaved PARP-1, and reduced the downregulated $\mathrm{Bcl}-2$ expression in MCAO mice. ${ }^{156}$

In summary, the protective effects of LBPs on MCAOinduced brain injuries are mainly attributed to the reduction of oxidative stress, inhibition of apoptosis, and increase in the integrity of BBB. LBPs treatment reduces the oxidative stress via increasing the SOD, GPx, CAT, and LDH activities, but decreasing the content of MDA and lipid peroxidation. LBPs also inhibit the apoptosis via decreasing the expression of cytochrome C, cleave caspase-9, caspase-3, Bax, and cleaved PARP-1, but increasing the expression level of Bcl-2. In addition, LBPs increase the integrity of BBB expression through the upregulation of expression of occludin, but downregulation of the expression of MMP-9 and AQP4 (Figure 10).

\section{$A \beta$-induced neuronal injury and $A D$}

$A \beta$ peptides are thought to be associated with the progressive neuronal death observed in AD. The effect of LBPs was investigated by $\mathrm{Yu}$ et $\mathrm{al}^{157}$ on the neuronal injury induced 


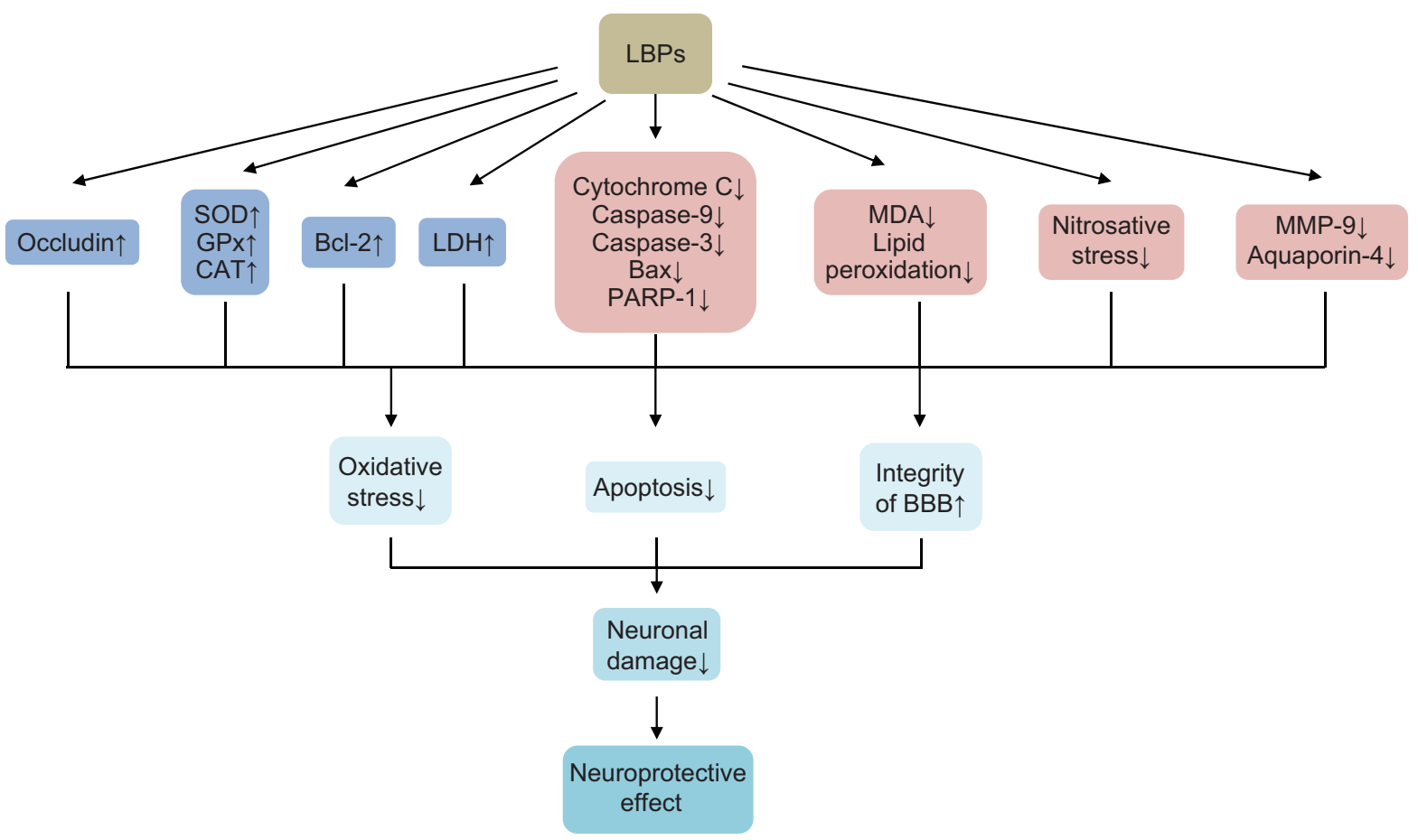

Figure 10 Possible mechanisms for the neuroprotective effects of LBPs against MCAO-induced brain injuries.

Notes: LBPs treatment protects neurons against MCAO-induced brain injuries mainly via reduction of oxidative stress, inhibition of apoptosis, and increase in the integrity of BBB in mice. LBPs increase the activities of SOD, GPx, CAT, and LDH, but decrease the content of MDA and lipid peroxidation, resulting in a reduction in oxidative stress. LBPs inhibit the expression of cytochrome C, cleave caspase-9, cleaved caspase-3, Bax, and cleaved PARP-I, but increase the expression level of Bcl-2, leading to inhibition of apoptosis. In addition, LBPs increase the expression of occludin but decrease the expression of MMP-9 and aquaporin-4, increasing the integrity of BBB.

Abbreviations: LBPs, Lycium barbarum polysaccharides; SOD, superoxide dismutase; CAT, catalase; GPx, glutathione peroxidase; LDH, lactate dehydrogenase; MCAO, middle cerebral artery occlusion; MDA, malondialdehyde; PARP, poly(ADP-ribose) polymerase; MMP-9, matrix metalloproteinase-9; BBB, blood-brain barrier; MHC-II, Class II major histocompatibility complex; TNF, tumor necrosis factor; IL, interleukin; IgG, immunoglobulin G; IFN, interferon; NK, natural killer; Tfh, follicular helper T cell; NKp30, natural killer cell p30-related protein.

by $A \beta 1-42$ and $A \beta 25-35$ peptides in primary rat cortical neurons. Remarkable apoptosis and necrosis in primary rat cortical neurons were observed when exposed to $\mathrm{A} \beta$ peptides. Pre-treatment with LBPs significantly reduced the release of LDH. In addition, LBPs attenuated $A \beta$ peptide-activated caspase-3-like activity. ${ }^{157} \mathrm{~A} \beta$ peptides induce a rapid activation of c-JNK by phosphorylation. Pre-treatment of LBPs markedly reduced the phosphorylation of JNK-1 at Thr183/ Tyr185 and its substrates c-Jun-I at Ser73 and c-Jun-II at Ser63. ${ }^{157}$ LPBs elicit dose-dependent neuroprotective effects via regulation of JNK-1 pathway.

$\mathrm{Yu}$ et al ${ }^{158}$ also investigated the effects of LBPs on the phosphorylation of the double-stranded RNA-dependent protein kinase (PKR) in rat cortical neurons exposed to $A \beta$ peptides. PKR is an intracellular sensor of stress and can arrest protein synthesis by phosphorylating the alpha subunit of the translation initiation factor eIF2. Pretreatment of LBPs effectively protected neurons against $A \beta$-induced apoptosis by reducing the activity of both caspase- 3 and -2 , but not caspase-8 and -9. LBPs markedly reduced $A \beta$-induced PKR phosphorylation. ${ }^{158}$
In summary, LBPs protect neurons against $A \beta$-induced apoptosis by reducing the activity of both caspase- 3 and -2 , but not caspase- 8 and -9 (Figure 11). LBPs inhibit the phosphorylation of JNK-1 at Thr183/Tyr185 and its substrates c-Jun-I at Ser73 and c-Jun-II at Ser63 in neurons. LBPs reduce the phosphorylation of Erk $1 / 2 \mathrm{~m}$ but not GSK3 $\beta$. LBPs also markedly reduced $A \beta$-induced PKR phosphorylation. LBPs also significantly reduce homocysteine-induced phosphorylation of Tau-1 at Ser198/199/202, pS396 at Ser396, and pS214 at Ser214 as well as cleavage of Tau.

\section{Scopolamine-induced brain injury}

A recent study by Chen et al ${ }^{154}$ reported the therapeutic effects of LBPs on learning and memory and neurogenesis in scopolamine (SCO)-treated adult male Sprague-Dawley rats. SCO was used to induce learning and memory deficits. LBPs were administered $0.2 \mathrm{mg} / \mathrm{kg}$ or $1 \mathrm{mg} / \mathrm{kg}$ body weight per day via gastric perfusion for 14 days before the onset of subcutaneous SCO treatment for a further 4 weeks. LBPs used were extracted with boiling water, followed by precipitation 


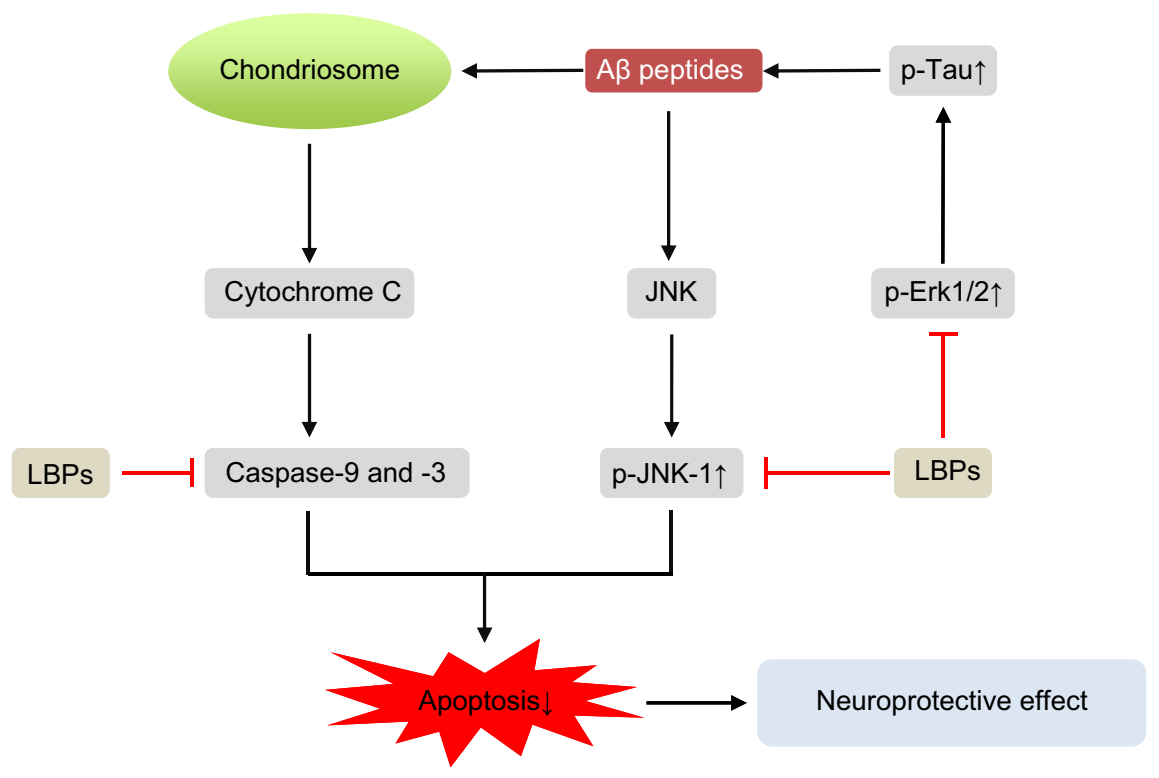

Figure II Possible mechanisms for the neuroprotective effects of LBPs against A $\beta$-induced neurotoxicity and Alzheimer's disease.

Notes: LBPs protect neurons against A $\beta$-induced apoptosis by reducing the activity of both caspase- 3 and -2 , but not caspase- 8 and -9 . LBPs inhibit the phosphorylation of JNK-I at Thr I83/Tyr I85 and its substrates c-Jun-I at Ser73 and c-Jun-II at Ser63 in neurons. LBPs reduce the phosphorylation of ErkI/2m but not GSK3 3 . LBPs also markedly reduced $A \beta$-induced PKR phosphorylation. PKR is an intracellular sensor of stress and can arrest protein synthesis by phosphorylating the alpha subunit of the translation initiation factor elF2. LBPs also significantly reduce homocysteine-induced phosphorylation of Tau-I at Ser 198/I99/202, pS396 at Ser396, and pS2I4 at Ser2I4 as well as cleavage of Tau.

Abbreviations: A $\beta$, amyloid- $\beta$; LBPs, Lycium barbarum polysaccharides; JNK, Jun N-terminal kinases; GSK3 $\beta$, glycogen synthase kinase 3 $\beta$; PKR, protein kinase; elF2, eukaryotic initiation factor 2

with ethanol, protein hydrolysis, dialysis, and fractionation with a diethylaminoethanol-Sepharose CL-6B column. An osmotic pump containing SCO solution at $440 \mathrm{mg} / \mathrm{mL}$ was subcutaneously embedded in the abdominal wall of rats and SCO release at a rate of $0.25 \mu \mathrm{L} / \mathrm{h}$ was maintained for 28 days and administration of LBPs was continued as before, throughout SCO treatment. LBPs at both doses almost restored the memory and learning abilities in SCO-treated rats. ${ }^{154}$ LBPs prevented SCO-induced reduction in neuronal proliferation and enhanced neuroblast differentiation in the hippocampal dentate gyrus of rats.

LBP treatment also protected the dendrites from damage by SCO. LBPs dose-dependently decreased the SCOinduced oxidative stress in hippocampus and reversed the increased ratio of Bax/Bcl-2 induced by SCO treatment. ${ }^{154}$ LBPs significantly increased hippocampal SOD and GPx activity and reduced MDA level in SCO-treated rats. However, LBPs did not affect the SCO-induced elevation of hippocampal acetylcholinesterase activity and decrease of brain-derived neurotrophic factor level. ${ }^{154}$ These results suggest that LBPs prevent SCO-induced cognitive and memory impairments and reductions in hippocampal cell proliferation and neuroblast differentiation. Anti-oxidation and anti-apoptosis are the two major mechanisms for the neuroprotective effects of LBPs in SCO-treated rats (Figure 12).

\section{Glutamate-induced neuronal injury}

Glutamate excitotoxicity is involved in many neurodegenerative diseases including AD. Attenuation of glutamate toxicity is one of the therapeutic strategies for AD. LBPs

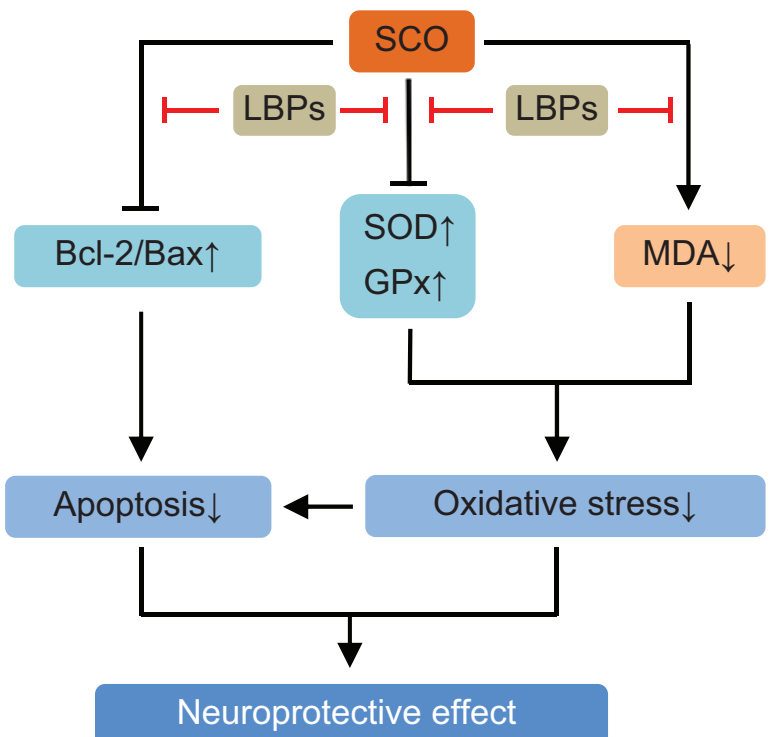

Figure 12 Possible mechanisms for the neuroprotective effects of LBPs against SCO-induced neurotoxicity.

Notes: LBPs protect neurons against SCO-induced neurotoxicity through the reduction of the oxidative stress and apoptosis. LBPs increase the activities of SOD and $\mathrm{GPx}$, restore the balance of $\mathrm{Bcl}-2$ to $\mathrm{Bax}$, but decrease the content of MDA.

Abbreviations: LBPs, Lycium barbarum polysaccharides; SCO, scopolamine; SOD, superoxide dismutase; GPx, glutathione peroxidase; MDA, malondialdehyde. 
were administrated to detect if they can prevent neurotoxicity elicited by glutamate in primary cultured neurons. ${ }^{166}$ The glutamate-induced cell death as detected by LDH assay and caspase-3-like activity assay was significantly reduced by LBPs at concentrations ranging from $10 \mu \mathrm{g} / \mathrm{mL}$ to $500 \mu \mathrm{g} / \mathrm{mL}$. LBPs provided neuroprotection even 1 hour after exposure to glutamate. In addition to glutamate, LBPs attenuated $N$-methylD-aspartate-induced neuronal damage, and glutamate-induced phosphorylation of JNK was reduced by treatment with LBPs (Figure 13). LBPs exerted significant neuroprotective effects on cultured cortical neurons exposed to glutamate.

\section{Manganese-induced neuronal injury}

Manganese could induce multiple organs injury especially in brain and show obvious cognitive and memory deficits. A study focused on the therapeutic effect of LBPs on neurogenesis and learning and memory of manganese poisoned mice. Healthy adult Kunming mice were used. The spatial learning and memory capacity of mice was determined by the Morris water maze training test. The neurogenic cells were labeled with bromodeoxyuridine (BrdU) and detected by immunohistochemistry. The average escape latency was significantly higher and the times of passing through platform were lower in the manganese treated group. BrdU-positive

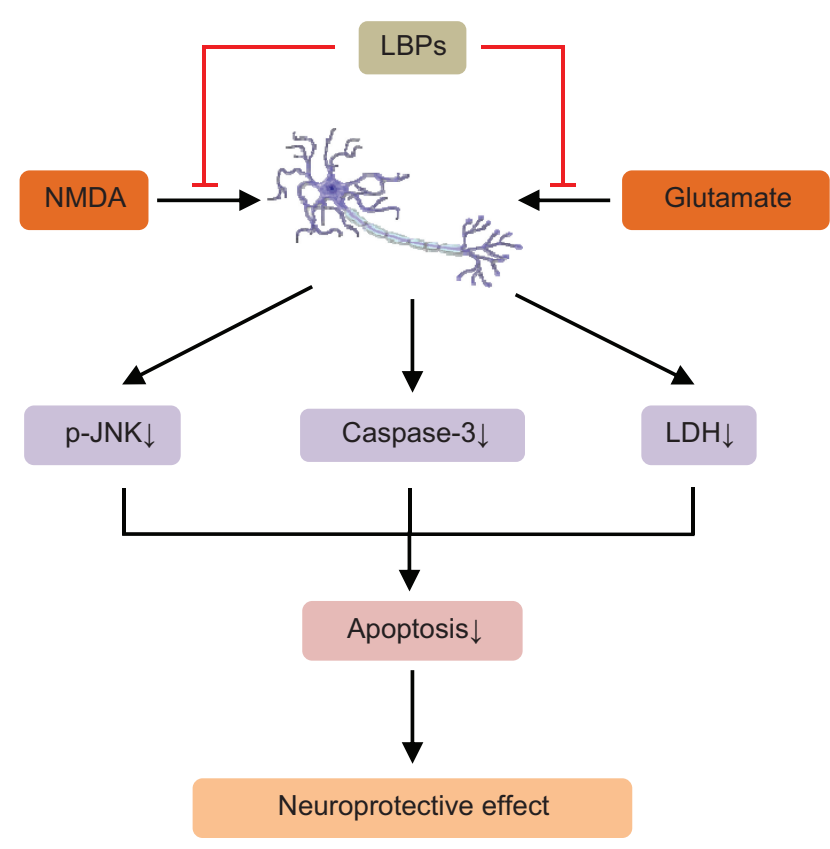

Figure 13 Possible mechanisms for the neuroprotective effects of LBPs against glutamate-induced neurotoxicity.

Notes: LBPs attenuate glutamate- and NMDA-induced neuronal damage. LBPs decrease the activity of LDH and inhibit the phosphorylation of JNK and the expression of caspase-3, resulting in a decrease in apoptosis.

Abbreviations: LBPs, Lycium barbarum polysaccharides; NMDA, N-methyl-D-aspartate; LDH, glutathione peroxidase; JNK, Jun N-terminal kinases; p, phosphorylated. cells in the LBPs-treated group were significantly more than those in the manganese-treated group. The author suggested that LBPs could enhance the learning and memory capability of the manganese poisoned mice by promoting neurogenesis in the hippocampus. ${ }^{167}$

\section{Homocysteine-induced neuronal injury}

Previous clinical and epidemiological studies have suggested that elevated plasma homocysteine levels increased the risk of AD. ${ }^{168}$ Homocysteine damages neurons by inducing apoptosis, DNA fragmentation, and Tau phosphorylation. ${ }^{169}$ Ho et $\mathrm{al}^{170}$ conducted in vitro and in vivo studies to study the beneficial effects of LBPs on neurotoxicity caused by homocysteine. LBA treatment significantly attenuated homocysteine-induced neuronal cell death and apoptosis in primary rat cortical neurons as determined by $\mathrm{LDH}$ release and caspase- 3 activity assays. LBPs also significantly reduced homocysteine-induced phosphorylation of Tau-1 at Ser198/199/202, pS396 at Ser396, and pS214 at Ser214 as well as cleavage of Tau. ${ }^{170}$ LBP treatment suppressed elevation of both phosphorylated extracellular-signalregulated kinases (Erk1/2) and phosphorylated JNK. However, the phosphorylation level of GSK3 $\beta$ at Ser9/Tyr 216 remained unchanged among different treatment groups. The data demonstrated that LBPs exerted neuroprotective effects on cortical neurons exposed to homocysteine via modulation of JNK and Erk1/2 pathways (Figure 14).

\section{High ambient temperature}

Yang et $\mathrm{al}^{171}$ investigated the effects of LBPs on the expression of neuropeptide Y (NPY) mRNA level in the hypothalamus, plasma concentration of corticotropin-releasing hormone (CRH), cortisol, HSP70, and epinephrine in rats subject to high ambient temperature. Compared to the control group, the plasma levels of CRH, cortisol, HSP70, and epinephrine were markedly increased, and the level of NPY mRNA was downregulated in the high ambient temperatureexposed rats. ${ }^{171}$ These effects were significantly reversed by LBP treatment in rats. LBPs have a potentially protective function against high temperature by increasing the expression of HSP70 and NPY.

\section{Traumatic neuroma}

Traumatic neuromas are tumors produced by a reactive process to regenerate injured nerves that result in a disordered proliferation of nerve bundles. These tumors are usually related to previous surgery or trauma. Fan et al ${ }^{172}$ investigated the effects of LBPs on the formation of traumatic 


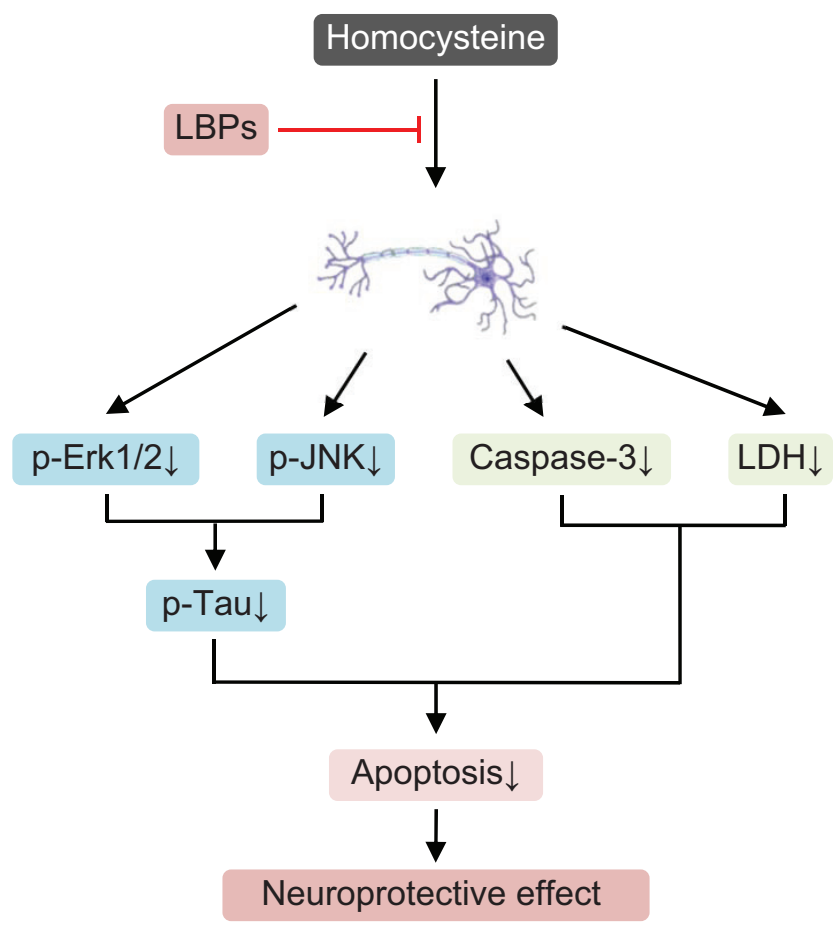

Figure 14 Possible mechanisms for the neuroprotective effects of LBPs against homocysteine-induced neurotoxicity.

Notes: LBPs exert neuroprotective effects on cortical neurons exposed to homocysteine via modulation of JNK and ErkI/2 pathways. LBPs suppress the phosphorylation of ErkI/2 and JNK, resulting in an inhibition of phosphorylation of Tau; LBPs also reduce the expression level of caspase- 3 and decrease the activity of LDH. Abbreviations: LBPs, Lycium barbarum polysaccharides; LDH, glutathione peroxidase; JNK, Jun N-terminal kinases; ErkI/2, extracellular signal-regulated kinase I/2 p, phosphorylated.

neuroma and pain after transection of sciatic nerve in rats. LBPs were intraperitoneally injected to the rats for 28 days. The study showed that there was less neuroma formed in the LBP-treated group than in the control group. Data from transmission electron microscopy showed that there were numerous axons in nerve tumor, more fusoid fibroblasts, more collagen fiber, and hyperplasia and degenerated myelin sheath in the control group, while in the LBP-treated group, there was less myelin sheath in the proximal end of injuring nerves, less Schwann cells and fibroblasts, and sparsed collagen fibers. LBPs can inhibit autophagy and the formation of traumatic neuroma after transection of sciatic nerve in rats.

\section{Protective effects against irradiation- or chemotherapy-induced organ toxicities}

Both irradiation and chemotherapy can induce severe organ toxicities. ${ }^{173,174}$ LBPs could serve as a very useful adjunct to the cancer therapies such as chemotherapy and radiotherapy. Therapeutic effects of LBPs on mitomycin C-induced myelosuppressive mice were investigated by Hai-Yang et al. ${ }^{175}$ Mice were intravenously injected with $150 \mathrm{mg} / \mathrm{kg}$ mitomycin C for 2 consecutive days to produce severe myelosuppression, and then treated by subcutaneous injection of $100 \mathrm{mg} / \mathrm{kg} /$ day or $200 \mathrm{mg} / \mathrm{kg} /$ day LBPs for 6 days. Blood samples were collected from the tail veins of mice on days $7,10,12,14$, $17,19,21,24$, and 27, and peripheral white blood cells, red blood cells, hemoglobin, and platelet counts were monitored. Administration of $100 \mathrm{mg} / \mathrm{kg}$ LBPs (LBP-L) on day 14 and $200 \mathrm{mg} / \mathrm{kg}$ LBPs (LBP-H) on days 10, 14, 17, 19, and 21 significantly increased peripheral red blood cells, hemoglobin, and hematocrit of myelosuppressive mice compared to mice treated with mitomycin C only. ${ }^{175}$ LBP-L on days 12 and 14 and LBP-H on days 10, 12, 14, 17, 19, and 21 significantly promoted peripheral platelet recovery of mitomycin C-treated mice compared with the control mice. LBP-H on days 12 , 17,19 , and 21 also significantly inhibited the increase of mean platelet volume of myelosuppressive mice compared to the control. ${ }^{175}$ These results indicate that LBPs significantly enhanced platelet recovery of myelosuppressive mice compared to the control, but did not significantly affect white blood cell recovery.

Gong et al ${ }^{176}$ investigated the effects of LBPs on irradiation or chemotherapy-induced bone marrow suppression in mice and cultured PBMCs. In the in vivo experiment, mice were irradiated with X-ray or intraperitoneally injected with carboplatin to produce severe myelosuppression. LBPs significantly increased peripheral white blood cell, red blood cell, and platelet counts compared to mice receiving irradiation only. LBPs also significantly increased peripheral white blood cell and red blood cell counts of chemotherapy-induced myelosuppressive mice. This study demonstrates that LBPs promoted the peripheral blood and bone marrow recovery from irradiation or chemotherapy-induced myelosuppression in mice, and the effects may be due to the release of GM-CSF from PBMCs.

\section{Protective effects on the reproductive system}

Wolfberry was described to exhibit pro-sexual effect by the Chinese herbalist Li Shizhen, and thus it was included in sexual-enhancing Chinese herbal remedies. Daily consumption of wolfberry juice in healthy subjects improves the well-being feeling toward sexuality, including increase in sexual activity and ability. ${ }^{27}$ Animal studies have demonstrated that LBPs exert beneficial effects on sexual performance and fertility, although the underlying mechanisms remain largely elusive.

\section{Bisphenol A-induced sperimatogenic damage}

LBPs showed protected effects against spermatogenic injuries induced by bisphenol $\mathrm{A}$ in mice. ${ }^{177}$ Bisphenol A was subcutaneously injected into mice at a dose of $20 \mathrm{mg} / \mathrm{kg}$ body 
weight for 7 consecutive days and LBPs were administered simultaneously with bisphenol A by gavage daily for 7 days. The results showed that the weights of testis and epididymis were all increased after supplementation with different dosages of LBPs compared with bisphenol A alone group, and the activities of SOD and GPx were significantly increased in LBP-treated groups, while MDA contents were gradually decreased. ${ }^{177}$ LBPs also showed significant positive effects on the expression of Bcl-2/Bax in bisphenol A-treated mice. The authors concluded that LBPs might be one of the potential ingredients protecting the adult male animals from bisphenol A-induced reproductive damage (Figure 15).

\section{Corticosterone-induced inhibition of sexual behavior}

In a recent study, ${ }^{159}$ the effects of LBPs on male sexual behavior of young adult male Sprague-Dawley rats were investigated. Oral administration of $1 \mathrm{mg} / \mathrm{kg}$ or $10 \mathrm{mg} / \mathrm{kg}$ LBPs for 21 days significantly improved the male copulatory performance including increase of copulatory efficiency, increase of ejaculation frequency, and shortening of ejaculation latency. Furthermore, sexual inhibition caused by chronic corticosterone was prevented by administration of $40 \mathrm{mg} / \mathrm{kg}$ LBPs for 21 days. Simultaneously, treatment of rats with corticosterone suppressed neurogenesis in the subventricular zone and hippocampus in adult rats, which could be reversed by LBPs. ${ }^{159}$ In the subventricular zone, the number of BrdUpositive cells in the corticosterone-treated animals was significantly lower than LBP-treatment groups. The neurogenic effect of LBPs was also shown in vitro using mouse C17.2 neural stem cells derived from the cerebellum of neonatal mice and immortalized by retrovirus-mediated v-myc gene transfection. Corticosterone treatment suppressed the cell proliferation of $\mathrm{C} 17.2$ cell line, while co-incubation with $10 \mu \mathrm{g} / \mathrm{mL}$ LBP reversed the growth suppression. Blocking neurogenesis in male rats abolished the pro-sexual effect of LBPs. These results demonstrate the pro-sexual effect of LBPs on normal and sexually inhibited rats, and LBP may modulate sexual behavior by regulating neurogenesis.

\section{Heat- or $\mathrm{H}_{2} \mathrm{O}_{2}$-induced testicular cell damage}

Luo et $\mathrm{l}^{178}$ investigated the effect of LBPs on rat testis damage induced by a physical factor $\left(43^{\circ} \mathrm{C}\right.$ heat exposure), on DNA damage of mouse testicular cells induced by a chemical factor $\left(\mathrm{H}_{2} \mathrm{O}_{2}\right)$, and on sexual behavior and reproductive function of hemicastrated male rats. The results showed that LBPs provided a protective effect against the testicular tissue damage induced by heat exposure. When compared with negative control, a suitable concentration of LBPs significantly increased testis and epididymis weights, improved SOD activity, and raised sexual hormone levels in

\section{Bisphenol A}
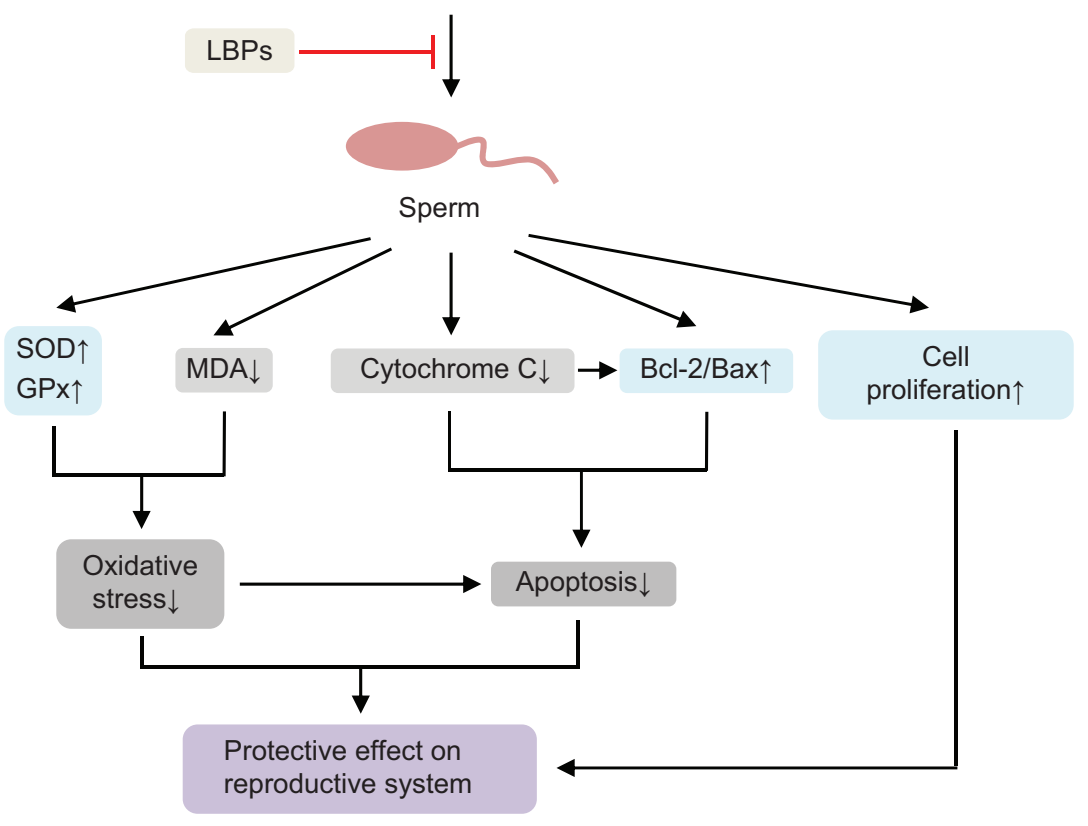

Figure 15 Possible mechanisms for the protective effects of LBPs against bisphenol A-induced sperimatogenic damage. Notes: LBPs exhibit protective effect on then reproductive system via the regulation of oxidative stress, apoptosis, and cell proliferation. LBPs increase the activities of SOD and GPx and restore the balance of Bcl-2 to Bax. LBPs promote cell proliferation but decrease the expression level of cytochrome C and the content of MDA. Abbreviations: LBPs, Lycium barbarum polysaccharides; SOD, superoxide dismutase; GPx, glutathione peroxidase; MDA, malondialdehyde. 
the damaged rat testes. ${ }^{178}$ LBPs exhibited a dose-dependent protective effect against DNA oxidative damage of mouse testicular cells induced by $\mathrm{H}_{2} \mathrm{O}_{2}$. LBPs also improved the copulatory performance and reproductive function of hemicastrated male rats, such as shortened penis erection latency and mount latency, regulated secretion of sexual hormones and increased hormone levels, raised accessory sexual organ weights, and improved sperm quantity and quality. ${ }^{178}$

LBPs could provide some protective effect against heat stress (HS)-induced apoptosis of germ cells in rats. ${ }^{179}$ Ninety male Sprague-Dawley rats were randomly divided into five groups of 18 each: control, HS, high-dose LBPs, median-dose LBPs, and low-dose LBPs. The rats of the three LBP groups were given LBPs by intragastric administration. Compared with the HS group, the three LBP groups showed statistically significant decreases in the apoptosis index, the expression level of caspase- 3 in germ cells, and the concentration of cytochrome $\mathrm{C}$ in the cytosol. ${ }^{179} \mathrm{LBPs}$ protected germ cells against apoptosis via modulation of the mitochondrial pathway. ${ }^{179}$

\section{Radiation-induced spermatogenic damage}

Zhang et a $\mathrm{l}^{180}$ explored the protective effects of LBPs on ${ }^{60} \mathrm{Co}-\gamma$-induced spermatogenic disturbance in mice and found that LBPs exhibited almost complete recovery from reproductive endocrine disorder and spermatogenic damage. Luo et $\mathrm{al}^{181}$ further confirmed the protective effects of LBPs on radiation-induced spermatogenic damage in male rats exposed to local subchronic ${ }^{60} \mathrm{Co}-\gamma$-irradiation. In this study, the effects of LBPs on sperm quantity and motility, sexual ability, serum hormone levels, oxidative status, and testicular tissue DNA damage on days 1, 7, and 14 postdosing were determined. The results showed that LBPs significantly increased the sperm quantity and motility; shortened the erection, capture, and ejaculation latencies; increased the number of captures and ejaculations; and improved the sexual ability of male rats. ${ }^{181}$ LBPs also played a significant role in the recovery of serum testosterone levels, increased superoxide dismutase activity, decreased MDA levels, promoted oxidative balance, and rescued testicular DNA damage. LBPs have significant protective effects against damage induced by local subchronic exposure to ${ }^{60} \mathrm{Co}-\gamma$ irradiation, allowing rats to achieve full recovery with LBP treatment.

\section{Aging}

Wei et al ${ }^{182}$ studied the protective mechanism of LBP administration for 30 days on the function of ovarian tissue in 14-month-old female senile rats. Radioimmunoassay was used to determine the blood levels of estrone and progesterone, and enzyme immunoassay was used to determine the ovarian levels of IGF-1. Daily oral LBPs (20 mg/kg, $40 \mathrm{mg} /$ $\mathrm{kg}$, or $60 \mathrm{mg} / \mathrm{kg}$ body weight) for 30 days significantly recovered uterine atrophy and restored serum IGF-1 level, estrone and progesterone levels that were decreased in older rats, and reduced the expression of IGF-binding protein-1 (IGFBP-1) in ovarian tissue that was increased in older rats. ${ }^{182}$

\section{Summary of protective effects of LBPs}

on the reproductive system

The protective effect of LPBs on the reproductive system is, at least in part, ascribed to antioxidation, promotion of cell proliferation, and anti-apoptosis. It has been shown that LBPs protect mice from bisphenol A-induced reproductive system damage by increasing the activities of SOD and GPx, and that LBPs increase sexual organ weight in rats (Figure 15). Moreover, LBPs decrease the ratio of Bcl-2/Bax, the expression level of caspase-3, and the concentration of cytosolic cytochrome $\mathrm{C}$, and they increase cell proliferation in vitro.

\section{Conclusion and future directions}

The success rate of the synthetic route for developing new medicinal agents may be 1/10,000; however, the success rate with the search for new therapeutic moieties based on medicinal plants used in the traditional medicinal system can be as high as $1 / 4$ or more. ${ }^{183}$ However, drug discovery based on natural compounds also has limitations. When herbal medicines such as LBPs are used as therapeutic agents, the clinical evidence supporting their use in humans is often weak or lacking. A better understanding of their safety, disposition pathways, and therapeutic targets will help with the optimal use. Standardization in the planting, harvesting, processing, and manufacturing is also important for the quality control of herbal products.

Although there are no reports on the severe toxicity of LBPs in humans, two cases of possible interactions between warfarin and LBPs have been reported, indicating a potential risk of LBP-drug and Goji-drug interaction. ${ }^{184-186}$ Clinicians should question patients about their use of herbal therapies like LBPs and document such use in their medical records before prescribing drugs such as warfarin.

LBPs as a mixture of active polysaccharides from Goji berries have shown multiple pharmacological activities, including anti-aging, antioxidative, anti-fatigue, anticancer, anti-diabetic, anti-viral, hepatoprotective, cardioprotective, neuroprotective, hypolipidemic, radioprotective, anti-osteoporosis, anti-inflammatory, and immunomodulating 
effects. The mechanisms for these beneficial effects are multifaceted, involving a number of signaling molecules and pathways. A better understanding of how LBPs act on these signaling pathways and molecules can improve our knowledge on glycobiology. Further studies using systems pharmacology approaches such as proteomic and metabolomic analysis are needed to uncover the molecular target networks of LBPs.

Despite the importance of Goji in the traditional Chinese medicine and increased popularity in Western countries, clinical safety data on LBPs are sparse. A safe and optimal use of herbal medicines like LBPs requires a full understanding of their pharmacokinetics, side effects, and mechanisms of action. ${ }^{187}$ The dose-response and dose-toxicity relationships of LBPs should be established in animal and human studies. It is essential to develop new formulations to ensure the maximum efficacy and effectiveness and minimum side effects of LBP-related health products.

\section{Acknowledgment}

The authors gratefully acknowledge the financial support provided by Natural Science Foundation of Ningxia, Yinchuan, Ningxia, People's Republic of China (Grant No. NZ14123).

\section{Disclosure}

The authors report no conflicts of interest in this work.

\section{References}

1. Potterat O. Goji (Lycium barbarum and L. chinense): phytochemistry, pharmacology and safety in the perspective of traditional uses and recent popularity. Planta Med. 2010;76(1):7-19.

2. Chang RC, So KF. Use of anti-aging herbal medicine, Lycium barbarum, against aging-associated diseases. What do we know so far? Cell Mol Neurobiol. 2008;28(5):643-652.

3. Ulbricht C, Bryan JK, Costa D, et al. An evidence-based systematic review of Goji (Lycium spp.) by the Natural Standard Research Collaboration. J Diet Suppl. Epub 2014 May 7.

4. Toyoda-Ono Y, Maeda M, Nakao M, Yoshimura M, Sugiura-Tomimori N, Fukami H. 2-O-( $\beta$-D-glucopyranosyl)ascorbic acid, a novel ascorbic acid analogue isolated from Lycium fruit. J Agric Food Chem. 2004;52(7):2092-2096.

5. Huang LJ, Tian GY, Ji GZ. Structure elucidation of glycan of glycoconjugate LbGp3 isolated from the fruit of Lycium barbarum L. J Asian Nat Prod Res. 1999;1(4):259-267.

6. Peng X, Tian G. Structural characterization of the glycan part of glycoconjugate LbGp2 from Lycium barbarum L. Carbohydr Res. 2001;331(1):95-99.

7. Jin M, Huang Q, Zhao K, Shang P. Biological activities and potential health benefit effects of polysaccharides isolated from Lycium barbarum $\mathrm{L}$. Int J Biol Macromol. 2013;54:16-23.

8. Amagase H, Farnsworth NR. A review of botanical characteristics, phytochemistry, clinical relevance in efficacy and safety of Lycium barbarum fruit (Goji). Food Res Intern. 2011;44(7):1702-1717.
9. Bucheli P, Gao Q, Redgwell R, Vidal K, Wang J, Zhang W. Biomolecular and clinical aspects of Chinese wolfberry. In: Benzie IFF, Wachtel-Galor S, editors. Herbal Medicine: Biomolecular and Clinical Aspects. 2nd ed. Boca Raton, FL: CRC Press; 2011.

10. Salama R, Sadaie M, Hoare M, Narita M. Cellular senescence and its effector programs. Genes Dev. 2014;28(2):99-114.

11. Fulop T, Le Page A, Fortin C, Witkowski JM, Dupuis G, Larbi A. Cellular signaling in the aging immune system. Curr Opin Immunol. 2014;29C:105-111.

12. Long YC, Tan TM, Takao I, Tang BL. The biochemistry and cell biology of aging: metabolic regulation through mitochondrial signaling. Am J Physiol Endocrinol Metab. 2014;306(6):E581-E591.

13. Dai DF, Chiao YA, Marcinek DJ, Szeto HH, Rabinovitch PS. Mitochondrial oxidative stress in aging and healthspan. Longev Healthspan. 2014;3:6

14. Rufini A, Tucci P, Celardo I, Melino G. Senescence and aging: the critical roles of p53. Oncogene. 2013;32(43):5129-5143.

15. Xia G, Xin N, Liu W, Yao H, Hou Y, Qi J. Inhibitory effect of Lycium barbarum polysaccharides on cell apoptosis and senescence is potentially mediated by the p53 signaling pathway. Mol Med Rep. 2014;9(4): 1237-1241.

16. Li XM, Ma YL, Liu XJ. Effect of the Lycium barbarum polysaccharides on age-related oxidative stress in aged mice. J Ethnopharmacol. 2007;111(3):504-511.

17. Li XM. Protective effect of Lycium barbarum polysaccharides on streptozotocin-induced oxidative stress in rats. Int J Biol Macromol. 2007;40(5):461-465.

18. Wu HT, He XJ, Hong YK, Ma T, Xu YP, Li HH. Chemical characterization of Lycium barbarum polysaccharides and its inhibition against liver oxidative injury of high-fat mice. Int J Biol Macromol. 2010;46(5):540-543.

19. Niu AJ, Wu JM, Yu DH, Wang R. Protective effect of Lycium barbarum polysaccharides on oxidative damage in skeletal muscle of exhaustive exercise rats. Int J Biol Macromol. 2008;42(5):447-449.

20. Dall'Olio F, Vanhooren V, Chen CC, Slagboom PE, Wuhrer M, Franceschi C. N-glycomic biomarkers of biological aging and longevity: a link with inflammaging. Ageing Res Rev. 2013;12(2):685-698.

21. Yi R, Liu XM, Dong Q. A study of Lycium barbarum polysaccharides (LBP) extraction technology and its anti-aging effect. Afr $J$ Tradit Complement Altern Med. 2013;10(4):171-174.

22. Tang T, He B. Treatment of D-galactose induced mouse aging with Lycium barbarum polysaccharides and its mechanism study. Afr $J$ Tradit Complement Altern Med. 2013;10(4):12-17.

23. Deng HB, Cui DP, Jiang JM, Feng YC, Cai NS, Li DD. Inhibiting effects of Achyranthes bidentata polysaccharide and Lycium barbarum polysaccharide on nonenzyme glycation in D-galactose induced mouse aging model. Biomed Environ Sci. 2003;16(3):267-275.

24. Liu L, Wang XN, Liu Z, et al. [Effect of Lycium bararum polysaccharides on angiotensin II-induced senescence of human umbilical vein endothelial cells and expressions of $\mathrm{p} 53$ and p16]. Nan Fang Yi Ke Da Хие Хие Baо. 2011;31(7):1212-1215. Chinese.

25. Rayess H, Wang MB, Srivatsan ES. Cellular senescence and tumor suppressor gene p16. Int J Cancer. 2012;130(8):1715-1725.

26. Amagase H, Nance DM. A randomized, double-blind, placebocontrolled, clinical study of the general effects of a standardized Lycium barbarum (Goji) Juice, GoChi. J Altern Complement Med. 2008;14(4):403-412.

27. Amagase H, Sun B, Borek C. Lycium barbarum (goji) juice improves in vivo antioxidant biomarkers in serum of healthy adults. Nutr Res. 2009;29(1):19-25.

28. Paul Hsu CH, Nance DM, Amagase H. A meta-analysis of clinical improvements of general well-being by a standardized Lycium barbarum. J Med Food. 2012;15(11):1006-1014.

29. Ferlay J, Soerjomataram I, Ervik M, et al. GLOBOCAN 2012 v1.0, Cancer Incidence and Mortality Worldwide: IARC CancerBase No. 11 [Internet]. Lyon, France: International Agency for Research on Cancer; 2013. 
30. Tang WM, Chan E, Kwok CY, et al. A review of the anticancer and immunomodulatory effects of Lycium barbarum fruit. Inflammopharmacology. 2012;20(6):307-314.

31. DeSantis C, Ma J, Bryan L, Jemal A. Breast cancer statistics, 2013. CA Cancer J Clin. 2014;64(1):52-62.

32. Li G, Sepkovic DW, Bradlow HL, Telang NT, Wong GY. Lycium barbarum inhibits growth of estrogen receptor positive human breast cancer cells by favorably altering estradiol metabolism. Nutr Cancer. 2009; 61(3):408-414.

33. Shen L, Du G. Lycium barbarum polysaccharide stimulates proliferation of MCF-7 cells by the ERK pathway. Life Sci. 2012; 91(9-10):353-357.

34. Telang N, Li G, Sepkovic D, Bradlow HL, Wong GY. Comparative efficacy of extracts from Lycium barbarum bark and fruit on estrogen receptor positive human mammary carcinoma MCF-7 cells. Nutr Cancer. 2014;66(2):278-284.

35. Hu Q, Gao T, Zhao C, et al. The effect of active components of Lycium barbarum and garlic (LB-GO) on the synthesis of DNA and ultrastructure of u14 cervix cancer cells in mice. Chin J Cancer Res. 1994;6(4):266-273.

36. Zhu CP, Zhang SH. Lycium barbarum polysaccharide inhibits the proliferation of HeLa cells by inducing apoptosis. J Sci Food Agric. 2013;93(1):149-156.

37. Siegel R, Desantis C, Jemal A. Colorectal cancer statistics, 2014. CA Cancer J Clin. 2014;64(2):104-117.

38. Mao F, Xiao B, Jiang Z, Zhao J, Huang X, Guo J. Anticancer effect of Lycium barbarum polysaccharides on colon cancer cells involves $\mathrm{G}_{0} / \mathrm{G}_{1}$ phase arrest. Med Oncol. 2011;28(1):121-126.

39. Hartgrink HH, Jansen EP, van Grieken NC, van de Velde CJ. Gastric cancer. Lancet. 2009;374(9688):477-490.

40. Siegel R, Ma J, Zou Z, Jemal A. Cancer statistics, 2014. CA Cancer J Clin. 2014;64(1):9-29.

41. Takahashi T, Saikawa Y, Kitagawa Y. Gastric cancer: current status of diagnosis and treatment. Cancers (Basel). 2013;5(1):48-63.

42. DeSantis CE, Lin CC, Mariotto AB, et al. Cancer treatment and survivorship statistics, 2014. CA Cancer J Clin. 2014;64(4):252-271.

43. Miao Y, Xiao B, Jiang Z, et al. Growth inhibition and cell-cycle arrest of human gastric cancer cells by Lycium barbarum polysaccharide. Med Oncol. 2010;27(3):785-790.

44. Gan L, Wang J, Zhang S. [Inhibition the growth of human leukemia cells by Lycium barbarum polysaccharide]. Wei Sheng Yan Jiu. 2001; 30(6):333-335. Chinese.

45. Zhang M, Chen H, Huang J, Li Z, Zhu C, Zhang S. Effect of Lycium barbarum polysaccharide on human hepatoma QGY7703 cells: inhibition of proliferation and induction of apoptosis. Life Sci. 2005;76(18):2115-2124.

46. Chao JC, Chiang SW, Wang CC, Tsai YH, Wu MS. Hot water-extracted Lycium barbarum and Rehmannia glutinosa inhibit proliferation and induce apoptosis of hepatocellular carcinoma cells. World J Gastroenterol. 2006;12(28):4478-4484.

47. Zhang M, Tang X, Wang F, Zhang Q, Zhang Z. Characterization of Lycium barbarum polysaccharide and its effect on human hepatoma cells. Int J Biol Macromol. 2013;61:270-275.

48. Lauer S, Gardner JM. Soft tissue sarcomas - new approaches to diagnosis and classification. Curr Probl Cancer. 2013;37(2):45-61.

49. Gan L, Hua Zhang S, Liang Yang X, Bi Xu H. Immunomodulation and antitumor activity by a polysaccharide-protein complex from Lycium barbarum. Int Immunopharmacol. 2004;4(4):563-569.

50. Ahmed HU. Prostate cancer: time for active surveillance of intermediaterisk disease? Nat Rev Urol. 2013;10(1):6-8.

51. U.S. Cancer Statistics Working Group. United States Cancer Statistics: 1999-2010 Incidence and Mortality Web-based Report. Atlanta, GA: U.S. Cancer Statistics Working Group; 2013.

52. Cancer Research UK. Cancer Statistics Report: Cancer Incidence and Mortality in the UK for the 10 Most Common Cancers. London: Cancer Research UK; 2013.
53. Luo Q, Li Z, Yan J, Zhu F, Xu RJ, Cai YZ. Lycium barbarum polysaccharides induce apoptosis in human prostate cancer cells and inhibits prostate cancer growth in a xenograft mouse model of human prostate cancer. J Med Food. 2009;12(4):695-703.

54. Cao GW, Yang WG, Du P. [Observation of the effects of LAK/IL-2 therapy combining with Lycium barbarum polysaccharides in the treatment of 75 cancer patients]. Zhonghua Zhong Liu Za Zhi. 1994;16(6):428-431. Chinese.

55. Moss-Morris R, Deary V, Castell B. Chronic fatigue syndrome. Handb Clin Neurol. 2013;110:303-314.

56. Werker CL, Nijhof SL, van de Putte EM. Clinical practice: chronic fatigue syndrome. Eur J Pediatr. 2013;172(10):1293-1298.

57. Tanaka M, Ishii A, Watanabe Y. Neural mechanisms underlying chronic fatigue. Rev Neurosci. 2013;24(6):617-628.

58. Brown BI. Chronic fatigue syndrome: a personalized integrative medicine approach. Altern Ther Health Med. 2014;20(1):29-40.

59. Luo Q, Yan J, Zhang S. [Isolation and purification of Lycium barbarum polysaccharides and its antifatigue effect]. Wei Sheng Yan Jiu. 2000;29(2):115-117. Chinese.

60. Wang J, Hu Y, Wang D, et al. Lycium barbarum polysaccharide inhibits the infectivity of Newcastle disease virus to chicken embryo fibroblast. Int J Biol Macromol. 2010;46(2):212-216.

61. Finegold JA, Asaria P, Francis DP. Mortality from ischaemic heart disease by country, region, and age: statistics from World Health Organisation and United Nations. Int J Cardiol. 2013;168(2):934-945.

62. Centers for Disease C, Prevention. Prevalence of coronary heart disease - United States, 2006-2010. MMWR Morb Mortal Wkly Rep. 2011;60(40):1377-1381.

63. Lu SP, Zhao PT. Chemical characterization of Lycium barbarum polysaccharides and their reducing myocardial injury in ischemia/ reperfusion of rat heart. Int J Biol Macromol. 2010;47(5):681-684.

64. Xin Y, Zhang S, Gu L, et al. Electrocardiographic and biochemical evidence for the cardioprotective effect of antioxidants in acute doxorubicin-induced cardiotoxicity in the beagle dogs. Biol Pharm Bull. 2011;34(10):1523-1526.

65. Xin YF, Wan LL, Peng JL, Guo C. Alleviation of the acute doxorubicin-induced cardiotoxicity by Lycium barbarum polysaccharides through the suppression of oxidative stress. Food Chem Toxicol. 2011;49(1):259-264.

66. Xin YF, Zhou GL, Deng ZY, et al. Protective effect of Lycium barbarum on doxorubicin-induced cardiotoxicity. Phytother Res. 2007; 21(11):1020-1024.

67. Bhattacharyya A, Chattopadhyay R, Mitra S, Crowe SE. Oxidative stress: an essential factor in the pathogenesis of gastrointestinal mucosal diseases. Physiol Rev. 2014;94(2):329-354.

68. Neurath MF. Cytokines in inflammatory bowel disease. Nat Rev Immunol. 2014;14(5):329-342.

69. Corridoni D, Arseneau KO, Cominelli F. Inflammatory bowel disease. Immunol Lett. 2014;161(2):231-235.

70. Fakhoury M, Negrulj R, Mooranian A, Al-Salami H. Inflammatory bowel disease: clinical aspects and treatments. J Inflamm Res. 2014;7:113-120.

71. Conrad K, Roggenbuck D, Laass MW. Diagnosis and classification of ulcerative colitis. Autoimmun Rev. 2014;13(4-5):463-466.

72. Loftus EV Jr. Clinical epidemiology of inflammatory bowel disease: incidence, prevalence, and environmental influences. Gastroenterology. 2004;126(6):1504-1517.

73. Zhao L, Wu H, Zhao A, et al. The in vivo and in vitro study of polysaccharides from a two-herb formula on ulcerative colitis and potential mechanism of action. J Ethnopharmacol. 2014;153(1):151-159.

74. Lenaerts K, Ceulemans LJ, Hundscheid IH, Grootjans J, Dejong CH, Olde Damink SW. New insights in intestinal ischemia-reperfusion injury: implications for intestinal transplantation. Curr Opin Organ Transplant. 2013;18(3):298-303.

75. Yang X, Bai H, Cai W, et al. Lycium barbarum polysaccharides reduce intestinal ischemia/reperfusion injuries in rats. Chem Biol Interact. 2013;204(3):166-172. 
76. Li SY, Fu ZJ, Lo AC. Hypoxia-induced oxidative stress in ischemic retinopathy. Oxid Med Cell Longev. 2012;2012:426769.

77. Li SY, Yang D, Yeung CM, et al. Lycium barbarum polysaccharides reduce neuronal damage, blood-retinal barrier disruption and oxidative stress in retinal ischemia/reperfusion injury. PLoS One. 2011;6(1):e16380

78. He M, Pan H, Chang RC, So KF, Brecha NC, Pu M. Activation of the Nrf2/HO-1 antioxidant pathway contributes to the protective effects of Lycium barbarum polysaccharides in the rodent retina after ischemiareperfusion-induced damage. PLoS One. 2014;9(1):e84800.

79. Mi XS, Feng Q, Lo AC, et al. Protection of retinal ganglion cells and retinal vasculature by Lycium barbarum polysaccharides in a mouse model of acute ocular hypertension. PLoS One. 2012;7(10):e45469.

80. Li H, Liang Y, Chiu K, et al. Lycium barbarum (wolfberry) reduces secondary degeneration and oxidative stress, and inhibits JNK pathway in retina after partial optic nerve transection. PLoS One. 2013;8(7):e68881.

81. Chu PH, Li HY, Chin MP, So KF, Chan HH. Effect of Lycium barbarum (wolfberry) polysaccharides on preserving retinal function after partial optic nerve transection. PLoS One. 2013;8(12):e81339.

82. Chan HC, Chang RC, Koon-Ching Ip A, et al. Neuroprotective effects of Lycium barbarum Lynn on protecting retinal ganglion cells in an ocular hypertension model of glaucoma. Exp Neurol. 2007;203(1): 269-273.

83. Chiu K, Chan HC, Yeung SC, et al. Modulation of microglia by Wolfberry on the survival of retinal ganglion cells in a rat ocular hypertension model. J Ocul Biol Dis Infor. 2009;2(2):47-56.

84. Chiu K, Zhou Y, Yeung SC, et al. Up-regulation of crystallins is involved in the neuroprotective effect of wolfberry on survival of retinal ganglion cells in rat ocular hypertension model. J Cell Biochem. 2010;110(2):311-320.

85. Miranda M, Arnal E, Ahuja S, et al. Antioxidants rescue photoreceptors in rd1 mice: relationship with thiol metabolism. Free Radic Biol Med. 2010;48(2):216-222.

86. World Health Organization. Global Status Report on Alcohol and Health. Geneva: WHO; 2011.

87. O'Shea RS, Dasarathy S, McCullough AJ. Alcoholic liver disease. Am $J$ Gastroenterol. 2010;105(1):14-32.

88. Orman ES, Odena G, Bataller R. Alcoholic liver disease: pathogenesis, management, and novel targets for therapy. $J$ Gastroenterol Hepatol. 2013;28(suppl 1):77-84.

89. Tilg H, Day CP. Management strategies in alcoholic liver disease. Nat Clin Pract Gastroenterol Hepatol. 2007;4(1):24-34.

90. Cheng D, Kong H. The effect of Lycium barbarum polysaccharide on alcohol-induced oxidative stress in rats. Molecules. 2011; 16(3):2542-2550.

91. Xiao J, Zhu Y, Liu Y, Tipoe GL, Xing F, So KF. Lycium barbarum polysaccharide attenuates alcoholic cellular injury through TXNIPNLRP3 inflammasome pathway. Int J Biol Macromol. 2014; 69:73-78.

92. Dyson JK, Anstee QM, McPherson S. Non-alcoholic fatty liver disease: a practical approach to diagnosis and staging. Frontline Gastroenterol. 2014;5(3):211-218

93. Schwenger KJ, Allard JP. Clinical approaches to non-alcoholic fatty liver disease. World J Gastroenterol. 2014;20(7):1712-1723.

94. Wree A, Broderick L, Canbay A, Hoffman HM, Feldstein AE. From NAFLD to NASH to cirrhosis - new insights into disease mechanisms. Nat Rev Gastroenterol Hepatol. 2013;10(11):627-636.

95. Mazzella N, Ricciardi LM, Mazzotti A, Marchesini G. The role of medications for the management of patients with NAFLD. Clin Liver Dis. 2014;18(1):73-89.

96. Xiao J, Liong EC, Ching YP, et al. Lycium barbarum polysaccharides protect rat liver from non-alcoholic steatohepatitis-induced injury. Nutr Diabetes. 2013;3:e81.

97. Xiao J, Xing F, Huo J, et al. Lycium barbarum polysaccharides therapeutically improve hepatic functions in non-alcoholic steatohepatitis rats and cellular steatosis model. Sci Rep. 2014;4:5587.
98. Li W, Li Y, Wang Q, Yang Y. Crude extracts from Lycium barbarum suppress SREBP-1c expression and prevent diet-induced fatty liver through AMPK activation. Biomed Res Int. 2014;2014:196198.

99. Lin D, He H, Ji H, et al. Wolfberries potentiate mitophagy and enhance mitochondrial biogenesis leading to prevention of hepatic steatosis in obese mice: the role of AMP-activated protein kinase- $\alpha 2$ subunit. Mol Nutr Food Res. 2014;58(5):1005-1015.

100. Xiao J, Liong EC, Ching YP, et al. Lycium barbarum polysaccharides protect mice liver from carbon tetrachloride-induced oxidative stress and necroinflammation. J Ethnopharmacol. 2012;139(2):462-470.

101. Perkins ND. Integrating cell-signalling pathways with NF- $\kappa B$ and IKK function. Nat Rev Mol Cell Biol. 2007;8(1):49-62.

102. Ahn M, Park JS, Chae S, et al. Hepatoprotective effects of Lycium chinense Miller fruit and its constituent betaine in $\mathrm{CCl}_{4}$-induced hepatic damage in rats. Acta Histochem. 2014;116(6):1104-1112.

103. Holman RR. Type 2 diabetes mellitus in 2012: optimal management of T2DM remains elusive. Nat Rev Endocrinol. 2013;9(2):67-68.

104. Seo HA, Lee IK. The role of Nrf2: adipocyte differentiation, obesity, and insulin resistance. Oxid Med Cell Longev. 2013;2013:184598.

105. Zhu J, Liu W, Yu J, et al. Characterization and hypoglycemic effect of a polysaccharide extracted from the fruit of Lycium barbarum $\mathrm{L}$. Carbohydr Polym. 2013;98(1):8-16.

106. Wu H, Guo H, Zhao R. Effect of Lycium barbarum polysaccharide on the improvement of antioxidant ability and DNA damage in NIDDM rats. Yakugaku Zasshi. 2006;126(5):365-371.

107. Luo Q, Cai Y, Yan J, Sun M, Corke H. Hypoglycemic and hypolipidemic effects and antioxidant activity of fruit extracts from Lycium barbarum. Life Sci. 2004;76(2):137-149.

108. Zhao R, Li Q, Xiao B. Effect of Lycium barbarum polysaccharide on the improvement of insulin resistance in NIDDM rats. Yakugaku Zasshi. 2005;125(12):981-988.

109. Zhao R, Qiu B, Li Q, et al. LBP-4a improves insulin resistance via translocation and activation of GLUT4 in OLETF rats. Food Funct. 2014;5(4):811-820.

110. Yang Y, Li W, Li Y, Wang Q, Gao L, Zhao J. Dietary Lycium barbarum polysaccharide induces Nrf2/ARE pathway and ameliorates insulin resistance induced by high-fat via activation of PI3K/AKT signaling. Oxid Med Cell Longev. 2014;2014:145641.

111. Klip A, Sun Y, Chiu TT, Foley KP. Signal transduction meets vesicle traffic: the software and hardware of GLUT4 translocation. Am J Physiol Cell Physiol. 2014;306(10):C879-C886.

112. Govers R. Molecular mechanisms of GLUT4 regulation in adipocytes. Diabetes Metab. Epub 2014 October 16.

113. Ma Q. Role of nrf2 in oxidative stress and toxicity. Аnпu Rev Pharmacol Toxicol. 2013;53:401-426.

114. Nishikawa T, Araki E. Impact of mitochondrial ROS production in the pathogenesis of diabetes mellitus and its complications. Antioxid Redox Signal. 2007;9(3):343-353.

115. Srinivasan K, Ramarao P. Animal models in type 2 diabetes research: an overview. Indian J Med Res. 2007;125(3):451-472.

116. Amagase H, Nance DM. Lycium barbarum increases caloric expenditure and decreases waist circumference in healthy overweight men and women: pilot study. J Am Coll Nutr. 2011;30(5): 304-309.

117. Centers for Disease Control and Prevention. Vital signs: prevalence, treatment, and control of high levels of low-density lipoprotein cholesterol - United States, 1999-2002 and 2005-200. MMWR Morb Mortal Wkly Rep. 2011;60(4):109-114.

118. Tzianabos AO. Polysaccharide immunomodulators as therapeutic agents: structural aspects and biologic function. Clin Microbiol Rev. 2000;13(4):523-533.

119. Vannucci L, Krizan J, Sima P, et al. Immunostimulatory properties and antitumor activities of glucans (Review). Int J Oncol. 2013; 43(2):357-364.

120. Chen Z, Kwong Huat Tan B, Chan SH. Activation of T lymphocytes by polysaccharide-protein complex from Lycium barbarum L. Int Immunopharmacol. 2008;8(12):1663-1671. 
121. Macian F. NFAT proteins: key regulators of T-cell development and function. Nat Rev Immunol. 2005;5(6):472-484.

122. Waldmann TA. The biology of interleukin-2 and interleukin-15: implications for cancer therapy and vaccine design. Nat Rev Immunol. 2006;6(8):595-601.

123. Schoenborn JR, Wilson CB. Regulation of interferon- $\gamma$ during innate and adaptive immune responses. Adv Immunol. 2007;96:41-101.

124. Zhang XR, Zhou WX, Zhang YX, et al. Macrophages, rather than $T$ and $\mathrm{B}$ cells are principal immunostimulatory target cells of Lycium barbarum L. polysaccharide LBPF4-OL. J Ethnopharmacol. 2011; 136(3):465-472.

125. Locksley RM, Killeen N, Lenardo MJ. The TNF and TNF receptor superfamilies: integrating mammalian biology. Cell. 2001; 104(4):487-501.

126. Vidal K, Benyacoub J, Sanchez-Garcia J, et al. Intake of a milk-based wolfberry formulation enhances the immune response of young-adult and aged mice. Rejuvenation Res. 2010;13(1):47-53.

127. Zhang X, Li Y, Cheng J, et al. Immune activities comparison of polysaccharide and polysaccharide-protein complex from Lycium barbarum L. Int J Biol Macromol. 2014;65:441-445.

128. Cobaleda C, Schebesta A, Delogu A, Busslinger M. Pax5: the guardian of B cell identity and function. Nat Immunol. 2007;8(5):463-470.

129. Zhang XR, Qi CH, Cheng JP, et al. Lycium barbarum polysaccharide LBPF4-OL may be a new Toll-like receptor 4/MD2-MAPK signaling pathway activator and inducer. Int Immunopharmacol. 2014;19(1):132-141.

130. Gan L, Zhang SH, Liu Q, Xu HB. A polysaccharide-protein complex from Lycium barbarum upregulates cytokine expression in human peripheral blood mononuclear cells. Eur J Pharmacol. 2003;471(3):217-222.

131. Murray PJ, Wynn TA. Protective and pathogenic functions of macrophage subsets. Nat Rev Immunol. 2011;11(11):723-737.

132. Ginhoux F, Jung S. Monocytes and macrophages: developmental pathways and tissue homeostasis. Nat Rev Immunol. 2014 14(6):392-404.

133. Mills CD. M1 and M2 macrophages: oracles of health and disease Crit Rev Immunol. 2012;32(6):463-488.

134. Chen Z, Soo MY, Srinivasan N, Tan BK, Chan SH. Activation of macrophages by polysaccharide-protein complex from Lycium barbarum L. Phytother Res. 2009;23(8):1116-1122.

135. Teng P, Li Y, Cheng W, Zhou L, Shen Y, Wang Y. Neuroprotective effects of Lycium barbarum polysaccharides in lipopolysaccharide-induced BV2 microglial cells. Mol Med Rep. 2013;7(6): 1977-1981.

136. Kang KF, Wang XW, Chen XW, et al. Beclin 1 and nuclear factorКBp65 are upregulated in hepatocellular carcinoma. Oncol Lett. 2013;5(6):1813-1818.

137. Peng Q, Liu H, Shi S, Li M. Lycium ruthenicum polysaccharide attenuates inflammation through inhibiting TLR4/NF- $\mathrm{KB}$ signaling pathway. Int J Biol Macromol. 2014;67:330-335.

138. Vivier E, Raulet DH, Moretta A, et al. Innate or adaptive immunity? The example of natural killer cells. Science. 2011;331(6013): 44-49.

139. Moretta L, Pietra G, Montaldo E, et al. Human NK cells: from surface receptors to the therapy of leukemias and solid tumors. Front Immunol. 2014;5:87.

140. Huyan T, Li Q, Yang H, et al. Protective effect of polysaccharides on simulated microgravity-induced functional inhibition of human NK cells. Carbohydr Polym. 2014;101:819-827.

141. Dalod M, Chelbi R, Malissen B, Lawrence T. Dendritic cell maturation functional specialization through signaling specificity and transcriptional programming. EMBO J. 2014;33(10):1104-1116.

142. Lipscomb MF, Masten BJ. Dendritic cells: immune regulators in health and disease. Physiol Rev. 2002;82(1):97-130.

143. Zhu J, Zhao LH, Zhao XP, Chen Z. Lycium barbarum polysaccharides regulate phenotypic and functional maturation of murine dendritic cells. Cell Biol Int. 2007;31(6):615-619.
144. Chen Z, Lu J, Srinivasan N, Tan BK, Chan SH. Polysaccharide-protein complex from Lycium barbarum L. is a novel stimulus of dendritic cell immunogenicity. J Immunol. 2009;182(6):3503-3509.

145. Chen JR, Li EQ, Dai CQ, et al. The inducible effect of LBP on maturation of dendritic cells and the related immune signaling pathways in hepatocellular carcinoma (HCC). Curr Drug Deliv. 2012;9(4):414-420.

146. Schmitt N, Bentebibel SE, Ueno H. Phenotype and functions of memory Tfh cells in human blood. Trends Immunol. 2014;35(9): 436-442.

147. Su CX, Duan XG, Liang LJ, et al. Lycium barbarum polysaccharides as an adjuvant for recombinant vaccine through enhancement of humoral immunity by activating Tfh cells. Vet Immunol Immunopathol. 2014;158(1-2):98-104.

148. Ling Y, Li S, Yang J, Yuan J, He C. Co-administration of the polysaccharide of Lycium barbarum with DNA vaccine of Chlamydophila abortus augments protection. Immunol Invest. 2011;40(1):1-13.

149. Du X, Wang J, Niu X, Smith D, Wu D, Meydani SN. Dietary wolfberry supplementation enhances the protective effect of flu vaccine against influenza challenge in aged mice. J Nutr. 2014;144(2):224-229.

150. Amagase H, Sun B, Nance DM. Immunomodulatory effects of a standardized Lycium barbarum fruit juice in Chinese older healthy human subjects. J Med Food. 2009;12(5):1159-1165.

151. Vidal K, Bucheli $\mathrm{P}$, Gao Q, et al. Immunomodulatory effects of dietary supplementation with a milk-based wolfberry formulation in healthy elderly: a randomized, double-blind, placebo-controlled trial. Rejuvenation Res. 2012;15(1):89-97.

152. Zhang YK, Wang J, Liu L, Chang RC, So KF, Ju G. The effect of Lycium barbarum on spinal cord injury, particularly its relationship with $\mathrm{M}_{1}$ and $\mathrm{M}_{2}$ macrophage in rats. BMC Complement Altern Med. 2013;13:67.

153. Rui C, Yuxiang L, Yinju H, et al. Protective effects of Lycium barbarum polysaccharide on neonatal rat primary cultured hippocampal neurons injured by oxygen-glucose deprivation and reperfusion. $J$ Mol Histol. 2012;43(5):535-542.

154. Chen W, Cheng X, Chen J, et al. Lycium barbarum polysaccharides prevent memory and neurogenesis impairments in scopolamine-treated rats. PLoS One. 2014;9(2):e88076.

155. Yang D, Li SY, Yeung CM, et al. Lycium barbarum extracts protect the brain from blood-brain barrier disruption and cerebral edema in experimental stroke. PLoS One. 2012;7(3):e33596.

156. Wang T, Li Y, Wang Y, et al. Lycium barbarum polysaccharide prevents focal cerebral ischemic injury by inhibiting neuronal apoptosis in mice. PLoS One. 2014;9(3):e90780.

157. Yu MS, Leung SK, Lai SW, et al. Neuroprotective effects of antiaging oriental medicine Lycium barbarum against b-amyloid peptide neurotoxicity. Exp Gerontol. 2005;40(8-9):716-727.

158. Yu MS, Lai CS, Ho YS, et al. Characterization of the effects of antiaging medicine Fructus lycii on $\beta$-amyloid peptide neurotoxicity. Int J Mol Med. 2007;20(2):261-268.

159. Lau BW, Lee JC, Li Y, et al. Polysaccharides from wolfberry prevents corticosterone-induced inhibition of sexual behavior and increases neurogenesis. PLoS One. 2012;7(4):e33374.

160. van der Worp HB, van Gijn J. Clinical practice. Acute ischemic stroke. N Engl J Med. 2007;357(6):572-579.

161. Qureshi AI, Caplan LR. Intracranial atherosclerosis. Lancet. 2014;383(9921):984-998.

162. Uchiyama S. The concept of acute cerebrovascular syndrome. Front Neurol Neurosci. 2014;33:11-18.

163. Manzanero S, Santro T, Arumugam TV. Neuronal oxidative stress in acute ischemic stroke: sources and contribution to cell injury. Neurochem Int. 2013;62(5):712-718.

164. Chen SD, Yang DI, Lin TK, Shaw FZ, Liou CW, Chuang YC. Roles of oxidative stress, apoptosis, PGC-1 $\alpha$ and mitochondrial biogenesis in cerebral ischemia. Int J Mol Sci. 2011;12(10):7199-7215.

165. Wang HB, Li YX, Hao YJ, et al. Neuroprotective effects of LBP on brain ischemic reperfusion neurodegeneration. Eur Rev Med Pharmacol Sci. 2013;17(20):2760-2765. 
166. Ho YS, Yu MS, Yik SY, So KF, Yuen WH, Chang RC. Polysaccharides from wolfberry antagonizes glutamate excitotoxicity in rat cortical neurons. Cell Mol Neurobiol. 2009;29(8):1233-1244.

167. Wen J, Yang BN, Ren D. [Effect of Lycium barbarum polysaccharides on neurogenesis and learning and memory in manganese poisoning mice]. Zhongguo Zhong Xi Yi Jie He Za Zhi. 2010;30(3): 295-298. Chinese.

168. Hall JR, Wiechmann AR, Johnson LA, et al. Biomarkers of vascular risk, systemic inflammation, and microvascular pathology and neuropsychiatric symptoms in Alzheimer's disease. J Alzheimers Dis. 2013;35(2):363-371.

169. Zhuo JM, Wang H, Pratico D. Is hyperhomocysteinemia an Alzheimer's disease (AD) risk factor, an AD marker, or neither? Trends Pharmacol Sci. 2011;32(9):562-571.

170. Ho YS, Yu MS, Yang XF, So KF, Yuen WH, Chang RC. Neuroprotective effects of polysaccharides from wolfberry, the fruits of Lycium barbarum, against homocysteine-induced toxicity in rat cortical neurons. J Alzheimers Dis. 2010;19(3):813-827.

171. Yang M, Ding J, Zhou X, et al. Effects of Lycium barbarum polysaccharides on neuropeptide $Y$ and heat-shock protein 70 expression in rats exposed to heat. Biomed Rep. 2014;2(5):687-692.

172. Fan H, Deng C, Fu J, Ding L, Yin G, Ma Y. [Effects of Lycium barbarum polysaccharide on formation of traumatic neuroma and pain after transection of sciatic nerve in rats]. Zhongguo Xiu Fu Chong Jian Wai Ke Za Zhi. 2010;24(11):1298-1301. Chinese.

173. Livshits Z, Rao RB, Smith SW. An approach to chemotherapy-associated toxicity. Emerg Med Clin North Am. 2014;32(1):167-203.

174. Radvansky LJ, Pace MB, Siddiqui A. Prevention and management of radiation-induced dermatitis, mucositis, and xerostomia. Am J Health Syst Pharm. 2013;70(12):1025-1032.

175. Hai-Yang G, Ping S, Li JI, Chang-Hong X, Fu T. Therapeutic effects of Lycium barbarum polysaccharide (LBP) on mitomycin C (MMC)induced myelosuppressive mice. J Exp Ther Oncol. 2004;4(3): 181-187.

176. Gong H, Shen P, Jin L, Xing C, Tang F. Therapeutic effects of Lycium barbarum polysaccharide (LBP) on irradiation or chemotherapyinduced myelosuppressive mice. Cancer Biother Radiopharm. 2005;20(2):155-162.

177. Zhang C, Wang A, Sun X, et al. Protective effects of Lycium barbarum polysaccharides on testis spermatogenic injury induced by bisphenol A in mice. Evid Based Complement Alternat Med. 2013;2013:690808.
178. Luo Q, Li Z, Huang X, Yan J, Zhang S, Cai YZ. Lycium barbarum polysaccharides: protective effects against heat-induced damage of rat testes and $\mathrm{H}_{2} \mathrm{O}_{2}$-induced DNA damage in mouse testicular cells and beneficial effect on sexual behavior and reproductive function of hemicastrated rats. Life Sci. 2006;79(7):613-621.

179. Tan QH, An CX, Xiao Y, Liao ZM. [Protective effect of Lycium barbarum polysaccharides against heat stress-induced germ cell apoptosis in rats and its mechanism]. Zhonghua Nan Ke Xue. 2012;18(1):88-92. Chinese.

180. Zhang WX, Wang HL, Wang R, Li R, He W, Zhang TB. [Chinese medicinal monomer and compound for ${ }^{60} \mathrm{Co}-\gamma$-induced spermatogenic disturbance in mice]. Zhonghua Nan Ke Xue. 2010;16(5):474-479. Chinese.

181. Luo Q, Cui X, Yan J, et al. Antagonistic effects of Lycium barbarum polysaccharides on the impaired reproductive system of male rats induced by local subchronic exposure to ${ }^{60} \mathrm{Co}-\gamma$ irradiation. Phytother Res. 2011;25(5):694-701.

182. Wei M, Zheng SZ, Ma H, Lv Y. [Discussion of protective mechanism of Lyceum barbarum polysaccharides on ovarian tissue in female senile rats]. Zhong Yao Cai. 2011;34(12):1915-1918. Chinese.

183. Pan SY, Zhou SF, Gao SH, et al. New perspectives on how to discover drugs from herbal medicines: CAM's outstanding contribution to modern therapeutics. Evid Based Complement Alternat Med. 2013; 2013:627375.

184. Lam AY, Elmer GW, Mohutsky MA. Possible interaction between warfarin and Lycium barbarum L. Ann Pharmacother. 2001; 35(10):1199-1201.

185. Rivera CA, Ferro CL, Bursua AJ, Gerber BS. Probable interaction between Lycium barbarum (goji) and warfarin. Pharmacotherapy. 2012;32(3):e50-e53.

186. Leung H, Hung A, Hui AC, Chan TY. Warfarin overdose due to the possible effects of Lycium barbarum L. Food Chem Toxicol. 2008;46(5):1860-1862.

187. He SM, Chan E, Zhou SF. ADME properties of herbal medicines in humans: evidence, challenges and strategies. Curr Pharm Des. 2011; 17(4):357-407.

188. Seitz HK, Lieber CS, Stickel F, Salaspuro M, Schlemmer HP, Horie Y. Alcoholic liver disease: from pathophysiology to therapy. Alcohol Clin Exp Res. 2005;29(7):1276-1281.
Drug Design, Development and Therapy

\section{Publish your work in this journal}

Drug Design, Development and Therapy is an international, peerreviewed open-access journal that spans the spectrum of drug design and development through to clinical applications. Clinical outcomes, patient safety, and programs for the development and effective, safe, and sustained use of medicines are a feature of the journal, which

\section{Dovepress}

has also been accepted for indexing on PubMed Central. The manuscript management system is completely online and includes a very quick and fair peer-review system, which is all easy to use. Visit http://www.dovepress.com/testimonials.php to read real quotes from published authors. 